\title{
Ambivalent sexism and violence toward women: A meta-analysis
}

\author{
Elena Agadullina ${ }^{\mathrm{a}}$, Andrey Lovakov ${ }^{\mathrm{b}}$, Maryana Balezina ${ }^{\mathrm{a}}$, Olga A. Gulevich ${ }^{\mathrm{a}}$ \\ ${ }^{a}$ School of Psychology, HSE University, Moscow, Russia \\ ${ }^{\mathrm{b}}$ Center for Institutional Studies, HSE University, Moscow, Russia
}

Address correspondence to Elena Agadullina, School of Psychology, HSE University, 20 Myasnitskaya Ulitsa, Moscow 101000, Russia. E-mail: eagadullina@hse.ru. Phone number: +7 (499) 178-0392

Acknowledgements: The authors are grateful Jamie Hughes, Katherine Jongsma, Karin Arbach, David Fonte, Enrique Gracia, Jeffrey A. Hall, Emily Ann Harris, Kathryn R. Klement, Solveig Lelaurain, Ray Block, Manuela Thomae, Wai Yen Tang, Silvia Ubillos Landa, Alejandro Luna Bernal, Ezgi Toplu-Demirtaş, Mara Morelli, and Andrés Fernández-Fuertes for the additional data for this metaanalysis.

Funding statement: The manuscript was prepared in the framework of a research grant funded by the Ministry of Science and Higher Education of the Russian Federation (grant ID: 075-15-2020-978)

Conflict of interest disclosure and ethics approval statement: We declare no potential conflict of interest with respect to the research, authorship, and/or preparation of this research and publication of this article. We also confirm that this manuscript adheres to the APA ethical guidelines and the authors' national ethics guidelines.

Data availability statement: The data are publicly available in Open Science Framework https://osf.io/gepkb/ 


\begin{abstract}
The Ambivalent Sexism Theory suggests that there are two complementary types of sexism: hostile (subjectively negative attitude towards gender groups) and benevolent (subjectively positive attitude towards gender groups). In this meta-analysis we analyzed the relationship between ambivalent sexism and attitudes toward male-to-female violence or violent behavior. Violence type, the context of violence, respondents' gender, the countries' level of gender inequality, and sample type were tested as moderators. The results showed that both hostile and benevolent sexism independently impact on attitudes toward violence and violent behavior albeit to a different degree. Specifically, the relationship between hostile sexism and attitudes and behavior is stronger than for the benevolent sexism. The type and context of violence moderate the relationship between hostile sexism and attitudes toward violence and violent behavior. Only the country's gender inequality levels showed a moderation effect for benevolent sexism. Theoretical and practical implications of the results are discussed.
\end{abstract}

Keywords: sexism, violence, aggression, meta-analysis 
Violence toward women is an important societal challenge (Child et al., 2013). According to the World Health Organization (WHO), violence toward women is a global human rights and public health problem (Child et al., 2013; Garcia-Moreno et al., 2006), since it has a negative impact on female physical health (e.g., increased mortality, reproductive disorders, and poorer pregnancy outcomes) (Jordan et al., 2010; Plichta, 2004), psychological health (e.g., increased depression and posttraumatic stress disorder) (Beydoun et al., 2012), and social and economic status (e.g., decreased individual income (Zlotnick et al., 2006)). Moreover, women who experience violence in their lifetime also have a higher risk of unemployment, divorce (Byrne et al., 1999), and alcohol or drug addiction (Devries et al., 2014). Such serious consequences for women' well-being, health, and safety make it crucial to research predictors of violence.

Previous meta-analyses on predictors of violence toward women mainly focused on the perpetrators' or victims' characteristics. So, it was found that perpetrators are more likely to be younger, unemployed, and less educated (Capaldi et al., 2012; Stith et al., 2004), have a lower income (Stith et al., 2004), use alcohol and drugs (Capaldi et al., 2012; Foran \& O'Leary, 2008; Moore et al., 2008), experience depression, stress or low life satisfaction (Stith et al., 2004), and have experience of physical abuse in childhood (Smith-Marek et al., 2015; Stith et al., 2000). As for the victims, the studies have demonstrated that if a woman is young, has a low level of education, marired, uses alcohol or drugs, and has a unplanned pregnant, she is more likely to be a victim of violence (Cho, 2012; Yakubovich et al., 2018).

At the same time, violence toward women can be associated not only with the individual characteristics of abusers and victims but also with broader structural, social, and ideological factors (Flood \& Pease, 2009). Men and women have had an unequal social status for centuries. This inequality was supported by the invention of social ideologies that justified the differences and by establishing male-to-female violence as an authorized way to maintain the gender hierarchy (Eagly \& Wood, 2012). In their meta-analysis, Langhinrichsen-Rohling with colleagues (2012) studied the motivations of intimate partner violence: power/control, self-defense, negative emotions, 
communication difficulties, retaliation, jealousy, and others. They found that a desire to gain power and dominance is one of the motives for male violence toward women. In another meta-analysis, Sugarman and Frankel (1996) operationalized a patriarchal ideology (the beliefs that men should have more power and privilege than women) as positive attitudes toward violence, conservative gender attitudes, and gender schema and demonstrated that husbands who endorse these beliefs are more assaultive than those who are not. Altogether, these results emphasize that status differences between men and women can be an important factor in the manifestation of violence against women.

One of the social ideologies that support the unequal status of women and men is sexism (Swim \& Campbell, 2003). However, despite the existence of a large number of studies about the relationships between sexism and violence against women, there is no generalized analysis that would allow to determine the extent to which sexism is actually associated with violence. The present metaanalysis seeks to fill this gap.

\section{Ambivalent Sexism Theory}

Traditionally, sexism has been viewed as the holding of hostile and contemptuous attitudes toward women (Swim et al., 1995; for review see, Swim \& Hyers, 2009). In the past twenty years this view has changed and researchers have recognized the ambivalent nature of sexism (as both negative and positive attitudes toward women). According to the Ambivalent Sexism Theory (Glick \& Fiske, 1996, 2001), the relations between men and women are characterized by two main processes. On the one hand, these relationships can be perceived as a conflict since men try protect their high status from the encroachment of women. On the other hand, men and women are interdependent in intimate relationships and have to maintain close and friendly relations. These processes correspond to two complementary forms of sexist attitudes: hostile sexism and benevolent sexism.

Hostile sexism is a subjectively negative attitude, including the belief that women threaten the gender hierarchy in society by trying to control and dominate men in personal and public relations. According to hostile sexist beliefs, women are seeking to usurp men's power using underhanded ways 
such as sexual manipulation or falsely claiming discrimination at work. As a result, hostile sexism leads to negative evaluations of active and strong women who are perceived as insubordinate to men and as rivals in a struggle for power (e.g., feminists) (Gaunt, 2013; Glick et al., 2015).

Benevolent sexism is a subjectively positive attitude, including the belief that women have positive, warm qualities but are weak and defenseless, and consequently need the care and protection of men. Thus, it is based on the idea of passive and weak women who support the status-quo in gender relations. As a consequence, benevolent sexism leads to positive evaluations toward traditional female types who fit gender stereotypes (e.g., housewife) (Gaunt, 2013; Glick et al., 2015).

Despite the perceived contradiction between hostile and benevolent sexism, they interconnect and both contribute to maintaining gender inequality, justifying the existing system of gender relations, and reinforcing the higher status of men in society (Glick et al., 2000; Jost, Banaji, \& Nosek, 2004; Napier, Thorisdottir, \& Jost, 2010; Sibley \& Duckitt, 2008). Paternalism implied by benevolent sexism encourages traditional gender roles for women and discourages women's desire to change the status quo. If women try to gain more power and a higher social status, hostile sexism enters into force, which is also aimed at maintaining the status quo (Connor et al., 2016). In other words, both hostile and benevolent sexism as complementary tools of control reinforce male dominance over women.

Studies conducted in the framework of the Ambivalent Sexism Theory have shown that hostile and benevolent sexism can have opposite associations with violence toward women (Connor, Glick, \& Fiske, 2016), which led us to formulate the main aim of our research - to understand the relationship between ambivalent sexism and violence toward women by conducting a meta-analysis of relevant studies.

\section{Hostile and benevolent sexism and their link to violence}

Both hostile and benevolent sexism suggests that men should dominate women and, as described above, violence can be one way to ensure male domination and female submission. But do hostile and benevolent attitudes toward women make an equal contribution to support for, and manifestation of, violence? 
Hostile sexism includes hostility toward women as its central element (Forbes et al., 2004). It has repeatedly been shown that hostility toward women is associated with both violent behavior (Anderson \& Anderson, 2008; Murnen et al., 2002; Parrott \& Zeichner, 2003; Vivolo-Kantor et al., 2013) and attitudes toward violence (Forbes et al., 2004; Lonsway et al., 2008). Therefore, it should be expected that hostile sexism will be directly and strongly linked to violence toward women.

The more ambiguous situation is with benevolent sexism. On the one hand, benevolent sexism promises male protectiveness and affection, especially toward women who fit gender stereotypes, so it can be a protective factor against violence. Research has found that, in contrast to hostile sexism, benevolent sexism does not correlate with hostility toward women (Forbes et al., 2004) and different attitudes toward violence: attitudes toward wife abuse (Glick et al., 2002) and rape myth acceptance (Obierefu \& Ezeugwu, 2017). Moreover, it does not associate with the perpetration of dating violence (Allen et al., 2009; Morelli et al., 2016).

But on the other hand, some studies have shown that both hostile and benevolent sexism were positively associated with attitudes toward physical violence (Megías et al., 2018) and controlling behavior, threats, and insults of women (Martín-Fernández et al., 2018). Additionally, previous studies emphasized that benevolent sexism promotes violent behavior toward women who deviate from gender stereotypes as well as increasing violent attitudes toward them (e.g., victim blaming) (Abrams et al., 2003; Sakalli-Uğurlu et al., 2007). Thus, since benevolent sexism may also be a protective factor against violence, it can be assumed that hostile sexism should more strongly predicts violence than benevolent sexism.

\section{Potential moderators of the link between sexism and violence}

\section{Violence type}

Violence can manifest itself in various forms: physical, sexual, and psychological (Jordan et al., 2010). Physical violence is harming others physically (e.g. pushing, hitting, kicking or biting). This type of violence often leads to visible injuries and can even result in the death of a victim. Sexual 
violence includes behavior intended to compel another person to engage in unwanted sexual activity. Psychological violence is a form of abuse that includes coercive acts intended to produce emotional harm or threat of harm. Psychological abuse includes threatening behavior (e.g., insult, intimidation or manipulation), damaging a person's self-esteem, or restricting their personal freedom (Maiuro, 2001). In everyday perception, these forms of violence vary in the degree of their permissibility as a way to achieve dominance (Jordan et al., 2010).

Although in the framework of sexist attitudes men are perceived as strong, active, and dominant, physical male-to-female violence is considered as socially undesirable behavior. Supporting traditional gender stereotypes implies that from an early age boys are taught that 'it is unacceptable to hit girls' since girls are weak and defenseless (Rudman \& Glick, 2008). Such beliefs are well reflected in benevolent sexism which promises protection of 'good' women. If men break this rule, their behavior is considered cowardly and unworthy of men. Sugarman and Frankel (1996) conducted a meta-analysis that showed that men who shared traditional gender attitudes (belief that women must be warm, devoted, compassionate, etc.) did not support physical violence toward their wives. Thus, social norms and gender expectations embedded in sexist attitudes should not contribute to the manifestation of physical violence.

In contrast, sexual abuse is not seen as something negative within the framework of sexist beliefs. Benevolent sexists might consider sexual abuse as part of normal sexual activity between romantic partners or spouses, as stereotypes about traditional gender roles include the idea that women should be ready to satisfy men's sexual desires (especially in marriage) (Durán et al., 2011). Hostile sexists believe that women use their sexuality in order to control and manipulate men (Glick \& Fiske, 2001) and, as a result, consider the sexual exploitation of women (including objectification and sexual abuse) to be a normal part of the relationship between men and women. Abrams with colleagues (2003) demonstrated that the greater the hostile sexism, the greater the readiness is to rape a woman known to the man and to disagree that it is rape. Hall and Canterberry (2011) showed that men with 
high levels of hostile sexism are more likely to use assertive courtship strategies. Taken together, these findings suggest that both hostile and benevolent sexism support sexual violence.

As for psychological violence, due to the fact that both hostile and benevolent sexism imply that women should have less power and be dependent on men (Glick \& Fiske, 2001), it can be considered as a way to support women's financial and psychological dependence. Psychological abuse can be a convenient mean of suppressing women, since, as opposed to physical or sexual abuse, it predominantly features hidden consequences that are not noticeable to others (e.g., anxiety, depression, post-traumatic stress disorder) (Dokkedahl et al., 2019; Follingstad, 2007) and in lay perception it is represented as less harmful, abusive, deviating from social norms and deserving of punishment (Hammock et al., 2015; Williams et al., 2012). Rollero with colleagues (2019) found that the higher a person's level of hostile and benevolent sexism, the less they will believe that restricting a partner's freedom is a form of psychological violence, and for hostile sexists, the humiliation and bullying of a woman is not an example of psychological violence.

Thus, ambivalent sexism does not tend to support physical violence, as opposed to sexual and psychological ones, which may indicate that the type of violence may moderate the relationship between ambivalent sexism (both hostile and benevolent) and violence toward women.

\section{Context of violence}

Ambivalent sexism can manifest itself in different ways in various contexts: in the close relationships and outside of them. Benevolent sexism plays a significant role in the context of close relationships. The previous research demonstrated that some women prefer the benevolent sexists as a romantic partner and potential husbands since the partners' benevolent attitudes promise a protection and admiration (Gul \& Kupfer, 2019; Lee et al., 2010). Moreover, this type of sexism encourages women who fill traditional female roles (for example, mother and wife) that are mostly associated with intimate context (Gaunt, 2013; Glick et al., 2015). Men may prefer benevolent sexism as a way to control women in intimate relationships since it appears to offer more socially desirable beliefs and behavior than hostile sexism and include the idea of a certain social exchange: if a woman fulfills her 
gender role and does not violate the gender hierarchy, she receives the support and protection of a man (physical and financial). But when benevolent sexism no longer helps coerce women into traditional female behavior, hostile sexism may be activated, thereby increasing the probability of violence toward women. In other words, despite the fact that in close relationships most interactions can be based on benevolent attitudes, violence can swiftly replace protection and be perceived as a way to restore status and reputation, increase control over women, and return them to traditional gender behavior (Vandello \& Cohen, 2003). At the same time, Cross with colleagues (2017) showed that in close relationships, the relationship between hostile sexism and aggression toward a partner will depend on perceived partner's commitment. In particular, the less perceived female commitment to the relationship, the stronger association between male hostile sexism and daily aggression. Thus, in close relationships, hostile sexism may not always be strongly associated with violence.

Outside of an intimate context (for example, in a professional or political sphere), women are often perceived as competitors for power who violate gender roles and it leads to benevolent gender attitudes becoming less important. In this case, hostile sexism can largely determine men's behavior toward women. As mentioned earlier, hostility toward women is positively associated with violence against them, since violence can be seen as an adequate way to protect the gender hierarchy (Langhinrichsen-Rohling et al., 2012).

Thus, since in the context of close relationships, motivation to maintain friendly relationships is more important, while outside the intimate context, power struggles are more important, it can be expected that the relationship between ambivalent sexism and violence in various contexts will be different. In particular, outside the intimate context hostile sexism will be strongly associated with violence while in the intimate context, benevolent sexism will be strongly associated with violence. Summing up, the relationship between hostile and benevolent sexism and violence can be moderated by the context of violence. 


\section{Other potential moderators: characteristic of studies}

Since the studies' characteristics can be possible sources of variability in the relationship between sexism and violence, we considered the respondents' gender, the level of gender equality/inequality in the country where the data were collected, and the type of sample (general population or college students) as additional moderators.

Gender differences. The cross-cultural study by Glick with colleagues (2000) showed that men have a significantly higher level of hostile sexism than women, wherein women rejected hostile sexist attitudes but often accepted benevolent ones, such that in some countries, they endorse benevolent sexism more strongly than men.

Hostile sexism is significantly less pronounced among women since it assumes their punishment for deviation from gender stereotypes and expectations, whereas benevolent sexism promises the role of a 'princess' who is adored by her 'prince.' Benevolent sexism encourages the implementation of traditional female roles. In return, it offers 'good women' support and admiration. Previous studies have shown that women often base their identity on internalized gender stereotypes (Rudman \& Glick, 2008) and endorse the self-silencing beliefs which suggest that women should avoid conflicts in interpersonal relationships and base their behavior on external standards (e.g., gender roles) (Swim et al., 2010). Importantly, for women with high levels of benevolent sexism, another woman who deviates from the gender expectation is someone who threatens the 'good woman' identity. As a result, supporting and justifying violence toward a 'bad' woman can be a way to maintain a positive social identity (Marques \& Paez, 1994). One way to maintain a positive self-image in women with high levels of sexism is to justify the aggressor when victims are blamed for being physically or sexually abused, since if they behaved correctly, this would not happen to them (Diehl et al., 2012; Herrera et al., 2014). Therefore, it is benevolent sexism in women that may be associated with the maintenance of male-to-female violence.

For men, women whose beliefs and behavior correspond to traditional gender stereotypes are comfortable partners in life, since in this case nothing threatens the high status of men. In relation to 
such women, men often use benevolent sexism, which to some extent protects women from violence. In contrast, women who deviate from the traditional gender roles are a threat to men's social status (Gaunt, 2013; Glick et al., 2015). Hostile sexist beliefs which include the idea that women are playing a dishonest game in an attempt to get a power can help men justify extreme forms of maintaining their status (e.g., violence).

Thus, the respondents' gender can moderate the relationship between ambivalent sexism and attitudes toward male-to-female violence, such that for men, hostile sexism will be more strongly associated with positive attitudes toward violence than benevolent one, while for women, a pattern can be opposite.

Country. Countries differ in the level of gender equality between men and women. The Gender Inequality Index (GII) is one the most popular and frequently used measures of the level of gender inequality that includes three different aspects of human development - Reproductive health, Empowerment, and Economic status (Human Development Reports, 2019) and ranges from 0 to 1. A larger index value corresponds to greater gender inequality.

Based on data from 32 countries, Napier with colleagues (2010) demonstrated that gender equality on a national level is associated with low hostile sexism and not with benevolent justification of gender inequality. Social discourse that promotes equality is poorly compatible with attitudes that belittle other people (e.g., hostile sexism) and violence as a way to preserve hierarchy. Ebbeler, Grau, and Banse (2017) have shown in a cross-cultural study that the higher the level of gender equality, the lower the level of domestic violence against women (e.g., physical aggression). In contrast, in countries with high levels of inequality, unequal access to resources (health care or education) places women in a dependent position that increases the spread and support of hostile sexist attitudes that, in turn, increase the risk for interpersonal violence toward women (Montesanti \& Thurston, 2015). Yodanis (2004) found that in countries where the educational and occupational status of women is low, the prevalence of sexual violence against women tends to be higher. Archer (2006), using data from 52 nations, demonstrated that if women do not have high status, resources, power, or authority, the 
likelihood of violence toward them is increased, especially in close relationships. As a result, in countries with high levels of gender inequality, hostile sexism through the idea that violence is an acceptable way to control women may be significantly more associated with the manifestation of violence than in countries with high levels of equality, where hostile sexist attitudes are perceived as socially undesirable and violence as unacceptable.

As for benevolent sexism, since it is often not perceived as a real sexism (Barreto \& Ellemers, 2005), egalitarian discourse does not condemn it. Moreover, in some cases women prefer men with benevolent sexist attitudes as romantic partners (Lee et al., 2010) which may indicate the social desirability of such beliefs. Thus, benevolent sexist attitudes can be widespread in countries regardless of their level of gender equality. At the same time, in countries with a high level of equality, the relationship between benevolent sexism and violence against women can be lower than in countries with high levels of inequality, since in egalitarian countries institutions and social policies both provide protection of women and punish perpetrators for manifestations of violence (Corradi \& Stöckl, 2016).

Taken together, it can be assumed that the level of gender equality of a country can moderate the relationship between ambivalent sexism and violence.

Sample type. Previous studies have shown that lower age is associated with a higher level of liberal attitudes related to gender and sex roles (Morgan \& Walker, 1983). Younger people tend to be more open to new experience, and more politically and religiously liberal (Shackelford \& Besser, 2007). According to Hammond with colleagues (2018) and their study of a nationally representative panel sample in New Zealand, people tend to shift their ambivalent sexist beliefs with age: while hostile sexism generally declines in youger and older people independent of gender, benevolent sexism increases only for older women. Since the average age of respondents in the sample of students is younger than that of the general population, the type of sample can moderate the relationship between hostile and benevolent sexism and violence. 


\section{The current meta-analysis}

The main aim of this study was to investigate the relationship between ambivalent sexism and violence. Two research questions correspond to the aim of our study.

RQ1: How are subjectively negative (hostile) and subjectively positive (benevolent) sexist attitudes associated with violence toward women?

RQ2: How different variables moderate the relationship between hostile and benevolent sexism and violence?

The answers to these questions were sought through the testing of several hypotheses.

H1: Hostile sexism will be more strongly connected with violence toward women than benevolent sexism.

$\mathrm{H} 2$ : The type of violence will moderate the relationship between ambivalent sexism and violence toward women such that hostile and benevolent sexism will be least associated with physical violence and more strongly associated with sexual and psychological violence.

H3: The context of violence will moderate the relationship between ambivalent sexism and violence toward women such that outside the intimate context hostile sexism will be strongly associated with violence while in the intimate context, benevolent sexism will be strongly associated with violence.

H4: Respondents' gender will moderate the relationship between ambivalent sexism and violence toward women such that in a male subgroup, hostile sexism will be more associated with violence while in female subgroup benevolent sexism will be stronger assoviated with violence.

H5: The level of gender inequality in a country will moderate the relationship between ambivalent sexism and violence toward women such that in countries with low levels of gender equality, both hostile and benevolent sexism will be associated with violence, while in countries with higher gender equality, only benevolent sexism will be. 
H6: The sample type will moderate the relationship between ambivalent sexism and violence toward women such that for the general population, the links between hostile and benevolent sexism with violence will be stronger than for the student samples.

The meta-analysis presented here contributes to the existing findings related to sexism and violence in three ways. First, there are no generalized data on the relationship of sexists' attitudes toward women with support and justification of violence against them. In previous meta-analyses, researchers have shown that husbands who support patriarchal gender ideology are more offensive than those who do not (Sugarman \& Frankel, 1996) and that the 'combined measures of sexism' (benevolent sexism, ambivalent sexism, neo-sexism, hostile sexism, old-fashioned sexism, modern sexism) related significantly to the acceptance of rape myths (Suarez \& Gadalla, 2010). At the same time, these findings cannot say anything about how subjectively negative (hostile) and subjectively positive (benevolent) sexist attitudes are related to violence. Our analysis helps fill this gap. Moreover, we study the relationship of ambivalent sexism with the manifestation of various type of violence (physical, sexual, and psychological) and not only in close relationships, but also outside of this context. Taken together, this meta-analysis presents the first attempt to analyze violence in all its manifestations and reach comprehensive conclusions about the role of ambivalent sexism in the maintenance of violence against women.

Second, we separately analyzed the relationship between ambivalent sexism and attitudes toward violence and behavior. This separation allowed us, for the first time, to empirically evaluate the extent to which sexism is embedded in the discourse supporting violence (expressed in attitudes toward violence) and the extent to which benevolent and hostile sexism are associated with actual violent behavior. In general, researchers assume that attitudes often include shared elements, as individuals tend to bring their beliefs into some coherent system, increasing the likelihood of two similar, rather than conflicting, attitudes (Swann, 2012). With regards to sexism, beliefs in male dominance and stereotypical gender expectations belong to both sexist attitudes and attitudes that justify violence (Lonsway et al., 2008). Therefore, it is possible to assume that sexist individuals will also share 
positive attitudes toward male-to-female violence, as both include similar beliefs about gender roles.

As for violent behavior, previous studies demonstrated that many other factors impact violent behavior besides the individual's beliefs and attitudes - for example, the physical and psychological state of a potential aggressor (Capaldi et al., 2012; Moore et al., 2008) and social norms (Anderson \& Bushman, 2002). As a result, the contribution of sexism to violent behavior may not be very strong in comparison to attitudes toward violence (Diehl et al., 2012; Hefley, 2006). The results regarding the link between ambivalent sexism and violent behavior will undoubtedly allow a better assessment of the predictive potential of the ambivalent sexism theory and can be useful for developing more efficient programs to reduce violence against women.

Third, the Ambivalent Sexism Theory assumes that people simultaneously hold benevolent and hostile attitudes toward women because these attitudes are complementary ways to support the status quo in the gender relationships. Empirically, research confirms the connection between benevolent and hostile sexism across various countries (Glick et al., 2000). However, while both hostile and benevolent attitudes toward women are sexist, in lay thinking the benevolent attitudes are seen as more normative and socially acceptable than hostile ones (Connelly \& Heesacker, 2012). Barreto and Ellemers (2005) demonstrated that people perceived benevolent sexist beliefs as less sexist than hostile ones and did not consider them a type of prejudice. Lee with colleagues (2010) found that some women prefer men with benevolent sexist attitudes as romantic partners and perceived them more positively than men without such attitudes. As a result, the belief that it is hostility toward women that relates to violence against them leads to active combating against hostile sexism, while benevolent sexism remains a widespread ideology. Hovewer, the independent contribution of hostile and benevolent sexism in violence toward women is rarely studied (e.g., Allen et al., 2009; Eyssel \& Bohner, 2007). The lack of research does not allow to draw a reasonable conclusion about the extent to which benevolent sexism will be associated with violence against women if the level of hostile sexism is controlled and vice versa. The meta-analysis presented is the first attempt to systematically assess both the general and independent effects of benevolent and hostile sexism on violence. 


\section{Method}

\section{Literature search}

To identify as many studies as possible for inclusion in the meta-analysis, several steps were employed. First, we undertook computer-based searches in Scopus, Web of Science, EBSCO, APA resources (PsycExtra, PsycInfo, PsycArticle), and ProQuest Dissertations \& Theses database. The following keywords were used for the search: ambivalent sexis* OR hostile sexis $*$ OR benevolent sexis* OR hostile attitude* OR benevolent attitude ${ }^{* 1}$. We also limited our search to articles published since 1996 (the year of the publication of the Ambivalent Sexism Theory). All searches encompassed articles published up to February 2020. Second, to identify documents that might not be included in the main search we used additional search strategies. We reviewed the references from previous metaanalyses, including data about violence (e.g., Rotundo et al., 2001; Suarez \& Gadalla, 2010), references from different reviews about ambivalent sexism (e.g., Connor et al., 2016), and citations from two highly cited articles about ambivalent sexism (Glick \& Fiske, 1996, 2001); searched preprints and dissertations in various resources (e.g., www.opengrey.com, psyarxiv.com); sent a call for unpublished data to the listserv of the Social Psychology Network (https://www.socialpsychology.org/); and sent personalized emails to authors who have written articles on the relationship between violence and sexism.

The second and third authors performed the literature searches. After all searches were completed, duplicate references were deleted from the final list and 11,484 documents (including dissertations and unpublished data) were identified for initial review. The first and fourth authors

\footnotetext{
${ }^{1}$ The keywords related to violence were not included in the search since the violence-related measures could not be the main object of research. Consequently, some studies that fitted our aims may not have been caught by our search. Using broad search criteria allowed us to find the maximum number of relevant studies.
} 
independently reviewed titles and abstracts from the list of potentially relevant studies. After that, we identified 596 documents, including published papers and dissertations, as relevant for full-text analysis.

\section{Criteria for inclusion and exclusion}

Studies were included in the meta-analysis if they met the following criteria. First, sexism had to be measured by the Ambivalent Sexism Inventory (ASI) (Glick \& Fiske, 1996, 2001) and data about the relationship between ambivalent sexism and physical, psychological, or sexual violence reported in the study. Even though hostile and benevolent attitudes toward women can be measured in different ways, we included only ASI in the analysis. Such a strategy will help remove one of the strong sources of heterogeneity and make the operationalization of ambivalent sexism more homogeneous. As a result, the effect sizes about the relationship between violence and Attitudes Toward Women Scale (e.g., Shen et al., 2012) or Hostility toward women (e.g., Samji \& Vasquez, 2019) were not included in the meta-analysis.

Second, studies must have included effect sizes or the relevant statistics to enable calculation of effect sizes (correlations, mean and standard deviation for experimental studies). If the study met the first criterion but did not report relevant statistics, we contacted the paper's authors for pertinent information by email. Emails were sent to 69 authors, 17 of whom provided the requested information. These data were included in the meta-analysis. The theoretical papers, reviews, and studies with qualitative methodology were not included (e.g., Alvarez et al., 2018).

Third, studies must have included heterosexual women as the targets of violence and men as the aggressor, or to have investigated attitudes toward male-to-female violence. We did not include in the meta-analysis studies of violence in same-sex relationships, since there may be many additional stress factors (e.g., social isolation, the level of homonegativity), and gender expectations (e.g., that gay men are more feminine and less aggressive than heterosexual men, or that aggression in lesbian couples is harmless) that differentiate this type of relationship from heterosexual ones and can affect the 
manifestation of violence (De Barros et al., 2019; Rollè et al., 2018). Moreover, Messinger (2011) demonstrated that, in general, gay, lesbian, or bisexual people are more likely to experience all forms of abuse than heterosexual individuals.

Fourth, studies must not include samples that are homogeneous in terms of some specific characteristics. We did not include offender samples (Loveland \& Raghavan, 2017), victim of violence samples (e.g., LeMaire et al., 2016), police officer samples (e.g., Gölge et al., 2016), a clergy sample (Yuvarajan \& Stanford, 2016) and so on in our meta-analysis. In these cases, either specific role attitudes and expectations (as for police officers or clerks) or unique experience (offenders) can significantly determine the attitudes toward violence.

Fifth, the same results must be considered only once. If the same data were included in a paper and a dissertation, we coded them just once.

We did not put restrictions on the language in which the paper was written and in total, 152 documents in Russian, English, German, French, Spanish, Turkish, and Portuguese matched these criteria and were coded: 37 described the relationship between violent behavior and ambivalent sexism, and 124 the relationship between attitudes toward male-to-female violence and ambivalent sexism. As data about violence and attitudes toward violence could be presented simultaneously in the study, some of the studies were included in both meta-analyses. Figure 1 illustrates the final inclusion flow chart. 


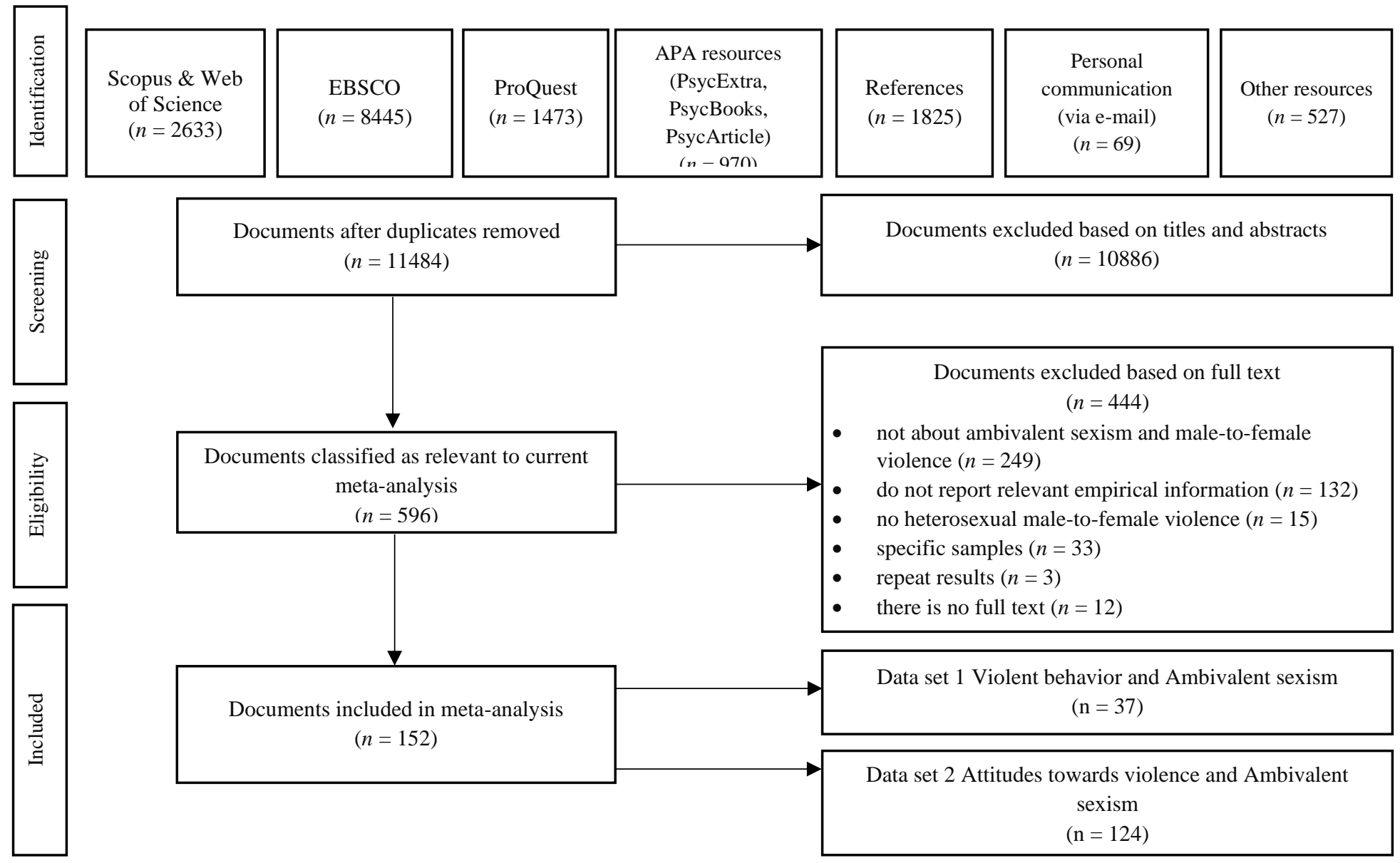

Figure 1. Flow chart of the literature search.

\section{Coding procedure}

All studies were coded by two independent coders (the first and fourth authors). For all documents, coders recoded the following characteristics.

Document characteristics. The document type (journal article, dissertation, conference paper or data), publication status (published, unpublished), authors, and year of publication.

Sample characteristics. Total sample size, respondents' sex (the number of men, women, and persons who missed this point or choose 'other'), sample description (university students, school student, or general population), and country of data collection. If country was not presented in the document, the country of the first author's affiliation was coded; if respondents from different countries were included in the sample and analysis was not carried out separately for countries, we coded 'not available'. 
Sexism type. The scale of Ambivalent Sexism Inventory (hostile sexism or benevolent sexism) (Glick \& Fiske, 1996).

Violence type. Violence was divided into four types: physical, sexual, psychological, and other. The category 'Physical violence' included studies about violent behavior which focused on selfreported physically violent tactics, most often measured by the 'physical violence' subscale from the Conflict tactic scale (e.g., Toplu Demirtaş et al., 2017) $(n=22)$ or the 'physical abuse' subscale from the Conflict in adolescent dating relationships inventory (e.g., Rojas-Solís \& Raimúndez, 2011) ( $n=$ 4), actual physically violent behavior measured by the Response-choice aggression paradigm (e.g., Hyatt et al., 2017) $(n=8)$. Also in this category were included attitudes towards violence (e.g., the Attitudes toward wife beating scale (e.g., Megías et al., 2018) $(n=19)$, the Attitudes toward wife abuse scale (Glick et al., 2002) $(n=4)$ or the Attitudes toward male physical dating violence scale (Erdem \& Sahin, 2017) $(n=2))$.

The category 'Sexual violence' included studies about violent behavior where self-reported sexual violence (e.g., the 'sexual violence' subscale from the Conflict tactic scale (e.g., Jongsma, 2019) $(n=7)$, the 'perpetration' version of the Sexual experiences survey (e.g., Forbes \& AdamsCurtis, 2001) $(n=8)$, or the 'sexual abuse' subscale from the Conflict in adolescent dating relationships inventory (Rojas-Solís \& Raimúndez, 2011) (n=2)), observed respondents' sexually violent behavior during an experiment (e.g., using sexual slurs and jokes (Diehl et al., 2018) or sending a sex video (Bosson et al., 2015) $(n=8)$ ). Also in this category were included attitudes toward sexual aggression (e.g., the Illinois rape myth acceptance scale (e.g., Chapleau et al., 2007) $(n=59)$, the Rape myth acceptance scale $(n=36)$, the Acceptance of modern myths about sexual aggression scale (e.g., Megías et al., 2018) $(n=31)$, the Likelihood to sexually harass scale (e.g., Begany \& Milburn, 2002) ( $n=13)$, the Illinois sexual harassment myth acceptance scale (e.g., Russell \& Oswald, 2016) $(n=15)$ and so on) were investigated.

The 'Psychological violence' category involved studies in which different self-reported or actual psychologically aggressive practices were measured, for example by the 'psychological abuse' 
subscale from the Conflict tactic scale (e.g., Forees et al., 2004) $(n=18)$, the 'verbal abuse' subscale from the Conflict in adolescent dating relationships inventory (Rojas-Solís \& Raimúndez, 2011) $(n=$ 4), the 'perpetration' version of the Multidimensional measure of emotional abuse (Toplu Demirtaş, 2015) ( $n=3$ ), self-reporting about the use of assertive strategies (Hall \& Canterberry, 2011) $(n=6)$, aggressive communication demonstrated during the experiment (Cross et al., 2017) $(n=2)$ and so on. This category also involved attitudes toward psychological violence. For example, the Attitudes toward male psychological dating violence scale (Erdem \& Sahin, 2017) $(n=2)$ or different Victim blaming measures (e.g., Riley \& Yamawaki, 2018) $(n=72)$. The last was considered as an example of psychological violence since such attitudes damage a person's self-esteem and demonstrate a denial of empathy for the victim. The category 'Other' consisted of studies that had no subscales of different type of violence, or in which the subscales were not analyzed separately (e.g., Allen et al., 2009).

Context of violence was determined based on either the content of the scale used or an example of a vignette. If the authors used different scales including statements about a close partner (e.g., the Conflict tactic scale, the Inventory of Beliefs about Wife Beating, or the Attitudes toward domestic violence scale) or intimate partners participated in the experiment, such studies were coded as 'women in intimate partnerships / yes' $(n=178)$. In all cases in which violent attitudes toward women in general were measured (e.g., different rape myth acceptance scales) or a female stranger was described or participated in the experiment, we coded the case as 'women in intimate partnerships / no' $(n=$ 453).

Scale alphas for hostile and benevolent sexism and violence measures also were coded. For continuous variables (sample size, scale alphas, and effect sizes) interrater reliability was high (ICC3k ranges from 0.88 to 1.00 ). For categorical variables (sample type, country of data collection, sexism type, violence type, and context of violence) interrater reliability was also high (Cohen's Kappa ranged from 0.80 to 1.00 ). All disagreements in coding were resolved by the consensus reached after discussion among the authors. 


\section{Collecting of effect sizes}

The correlation coefficient was used as an effect size in the meta-analysis. For each study, we collected the correlation coefficient for the relationship between violent behavior and hostile and benevolent sexism and between attitudes toward violence and hostile and benevolent sexism. Effect sizes were recoded to reflect a direct relationship (a high level of sexism, a high level of violent behavior or attitudes toward violence) if needed. We also collected the correlation coefficient for the relationship between hostile and benevolent sexism if it was available. This correlation coefficient is needed for estimation of the unique shares in the variation of the attitudes towards violence or violent behavior which are explained by hostile and benevolent sexism separately.

In six cases, the correlation coefficients between the benevolent sexism scale and violence were not reported, but the correlation coefficients between the three benevolent sexism subscales and violence were. In these cases, the averages of these three correlation coefficients were calculated and used as effect sizes in the meta-analysis. The same strategy was used when it was not possible to obtain the correlation coefficients between the sexism and violence scales but the correlation coefficients between the sexism and subscales of violence scales were reported (e.g., Beliefs about Wife Beating Scale (two cases); Illinois Rape Myth Acceptance Scale (eight cases); Multidimensional Measure of Emotional Abuse (three cases); Inventario de Pensamientos Distorsionados sobre la Mujer y la Violencia (IPDMV) (four cases); and Rape Perception (two cases)). In the single case of an experimental study, the correlation coefficient was calculated based on the means and standard deviations by the mes function from the compute.es package in R (Del Re, 2013). In 48 cases, the documents did not report Cronbach's alphas for sexism scales. Since the share of missing values is not high and size of the sample with known Cronbach's alphas is relatively large, we filled in missing Cronbach's alphas for benevolent and hostile sexism scales by arithmetic means calculated based on our sample. 


\section{Meta-analysis procedure}

At the first stage, correlation coefficients were corrected for measurement error. Following Hunter and Schmidt (2004), the individual correlation coefficient was divided by the square root of the reliability estimates (Cronbach's alpha) of the two correlated variables, when the reliability estimates were available. When reliabilities for the violence scale were not reported, or the measure consisted of only a single item, the individual correlation coefficient was divided by the square root of the reliability estimates of only one correlated variable (benevolent or hostile sexism). After the measurement error correction procedure, one correlation coefficient took a value greater than 1 (1.036). Since the correlation coefficient cannot take a value greater than 1 , we manually assigned the value .999 to this correlation coefficient. At the second stage, correlation coefficients were transformed to the Fisher's $z$ scale. Variances for each effect size were computed using the metafor package in $\mathrm{R}$ (Viechtbauer, 2010). Effect sizes and the main characteristics of studies are shown in Appendix. The dataset and R scripts for analysis are available via the Open Science Framework: https://osf.io/gepkb/.

All analyses were conducted using random effects models. First, separate bivariate metaanalyses were performed in order to evaluate the bivariate correlations between benevolent and hostile scales of sexism and violence. Most studies report correlations separately for the benevolent and hostile scales of sexism, as well as for several measures of violence at once, so the collected effect sizes are not independent. To take into account the dependence of effect sizes, we used the robust variance estimation (RVE) (Hedges et al., 2010) via the robumeta package in R (Fisher et al., 2017; Fisher \& Tipton, 2015). This method provides valid estimates and hypothesis tests even when the degree and structure of dependence between effect sizes are unknown. The overall correlation between ambivalent sexism and violence was estimated using an intercept-only meta-regression model, in which an intercept can be interpreted as the precision-weighted mean effect size of all studies, corrected for effect-size dependence.

Second, benevolent and hostile scales are correlated, so positive correlation between benevolent sexism and male-to-female violence may be due to its association with benevolent and hostile sexism. 
To estimate the unique effects that hostile and benevolent sexism exert on the attitudes toward violence or violent behavior we used one-stage Meta-Analytic Structural Equation Modeling (MASEM) using Shiny app "webMASEM" (Jak et al., 2021). MASEM is an appropriate technique when one needs to test a SEM (e.g., a path model) on the averaged correlations between research variables across several studies (Jak et al., 2021). The bivariate correlations between the three variables (benevolent sexism, hostile sexism, and attitudes toward violence/violent behavior) were used in this analysis. We estimated two averaged correlation matrices for these variables. Next, the two path models with two predictors and one outcome variable were fitted on the corresponding averaged correlation matrices. In the first model, attitudes toward violence was regressed on benevolent and hostile sexism. In the second model, violent behavior was regressed on benevolent and hostile sexism.

Third, moderator analysis was performed to test the effects of possible moderators on the relationship between hostile and benevolent sexism and violence. Moderator analysis was performed using meta-regression (RVE), in which the moderator variable was included as a predictor. Continuous moderators were included in a meta-regression without transformation. Categorical moderators were transformed into $k-1$ dummy-variables. When a categorical moderator variable has two levels, the regression coefficient for this dummy-variable should be interpreted as a difference in effect size between the two levels of the moderator, and an $t$-test for this coefficient can be used as a test of moderation. When a categorical moderator variable has more than two levels, the regression coefficient for the relevant dummy-variables represents the difference in effect size between only two levels of the moderator (the reference and the single comparison levels). To test the joint null hypothesis that average effect size is equal across all levels of the moderator, the Waldtest function from the clubSandwich package in R (Pustejovsky, 2017) was used. This function provides an $F$-type test with degrees of freedom estimated using the approximate Hotelling's method (abbreviated HTZ). The weighted mean effect sizes for different levels of moderators were estimated using metaregression without intercept. In the first step, separate meta-regression models were run with each moderator variable as a predictor to test the bivariate relationship of each moderator with the effect 
sizes. In the second step, we ran a meta-regression model with all moderators as predictors

simultaneously to control for possible confounds between moderators. For all meta-regression models, the in-study effect size correlation $(\rho)$ was set at .8 . The sensitivity analyses were conducted across varying values of $\rho(0, .2, .4, .6, .8,1.0)$ to check the robustness of the coefficient of meta-regression, standard error, and between-study variance in study-average effect sizes values. The estimated values of the coefficients, standard error, and between-study variance in study-average effect sizes are robust. There are no cases when the estimated value differs by more than .0002 across varying values of $\rho$. Detailed results of the sensitivity analyses are shown in the Supplemental Materials.

\section{Publication bias analysis}

We used three methods to estimate the degree of publication bias. First, we tested the publication status of each document (published or unpublished) as a moderator. Since published studies can have significantly larger effect sizes compared to unpublished studies, it may indicate publication bias. Second, we visually inspected funnel plots and tested their asymmetry by Egger's regression test. Egger's regression is a weighted, least squares regression of the effect size on standard errors. The significance of the coefficient associated with standard error (slope, $\left.b_{1}\right)$ in Egger's regression can be interpreted as a test of funnel plot asymmetry (Egger et al., 1997). Third, we used the Precision Effect Test - Precision Effect Estimate with Standard Errors technique (PET-PEESE, Stanley \& Doucouliagos, 2014). PET-PEESE is a two-step conditional procedure in which two weighted metaregression models are used: 1) regression of effect sizes on standard errors and 2) regression of effect sizes on variance (i.e., standard error squared). The intercepts $\left(b_{0}\right)$ of these regressions are interpreted as an estimate of the effect size when a standard error is zero, i.e. the weighted mean effect size corrected for publication bias. Stanley and Doucouliagos (2014) showed that PET underestimates the true effect when it is non-zero, whereas PEESE overestimates the true effect when it is null. Therefore, if the intercept $\left(b_{0}\right)$ from PET is significant, then intercept $\left(b_{0}\right)$ from PEESE should be used as the best estimate of the true effect, whereas if the intercept $\left(b_{0}\right)$ from PET is not significant, then intercept $\left(b_{0}\right)$ 
from PET should be used as the best estimate of the true effect. In practice, via a PET regression model one can both assess funnel plot asymmetry (the original Egger's regression test) using coefficient for the standard error (the slope coefficient, $b_{1}$ ) and estimate the true effect corrected for publication bias using intercept $\left(b_{0}\right)$ (Carter \& McCullough, 2014).

\section{Results}

\section{Description of dataset}

We identified 152 documents with 205 independent samples and 631 effect sizes about relationship between ambivalent sexism and violence. All studies were conducted or published between 1998 and 2020 (median year - 2015). There are significantly more studies investigating the relationship between both scales of ambivalent sexism and attitudes toward violence than toward violent behavior. 124 documents reported 498 effect sizes obtained from 173 independent samples (47877 participants) about the relationship between sexism and attitudes toward violence. 37 documents reported 133 effect sizes obtained from 42 independent samples (11190 participants) about the relationship between sexism and attitudes toward violence. 108 documents reported 250 effect sizes obtained from 145 independent samples about the relationship between benevolent sexism and hostile sexism. The vast majority of studies were conducted in the United States, the United Kingdom, Spain, and Turkey on student samples and using cross-sectional design. Most often, attitudes toward non-intimate partner were investigated, and violent behavior in relation to an intimate partner. Most research focuses on sexual abuse. The main characteristics of the dataset are described in Table 1 . 
Table 1. Characteristics of the datasets

\begin{tabular}{|c|c|c|c|c|c|c|c|c|}
\hline & \multicolumn{4}{|c|}{ Attitudes toward violence } & \multicolumn{4}{|c|}{ Violent behavior } \\
\hline & \multicolumn{2}{|c|}{ BS } & \multicolumn{2}{|c|}{ HS } & \multicolumn{2}{|c|}{ BS } & \multicolumn{2}{|l|}{ HS } \\
\hline & $k$ & $n$ & $k$ & $n$ & $k$ & $n$ & $k$ & $n$ \\
\hline Total & 151 & 234 & 170 & 264 & 30 & 57 & 42 & 76 \\
\hline \multicolumn{9}{|l|}{ Violence type } \\
\hline Physical & 15 & 15 & 15 & 15 & 9 & 15 & 14 & 20 \\
\hline Psychological & 44 & 50 & 48 & 54 & 14 & 20 & 20 & 26 \\
\hline Sexual & 90 & 121 & 99 & 131 & 9 & 13 & 14 & 20 \\
\hline Other (common) & 36 & 48 & 45 & 64 & 9 & 9 & 10 & 10 \\
\hline \multicolumn{9}{|l|}{ Context of violence } \\
\hline Intimate partner & 27 & 36 & 27 & 39 & 22 & 46 & 30 & 59 \\
\hline Non-intimate partner & 129 & 198 & 148 & 225 & 10 & 11 & 14 & 17 \\
\hline \multicolumn{9}{|l|}{ Country } \\
\hline Argentina & - & - & - & - & 1 & 3 & 1 & 3 \\
\hline Australia & 1 & 2 & 1 & 2 & - & - & - & - \\
\hline Belgium & 1 & 1 & 1 & 1 & - & - & - & - \\
\hline Brazil & 2 & 2 & 2 & 2 & - & - & - & - \\
\hline Canada & 2 & 2 & 4 & 5 & - & - & - & - \\
\hline Chile & 1 & 1 & 1 & 1 & - & - & - & - \\
\hline Colombia & 3 & 3 & 3 & 3 & - & - & - & - \\
\hline Cyprus & 1 & 1 & 1 & 1 & - & - & - & - \\
\hline France & 8 & 18 & 8 & 18 & - & - & - & - \\
\hline Germany & 7 & 8 & 10 & 11 & - & - & 5 & 7 \\
\hline Greece & 1 & 2 & 1 & 2 & - & - & - & - \\
\hline India & 1 & 1 & 1 & 1 & - & - & - & - \\
\hline Italy & 1 & 3 & 1 & 3 & 1 & 1 & 1 & 1 \\
\hline Japan & 1 & 2 & 1 & 2 & - & - & - & - \\
\hline Lebanon & 2 & 2 & 2 & 2 & - & - & - & - \\
\hline Mexico & 2 & 2 & 2 & 2 & 2 & 3 & 2 & 3 \\
\hline New Zealand & 3 & 6 & 3 & 6 & 6 & 6 & 6 & 6 \\
\hline Norway & 3 & 5 & 3 & 5 & - & - & - & - \\
\hline Portugal & 4 & 6 & 4 & 6 & - & - & - & - \\
\hline Spain & 22 & 32 & 27 & 41 & 4 & 7 & 4 & 7 \\
\hline Switzerland & 1 & 1 & 1 & 1 & - & - & - & - \\
\hline Turkey & 15 & 18 & 19 & 27 & 1 & 2 & 2 & 3 \\
\hline UK & 17 & 28 & 17 & 28 & - & - & - & - \\
\hline US & 49 & 81 & 54 & 87 & 12 & 30 & 18 & 41 \\
\hline Zimbabwe & 1 & 2 & 1 & 2 & - & - & - & - \\
\hline Unknown or mixed & - & - & - & - & 1 & 3 & 1 & 3 \\
\hline \multicolumn{9}{|l|}{ Sample type } \\
\hline General population & 54 & 86 & 60 & 101 & 14 & 29 & 20 & 38 \\
\hline Students & 100 & 148 & 113 & 163 & 16 & 28 & 22 & 38 \\
\hline \multicolumn{9}{|l|}{ Study design } \\
\hline Cross-sectional & 151 & 234 & 169 & 263 & 30 & 57 & 42 & 76 \\
\hline Experiment & - & - & 1 & 1 & - & - & - & - \\
\hline \multicolumn{9}{|l|}{ Published/Unpublished } \\
\hline Published & 130 & 201 & 145 & 225 & 25 & 37 & 35 & 53 \\
\hline
\end{tabular}


Unpublished

21

33

25

39

5

20

7

23

Note. $k$ - number of independent samples; $n$ - number of effect sizes.

\section{Ambivalent sexism and attitudes toward violence}

Sexism type

First, we calculated overall correlations of the hostile and benevolent sexism with attitudes toward violence. Both overall correlations are different from zero and significantly differ from each other, $t(170.0)=10.1, p<.001$. Fisher's $z$ for benevolent sexism and attitudes toward violence is $0.341,95 \%$ CI $[0.305,0.377]$ (equivalent to Pearson's $r=.328$ ) and for hostile sexism and attitudes toward violence is $0.572,95 \%$ CI $[0.524,0.621]$ (equivalent to Pearson's $r=.517$ ). The MASEM results confirmed that both hostile and benevolent sexism have the significant independent effects on attitudes toward male-to-female violence, and the effect of hostile sexism is stronger than the effect of benevolent one $(\beta=.42, p<.001 ; \beta=.09, p<.001 \text {, respectively })^{2}$. All together, these results support hypothesis 1.

\section{Moderator analyses}

The separate meta-regressions were run for each moderator to test the bivariate relationship of each moderator with the effect sizes. The results of these meta-regressions and weighted mean effect size for the relationship between ambivalent sexism and attitudes toward violence for each level of moderator variables are shown in Table 2 and Figures 2 and 3.

\section{Violence type}

Violence type moderated the relationship between benevolent sexism and attitude toward violence, $H T Z(49.0)=3.50, p=.022$. In comparison to attitudes toward psychological violence (Fisher's $z=0.326,95 \%$ CI [0.244, 0.408]), sexual violence (Fisher's $z=0.366,95 \%$ CI [0.322,

\footnotetext{
${ }^{2}$ Report with detailed webMASEM output is available on the OSF: https://osf.io/gepkb/.
} 
0.410], and other (common) violence (Fisher's $z=0.331,95 \%$ CI $[0.247,0.416]$ ) that did not differ from each other the smallest effect size was observed for attitudes toward physical violence (Fisher's $z=0.167,95 \%$ CI $[0.044,0.290])$.

Violence type also moderates the relationship between hostile sexism and attitudes toward violence, $\operatorname{HTZ}(51.7)=7.55, p<.001$. As in the case of benevolent sexism, the smallest effect size was observed for attitudes toward physical violence (Fisher's $z=0.386,95 \%$ CI $[0.265,0.506])$, whereas the largest effect size was observed for attitudes toward sexual violence (Fisher's $z=0.662,95 \% \mathrm{CI}$ $[0.595,0.730]$. Effect sizes for attitudes toward psychological violence (Fisher's $z=0.490,95 \%$ CI $[0.390,0.590])$ and toward other (common) violence (Fisher's $z=0.490,95 \%$ CI $[0.405,0.575]$ ) were in between (see Figure 2).

\section{Context of violence}

We found no evidence that the context of violence moderated the correlation between benevolent sexism and attitudes toward violence. Although mean effect size for an intimate relationship (Fisher's $z=0.242,95 \%$ CI $[0.123,0.362]$ ) were lower than for a non-intimate one (Fisher's $z=0.353,95 \%$ CI $[0.317,0.389])$, these differences are not statistically significant, $t(32.9)$ $=-1.83, p=.076$. The correlation between hostile sexism and attitudes toward violence was moderated by the context of violence, $t(31.8)=-2.82, p=.008$. Mean effect sizes for an intimate relationship (Fisher's $z=0.450,95 \%$ CI $[0.361,0.539]$ ) were lower than for a non-intimate one (Fisher's $z=0.592,95 \%$ CI $[0.539,0.644])$.

\section{Gender}

To test the role of gender as a moderator of the relationship between hostile and benevolent sexism and attitudes toward violence, we split the effect sizes into three groups: (1) effect sizes obtained from women-only samples, (2) effect sizes obtained from men-only samples, and (3) effect sizes obtained from mixed samples with both male and female participants. The meta-regression 
showed that there were no significant differences between these three groups, either in the case of benevolent sexism $(H T Z(96.2)=1.84, p=.165)$ or in that of hostile sexism $(H T Z(110.0)=2.60, p=$ .079). For estimated means of effect sizes for each group, see Table 2.

\section{Gender Inequality}

To test the role of the country where the study was conducted as a moderator of the relationship between hostile and benevolent sexism and attitudes toward violence, we included the values of the GII for each country as a predictor in the meta-regression. GII was a significant predictor of the relationship between benevolent sexism and attitudes toward violence, $t(38.1)=-3.81, p<.001$. In particular, the higher the value of the GII, the lower the correlation between benevolent sexism and attitudes toward violence $\left(b_{1}=-0.708,95 \% \mathrm{CI}[-1.084,-0.331]\right)$. The higher the equality, the higher the correlation between benevolent sexism and attitudes toward violence. However, the sample contained a limited number of countries (25) and the effect sizes were unevenly distributed among them, so this conclusion is not very strong and requires additional verification. In the case of hostile sexism, there was no evidence that gender inequality explains the variance of correlations with attitudes toward violence, $t(42.8)=-1.12, p=.270 ; b_{1}=-0.273,95 \%$ CI $[-0.765,0.219]$.

\section{Sample type}

We found no evidence that sample type moderated the relationship between benevolent sexism and attitudes toward violence, $t(105.5)=-0.91, p=.366$. Means of effect sizes received from the general population (Fisher's $z=0.358,95 \%$ CI $[0.297,0.420]$ ) and from the student samples (Fisher's $z=0.324,95 \%$ CI $[0.278,0.369]$ ) did not differ. In the case of hostile sexism, the means of effect sizes received from the general population (Fisher's $z=0.630,95 \%$ CI $[0.548,0.711]$ ) and from the student samples (Fisher's $z=0.541,95 \%$ CI $[0.483,0.600]$ ) seemed to be different. However, the formal test did not show a statistical difference at the conventional level $t(118.1)=-$ $1.76, p=.081$ 
Table 2. Effect sizes for the relationship between ambivalent sexism and attitudes toward violence by moderators

\begin{tabular}{|c|c|c|c|c|c|c|c|c|c|c|c|}
\hline \multirow[t]{2}{*}{ Moderator } & \multicolumn{7}{|c|}{ Summary effect } & \multicolumn{4}{|c|}{ Test of moderation } \\
\hline & $\mathbf{E S}$ & $95 \% \mathrm{CI}$ & $t$ & $d f$ & $p$ & $\boldsymbol{k}$ & $n$ & Statistic & $d f$ & $p$ & $I^{2}$ \\
\hline Sexism type & & & & & & & & $t=10.1$ & 170.0 & $\begin{array}{c}<.001 \\
\end{array}$ & 95.2 \\
\hline Benevolent sexism & .341 & $.305 / .377$ & 18.9 & 145.8 & $<.001$ & 151 & 234 & & & & \\
\hline Hostile sexism & .572 & $.524 / .621$ & 23.2 & 154.0 & $<.001$ & 170 & 264 & & & & \\
\hline \multicolumn{12}{|l|}{ Benevolent sexism } \\
\hline Violence type & & & & & & & & $H T Z=3.50$ & 49.0 & .022 & 92.6 \\
\hline Physical & .167 & $.044 / .290$ & 3 & 11.9 & .012 & 15 & 15 & & & & \\
\hline Psychological & .326 & $.244 / .408$ & 8 & 34.8 & $<.001$ & 44 & 50 & & & & \\
\hline Sexual & .366 & $.322 / .410$ & 16.5 & 82.2 & $<.001$ & 90 & 121 & & & & \\
\hline Other (common) & .331 & $.247 / .416$ & 7.9 & 32.4 & $<.001$ & 36 & 48 & & & & \\
\hline Context of violence & & & & & & & & $t=-1.83$ & 32.9 & .076 & 92.5 \\
\hline Intimate partner & .242 & $.123 / .362$ & 4.2 & 23.6 & $<.001$ & 27 & 36 & & & & \\
\hline $\begin{array}{l}\text { Non-intimate } \\
\text { partner }\end{array}$ & .353 & $.317 / .389$ & 19.3 & 126.0 & $<.001$ & 129 & 198 & & & & \\
\hline Sample type & & & & & & & & $t=-0.91$ & 105.5 & .366 & 93.0 \\
\hline General population & .358 & $.297 / .420$ & 11.6 & 51.5 & $<.001$ & 54 & 86 & & & & \\
\hline Students & .324 & $.278 / .369$ & 14.2 & 96.7 & $<.001$ & 100 & 148 & & & & \\
\hline Gender & & & & & & & & $H T Z=1.84$ & 96.2 & .165 & 92.6 \\
\hline Women only & .371 & $.300 / .443$ & 10.6 & 34.4 & $<.001$ & 36 & 53 & & & & \\
\hline Men only & .293 & $.243 / .342$ & 11.9 & 52.0 & $<.001$ & 54 & 92 & & & & \\
\hline Mixed & .340 & $.278 / .402$ & 10.9 & 60.7 & $<.001$ & 62 & 86 & & & & \\
\hline Publication status & & & & & & & & $t=-1.28$ & 27.0 & .211 & 93.1 \\
\hline Published & .345 & $.305 / .384$ & 17.2 & 127.6 & $<.001$ & 130 & 201 & & & & \\
\hline Unpublished & .283 & $.191 / .374$ & 6.4 & 20.0 & $<.001$ & 21 & 33 & & & & \\
\hline $\begin{array}{l}\text { Gender Inequality } \\
\text { Index }\end{array}$ & & & & & & & & $t=-3.81$ & 38.1 & $<.001$ & 91.7 \\
\hline \multicolumn{12}{|l|}{ Hostile sexism } \\
\hline Violence type & & & & & & & & $H T Z=7.55$ & 51.7 & $<.001$ & 95.8 \\
\hline Physical & .386 & $.265 / .506$ & 7.0 & 11.9 & $<.001$ & 15 & 15 & & & & \\
\hline Psychological & .490 & $.390 / .590$ & 9.9 & 38.5 & $<.001$ & 48 & 54 & & & & \\
\hline Sexual & .662 & $.595 / .730$ & 19.6 & 91.8 & $<.001$ & 99 & 131 & & & & \\
\hline Other (common) & .490 & $.405 / .575$ & 11.6 & 41.2 & $<.001$ & 45 & 64 & & & & \\
\hline Context of violence & & & & & & & & $t=-2.82$ & 31.8 & .008 & 96.1 \\
\hline Intimate partner & .450 & $.361 / .539$ & 10.4 & 23.7 & $<.001$ & 27 & 39 & & & & \\
\hline $\begin{array}{l}\text { Non-intimate } \\
\text { partner }\end{array}$ & .592 & $.539 / .644$ & 22.2 & 145.9 & $<.001$ & 148 & 225 & & & & \\
\hline Sample type & & & & & & & & $t=-1.76$ & 118.1 & .081 & 96.2 \\
\hline General population & .630 & $.548 / .711$ & 15.5 & 57.9 & $<.001$ & 60 & 101 & & & & \\
\hline Students & .541 & $.483 / .600$ & 18.4 & 110.3 & $<.001$ & 113 & 163 & & & & \\
\hline Gender & & & & & & & & $H T Z=2.60$ & 110.0 & .079 & 96.1 \\
\hline Women only & .485 & $.408 / .563$ & 12.6 & 38.7 & $<.001$ & 40 & 60 & & & & \\
\hline Men only & .579 & $.518 / .639$ & 19.2 & 65.4 & $<.001$ & 67 & 112 & & & & \\
\hline Mixed & .610 & $.513 / .707$ & 12.6 & 62.9 & $<.001$ & 64 & 89 & & & & \\
\hline Publication status & & & & & & & & $t=-1.02$ & 33.0 & .316 & 96.3 \\
\hline Published & .582 & $.530 / .634$ & 22.1 & 143.5 & $<.001$ & 145 & 225 & & & & \\
\hline Unpublished & .516 & $.395 / .637$ & 8.8 & 24.0 & $<.001$ & 25 & 39 & & & & \\
\hline
\end{tabular}


Gender Inequality

$t=-1.12$

42.8

.270

96.3

Index

Note. ES - Fisher's $z ; k$ - number of independent samples; $n$ - number of effect sizes; $d f-$

Satterthwaite degrees of freedom (if the Satterthwaite degrees of freedom are less than 4, the

probability of a Type I error is much higher than .05 and one should not trust the results); $I^{2}$ - ratio of true heterogeneity to total variance across the observed effect sizes.
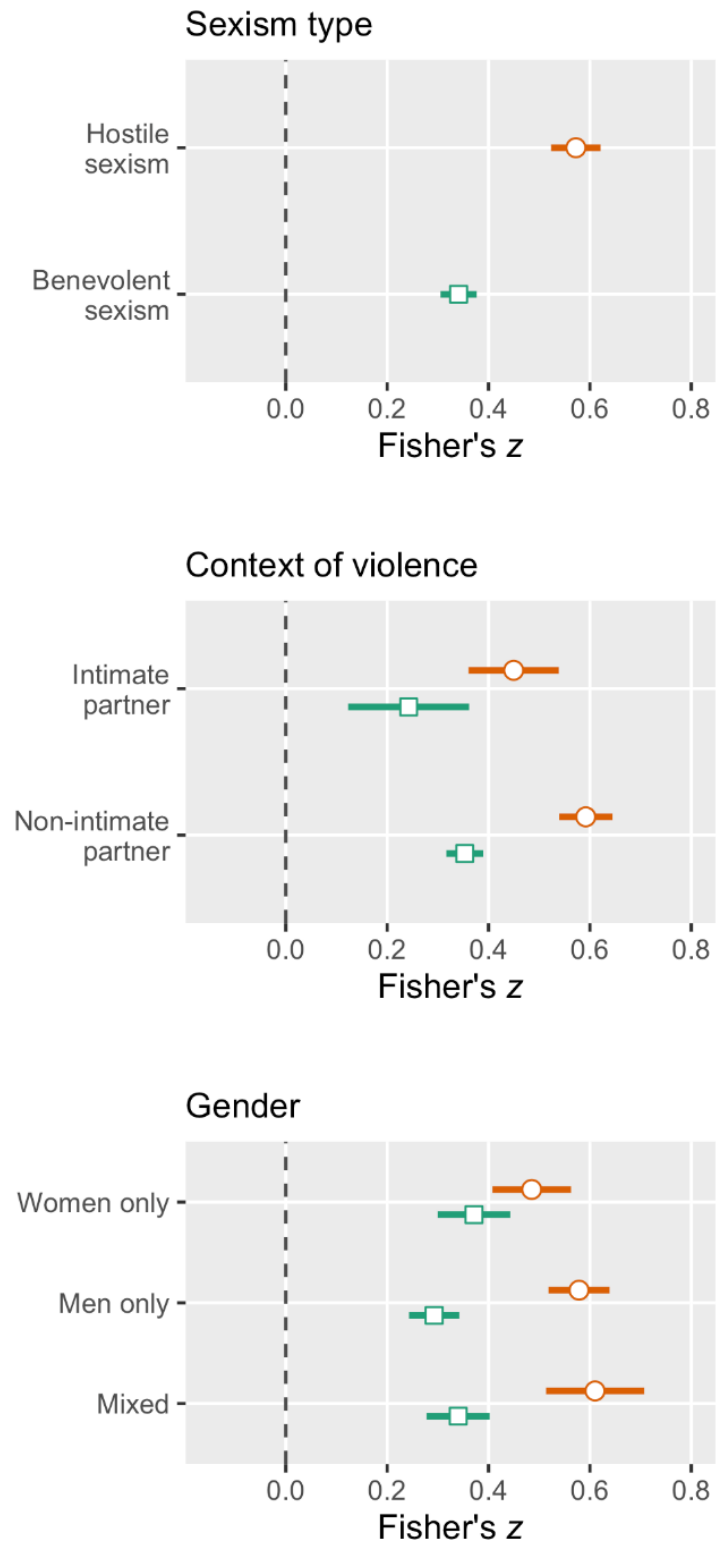

Violence type

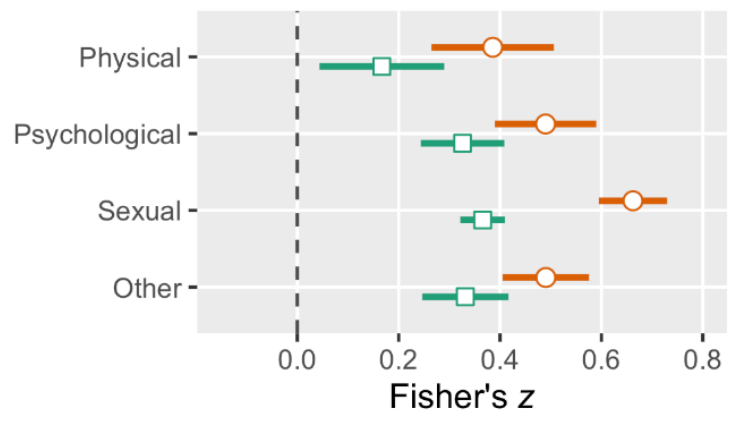

Sample type

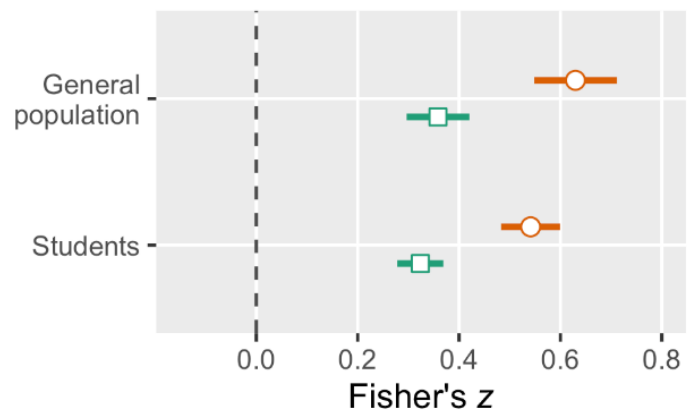

Publication status

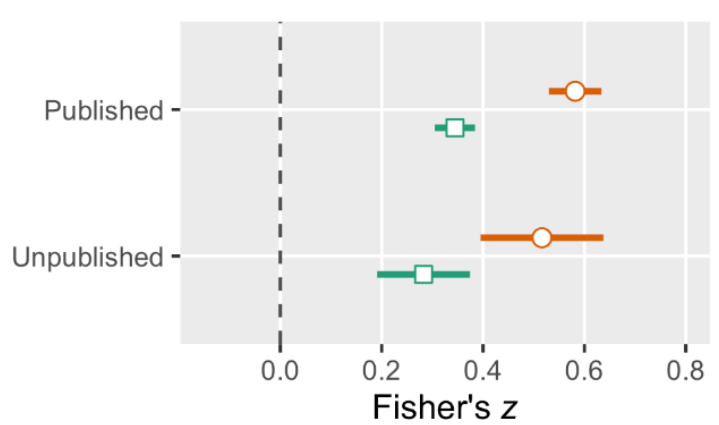

$=\square$ Benevolent sexism $=0$ Hostile sexism

Figure 2. Mean effect size for relationship between ambivalent sexism and attitudes toward violence for each level of categorical moderator variables. 

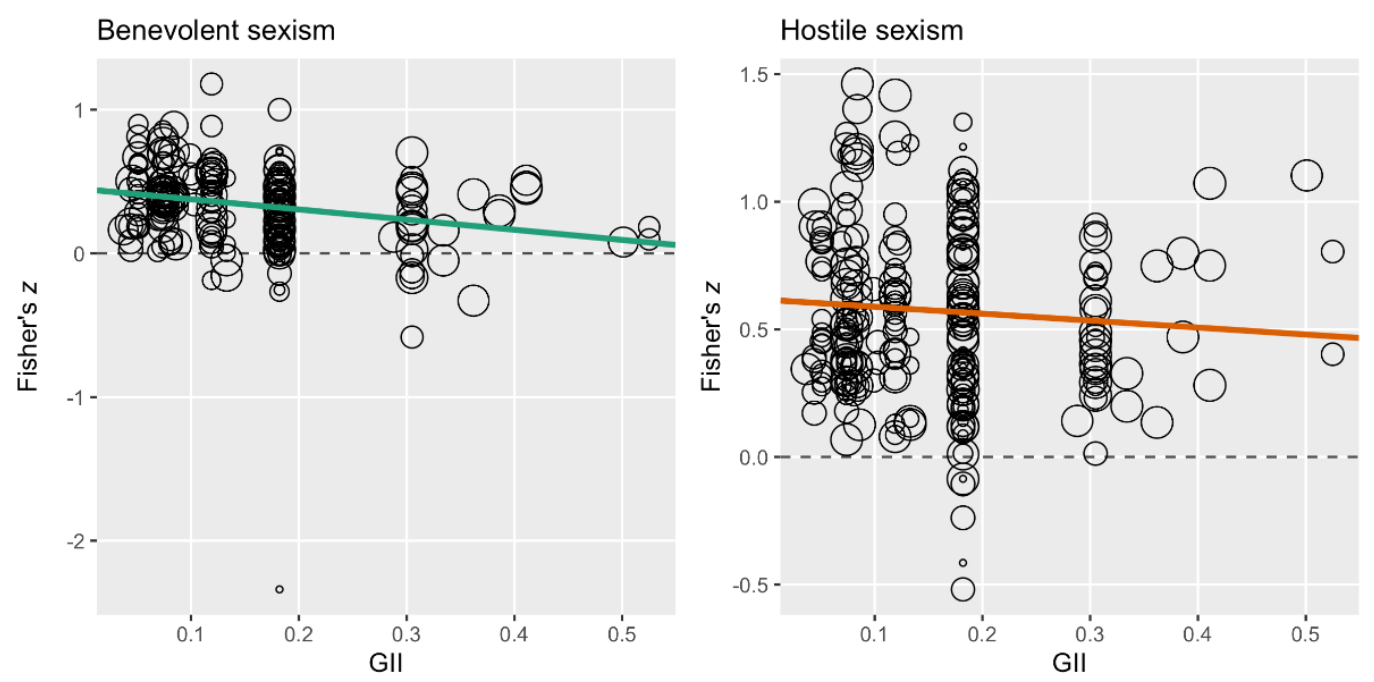

Figure 3. Moderation of the relationship between benevolent and hostile sexism and attitudes toward violence by level of gender inequality. The lines represent the weighted RVE meta-regressions of effect size on the Gender Inequality Index. Circle size shows effect size weight.

\section{Multiple moderators}

Table 3 shows the summary of the meta-regression model predicting effect sizes for the relationship between ambivalent sexism and attitudes toward violence with multiple moderators as predictors. The model for benevolent sexism including all predictors was significant, $\operatorname{HTZ}(55.5)=$ $2.45, p=.020$. However, the only significant predictor in this model was GII, $t(30.1)=-3.1, p=.004$. Neither violence type, $\operatorname{HTZ}(49.4)=1.55, p=.212$ nor context of violence, $t(32.1)=-0.5, p=.651$ were predictors of the effect size. Although the effect size for men-only samples looks lower compared to women-only samples, the test of the joint null hypothesis, that average effect sizes are equal across all levels of the moderator (men-only, women-only, and mixed samples), did not show significant differences, $\operatorname{HTZ}(86.7)=2.60, p=.080$. Thus, only gender inequality tended to explain a unique proportion of effect size heterogeneity in the relationship between benevolent sexism and attitudes toward violence when controlling for the influence of the other moderators (hypothesis 5) while hypotheses 2-4 and hypothesis 6 can not be accepted. 
The model for hostile sexism including all predictors was also significant, $H T Z(62.6)=3.48, p$ $=.002$. Violence type still emerged as a significant moderator, $\operatorname{HTZ}(56.3)=5.57, p=.002$, while context of violence ceased to be a significant moderator, $t(31.9)=-0.3, p=.743$. At the same time, the sample type also became a significant moderator, showing that the mean effect size obtained from the student sample was lower than that from the general population, $t(99.6)=-2.2, p=.032$. The test of the joint null hypothesis, that average effect sizes are equal across all levels of the gender moderator (men-only, women-only, and mixed samples), again did not show significant differences, $\operatorname{HTZ}(97.3)=2.44, p=.092$. There were no other significant predictors in the multiple regression. Thus, only violence type (hypothesis 2) and sample type (hypothesis 6) explain a unique proportion of effect size heterogeneity in the relationship between hostile sexism and attitudes toward violence while other hypothesis cannot be accepted. In the cases of both benevolent and hostile sexism metaregression models, most of the observed variance remains unexplained.

One possible explanation for moderators found in bivariate analysis to no longer be significant in multiple analysis could be the correlation of the moderators themselves. To test this, we cross tabulated the moderators. Indeed, the type of violence is related to the context of violence. For example, almost all effect sizes dealing with psychological and sexual violence are cases of a nonintimate relationship (sexual: 120 vs 1 and 130 vs 1; psychological: 45 vs 5 and 49 vs 5). In the case of physical violence, on the contrary, most effect sizes are intimate relationship cases (4 vs 11 and 4 vs 11). Report with detailed cross tabulation output is shown in the Supplemental Materials. 
Table 3. Summary of the meta-regression model predicting effect sizes for the relationship between ambivalent sexism and attitudes toward violence from multiple moderators

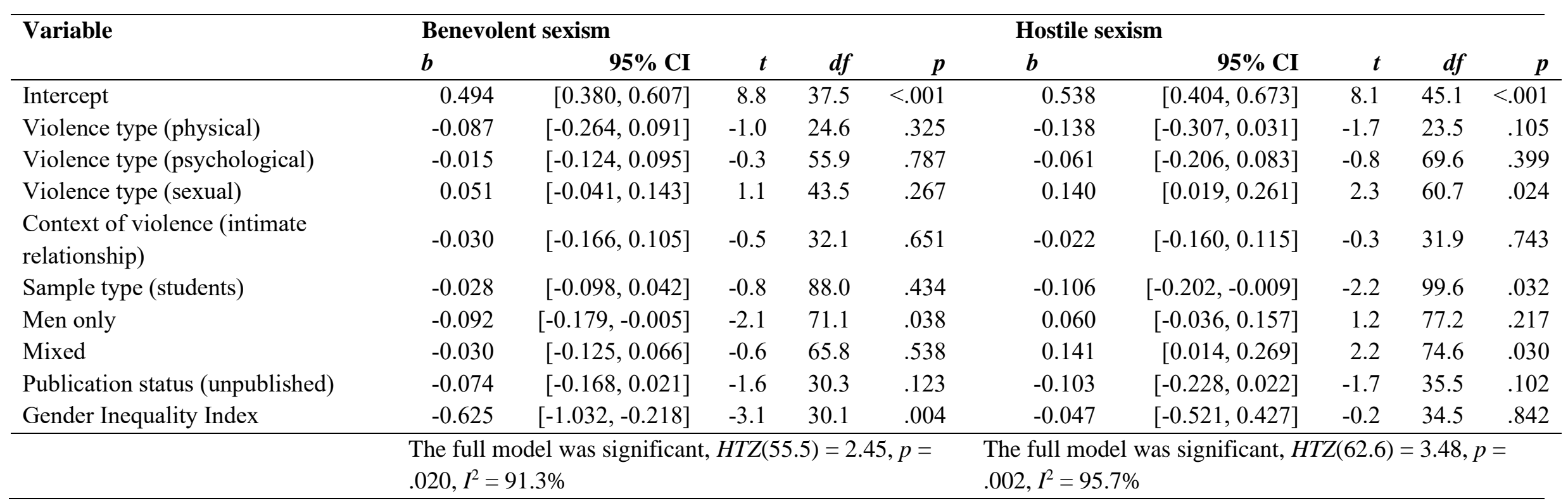

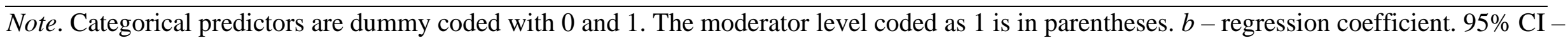

95\% confidence interval for regression coefficient. $t-t$-value testing whether the regression coefficient is significantly different from zero. $d f-$

Satterthwaite degrees of freedom (if the Satterthwaite degrees of freedom are less than 4 , the probability of a Type I error is much higher than .05 and one should not trust the results). $p-p$-value associated with the $t$ value. 


\section{Ambivalent sexism and violent behavior}

Sexism type

First, we calculated overall correlations of the hostile and benevolent sexism with violent behavior. Both overall correlations are different from zero and each other, $t(37.1)=5.97, p<.001$. Fisher's $z$ for benevolent sexism and violent behavior is $0.048,95 \%$ CI $[0.005,0.091]$ (equivalent to Pearson's $r=.048$ ) and for hostile sexism and violent behavior is $0.255,95 \%$ CI $[0.196,0.314]$ (equivalent to Pearson's $r=.250$ ). However, the MASEM showed that although the independent effects of both benevolent sexism and hostile sexism on violent behavior were significantly different from zero, the effect of benevolent sexism turned negative $(\beta=-.07, p<.001)$ after controlling for the effect of hostile sexism $(\beta=.25, p<.001)^{3}$. In general, these results support hypothesis 1 .

\section{Moderator analyses}

The results of the the separate meta-regressions for each moderator and weighted mean effect sizes for the bivariate relationship between ambivalent sexism and violent behavior for each level of moderator variables are shown in Table 4 and Figure 4. In this case, gender was not tested as a moderator of the relationship between ambivalent sexism and violent behavior because data came from only male samples. Gender inequality also was not tested as a moderator of this relationship because data came from only eight countries with a relatively high level of gender equality, which means a lack of variability of the moderator variable.

\section{Violence type}

Violence type did not moderate the relationship between benevolent sexism and violent behavior, $\operatorname{HTZ}(14.7)=1.18, p=.351$. Mean effect sizes for physical violent behavior (Fisher's $z=$ $0.038,95 \%$ CI $[-0.056,0.131])$, psychological violent behavior (Fisher's $z=0.088,95 \%$ CI [0.037, 0.140]), sexual violent behavior (Fisher's $z=0.077,95 \%$ CI [-0.039, 0.193]), and other (common)

\footnotetext{
${ }^{3}$ Report with detailed webMASEM output is available on the OSF: https://osf.io/gepkb/.
} 
violent behavior (Fisher's $z=-0.007,95 \%$ CI $[-0.128,0.114]$ ) were almost indistinguishable from zero. At the same time, the relationship between hostile sexism and violent behavior was moderated by violence type, $H T Z(23.5)=5.68, p=.004$. Mean effect sizes for physical violent behavior (Fisher's $z=0.116,95 \%$ CI $[0.029,0.203]$ ) were the lowest of the four types, while for psychological violent behavior (Fisher's $z=0.279,95 \%$ CI $[0.211,0.347]$ ), sexual violent behavior (Fisher's $z=$ $0.284,95 \% \mathrm{CI}[0.186,0.382]$ ), and other (common) violent behavior (Fisher's $z=0.315,95 \% \mathrm{CI}$ $[0.209,0.421])$ mean effect sizes were comparable.

\section{Context of violence}

We found no evidence that the context of violence moderates the correlation between benevolent sexism and violent behavior, $t(15.4)=-1.34, p=.200$. Mean effect sizes were equal for both intimate relationship (Fisher's $z=0.037,95 \%$ CI $[-0.020,0.094]$ ) and non-intimate relationship (Fisher's $z=0.089,95 \%$ CI $[0.025,0.152]$ ). In the case of hostile sexism, the mean effect size looks lower in an intimate relationship (Fisher's $z=0.228,95 \%$ CI $[0.172,0.283]$ ) when in a non-intimate relationship (Fisher's $z=0.321,95 \%$ CI $[0.240,0.403]$ ). However, the formal test did not show robust and strong evidence of the role of the context of violence as a moderator of the relationship between hostile sexism and violent behavior, $t(22.3)=-2.06, p=.051$.

\section{Sample type}

We found no evidence that sample type moderated the relationship between benevolent sexism and violent behavior, $t(26.3)=-0.29, p=.776$. Means of effect sizes received from the general population (Fisher's $z=0.060,95 \%$ CI $[0.012,0.107]$ ) and from the student samples (Fisher's $z=$ $0.048,95 \%$ CI $[-0.029,0.124])$ did not differ. Sample type also did not moderate the relationship between hostile sexism and violent behavior, $t(38.8)=-1.46, p=.153$. Means of effect sizes received from the general population (Fisher's $z=0.289,95 \%$ CI $[0.213,0.366])$ and from the student samples (Fisher's $z=0.223,95 \%$ CI $[0.167,0.279]$ ) did not statistically differ. 
Table 4. Effect sizes for the relationship between ambivalent sexism and violent behavior by moderators

\begin{tabular}{|c|c|c|c|c|c|c|c|c|c|c|c|}
\hline \multirow[t]{2}{*}{ Moderator } & \multicolumn{5}{|c|}{ Summary effect } & \multicolumn{6}{|c|}{ Test of moderation } \\
\hline & ES & $95 \% \mathrm{CI}$ & $t$ & $d f$ & $p$ & $k$ & $n$ & Statistic & $d f$ & $p$ & $I^{2}$ \\
\hline Sexism type & & & & & & & & $t=5.97$ & 37.1 & $<.001$ & 81.4 \\
\hline Benevolent sexism & .048 & $.005 / .091$ & 2.3 & 28.4 & .029 & 30 & 57 & & & & \\
\hline Hostile sexism & .255 & $.196 / .314$ & 8.8 & 34.6 & $<.001$ & 42 & 76 & & & & \\
\hline \multicolumn{12}{|l|}{ Benevolent sexism } \\
\hline Violence type & & & & & & & & $H T Z=1.18$ & 14.7 & .351 & 56.4 \\
\hline Physical & .038 & $-.056 / .131$ & 1.0 & 6.2 & .364 & 9 & 15 & & & & \\
\hline Psychological & .088 & $.037 / .140$ & 3.8 & 9.9 & .003 & 14 & 20 & & & & \\
\hline Sexual & .077 & $-.039 / .193$ & 1.6 & 5.8 & .155 & 9 & 13 & & & & \\
\hline Other (common) & -.007 & $-.128 / .114$ & -0.1 & 6.9 & .898 & 9 & 9 & & & & \\
\hline Context of violence & & & & & & & & $t=-1.34$ & 15.4 & .200 & 58.2 \\
\hline Intimate partner & .037 & $-.020 / .094$ & 1.4 & 19.2 & .188 & 22 & 46 & & & & \\
\hline $\begin{array}{l}\text { Non-intimate } \\
\text { partner }\end{array}$ & .089 & $.025 / .152$ & 3.2 & 7.8 & .012 & 10 & 11 & & & & \\
\hline Sample type & & & & & & & & $t=-0.29$ & 26.3 & .776 & 60.0 \\
\hline General population & .060 & $.012 / .107$ & 2.7 & 12.2 & .018 & 14 & 29 & & & & \\
\hline Students & .048 & $-.029 / .124$ & 1.3 & 14.2 & .205 & 16 & 28 & & & & \\
\hline Publication status & & & & & & & & $t=1.43$ & 5.5 & .206 & 53.6 \\
\hline Published & .039 & $-.003 / .080$ & 1.9 & 22.3 & .068 & 25 & 37 & & & & \\
\hline Unpublished & .128 & $-.042 / .297$ & 2.2 & 3.7 & .102 & 5 & 20 & & & & \\
\hline \multicolumn{12}{|l|}{ Hostile sexism } \\
\hline Violence type & & & & & & & & $H T Z=5.68$ & 23.5 & .004 & 78.3 \\
\hline Physical & .116 & $.029 / .203$ & 2.9 & 11.0 & .013 & 14 & 20 & & & & \\
\hline Psychological & .279 & $.211 / .347$ & 8.7 & 15.7 & $<.001$ & 20 & 26 & & & & \\
\hline Sexual & .284 & $.186 / .382$ & 6.4 & 10.8 & $<.001$ & 14 & 20 & & & & \\
\hline Other (common) & .315 & $.209 / .421$ & 6.9 & 8.0 & $<.001$ & 10 & 10 & & & & \\
\hline Context of violence & & & & & & & & $t=-2.06$ & 22.3 & .051 & 78.0 \\
\hline Intimate partner & .228 & $.172 / .283$ & 8.4 & 27.6 & $<.001$ & 30 & 59 & & & & \\
\hline $\begin{array}{l}\text { Non-intimate } \\
\text { partner }\end{array}$ & .321 & $.240 / .403$ & 8.7 & 11.7 & $<.001$ & 14 & 17 & & & & \\
\hline Sample type & & & & & & & & $t=-1.46$ & 38.8 & .153 & 78.9 \\
\hline General population & .289 & $.213 / .366$ & 7.9 & 18.5 & $<.001$ & 20 & 38 & & & & \\
\hline Students & .223 & $.167 / .279$ & 8.3 & 20.3 & $<.001$ & 22 & 38 & & & & \\
\hline Publication status & & & & & & & & $t=-1.62$ & 8.5 & .142 & 82.6 \\
\hline Published & .278 & $.232 / .325$ & 12.2 & 33.2 & $<.001$ & 35 & 53 & & & & \\
\hline Unpublished & .153 & $-.029 / .335$ & 2.1 & 5.9 & .086 & 7 & 23 & & & & \\
\hline
\end{tabular}

Note. ES - Fisher's $z ; k$ - number of independent samples; $n$ - number of effect sizes; $d f-$

Satterthwaite degrees of freedom (if the Satterthwaite degrees of freedom are less than 4, the probability of a Type I error is much higher than .05 and one should not trust the results); $I^{2}$ - ratio of true heterogeneity to total variance across the observed effect sizes. 

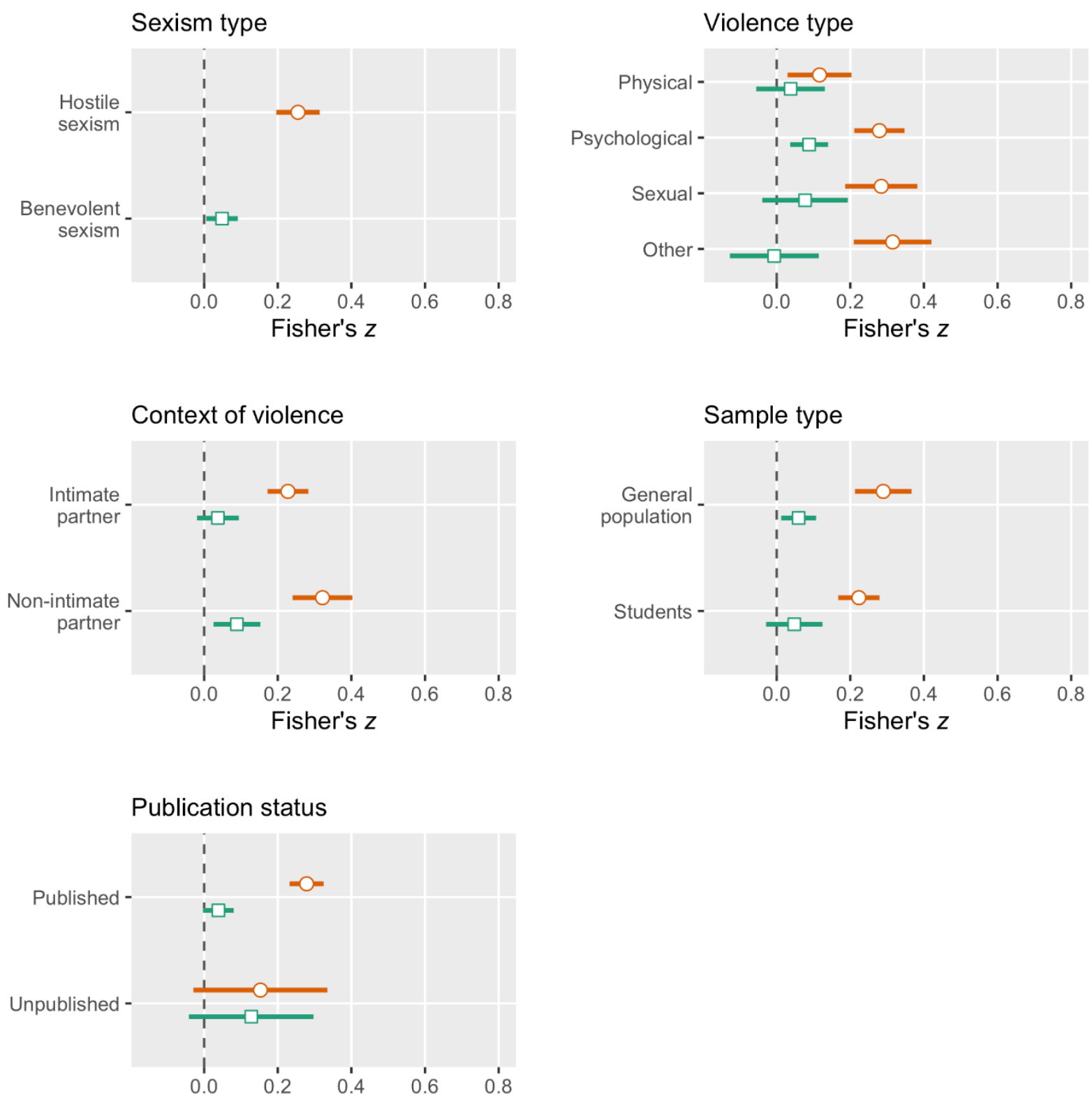

Fisher's $z$

Benevolent sexism $=0$ - Hostile sexism

Figure 4. Mean effect size for relationship between ambivalent sexism and violent behavior for each level of moderator variables.

\section{Multiple moderators}

Table 5 shows the summary of the meta-regression model predicting effect sizes for the relationship between ambivalent sexism and violent behavior with multiple moderators as predictors. 
Results of the multiple analysis partially replicate the results of the bivariate analysis. The model for benevolent sexism including all predictors was not significant, $\operatorname{HTZ}(8.7)=1.03, p=.466$, which means that none of the hypotheses can be supported for benevolent sexism and violent behavior. The model for hostile sexism including all predictors was significant, $\operatorname{HTZ}(16.0)=5.65, p=.003$. Both violence type, $\operatorname{HTZ}(21.9)=4.94, p=.009$ (hypothesis 2 ) and context of violence, $t(19.4)=-2.7, p=$ .015 (hypothesis 3 ) emerged as a significant moderators when controlling for the influence of the other moderators. Thus, for hostile sexism and violent behavior only hypothesis 6 can not be accepted. 
Table 5. Summary of the meta-regression model predicting effect sizes for the relationship between ambivalent sexism and violent behavior from multiple moderators

\begin{tabular}{|c|c|c|c|c|c|c|c|c|c|c|}
\hline \multirow[t]{2}{*}{ Variable } & \multicolumn{5}{|c|}{ Benevolent sexism } & \multicolumn{5}{|c|}{ Hostile sexism } \\
\hline & $b$ & $95 \% \mathrm{CI}$ & $t$ & $d f$ & $p$ & $b$ & $95 \% \mathrm{CI}$ & $t$ & $d f$ & $p$ \\
\hline Intercept & 0.023 & {$[-0.128,0.173]$} & 0.3 & 12.5 & .748 & 0.414 & {$[0.294,0.534]$} & 7.3 & 15.9 & $<.001$ \\
\hline Violence type (physical) & 0.045 & {$[-0.138,0.228]$} & 0.5 & 11.3 & .602 & -0.176 & {$[-0.305,-0.048]$} & -2.9 & 18.6 & .010 \\
\hline Violence type (psychological) & 0.078 & {$[-0.068,0.225]$} & 1.1 & 14.0 & .271 & -0.013 & {$[-0.130,0.104]$} & -0.2 & 18.0 & .818 \\
\hline Violence type (sexual) & 0.064 & {$[-0.096,0.223]$} & 0.9 & 8.3 & .387 & -0.019 & {$[-0.151,0.113]$} & -0.3 & 14.2 & .762 \\
\hline $\begin{array}{l}\text { Context of violence (intimate } \\
\text { relationship) }\end{array}$ & -0.029 & {$[-0.136,0.079]$} & -0.6 & 13.4 & .575 & -0.102 & {$[-0.182,-0.022]$} & -2.7 & 19.4 & .015 \\
\hline Sample type (students) & -0.024 & {$[-0.130,0.082]$} & -0.5 & 15.1 & .633 & -0.044 & {$[-0.133,0.045]$} & -1.0 & 26.3 & .321 \\
\hline Publication status (unpublished) & 0.065 & {$[-0.088,0.218]$} & 1.0 & 5.9 & .337 & -0.124 & {$[-0.269,0.021]$} & -1.9 & 9.2 & .086 \\
\hline
\end{tabular}

Note. Categorical predictors are dummy coded with 0 and 1 . The moderator level coded as 1 is in parentheses. $b-$ regression coefficient. $95 \%$ CI -

95\% confidence interval for regression coefficient. $t-t$-value testing whether the regression coefficient is significantly different from zero. $d f-$

Satterthwaite degrees of freedom (if the Satterthwaite degrees of freedom are less than 4, the probability of a Type I error is much higher than .05 and one should not trust the results). $p-p$-value associated with the $t$ value. 


\section{Publication bias tests}

Publication status. The mean of effect sizes for the relationship between benevolent sexism and attitudes toward violence reported in published studies (Fisher's $z=0.345,95 \%$ CI [0.305, 0.384]) did not statistically differ from the mean of the effect sizes reported in unpublished studies (Fisher's $z$ $=0.283,95 \%$ CI $[0.191,0.374]), t(27.0)=-1.28, p=.212$ (see Table 2 and Figure 2$).$ The same conclusion should be made for hostile sexism. The mean based on effect sizes from published studies (Fisher's $z=0.582,95 \%$ CI $[0.530,0.634]$ ) did not statistically differ from the mean based on the effect sizes from unpublished studies (Fisher's $z=0.516,95 \%$ CI $[0.395,0.637]), t(33.0)=-1.02, p=$ .316. The publication status also did not moderate the relationship between ambivalent sexism and violence behaviour. The mean of effect sizes for the relationship between benevolent sexism and violence behaviour reported in published studies (Fisher's $z=0.039,95 \%$ CI $[-0.003,0.080]$ ) did not statistically differ from the mean of the effect sizes reported in unpublished studies (Fisher's $z=$ $0.128,95 \%$ CI $[-0.042,0.297]), t(5.5)=1.43, p=.206$ (see Table 4 and Figure 4). Results for hostile sexism were the same. The mean based on effect sizes from published studies (Fisher's $z=0.278$, 95\% CI $[0.232,0.325])$ did not statistically differ from the mean based on the effect sizes from unpublished studies (Fisher's $z=0.153,95 \%$ CI $[-0.029,0.335]), t(8.5)=-1.62, p=.142$.

Funnel plots. Funnel plots for the four subsamples of effect sizes are shown in Figure 5. Visual inspection of all four funnel plots did not show substantial asymmetry for either hostile and benevolent sexism and attitudes toward violence, or hostile and benevolent sexism and violent behavior. Egger's regression test (Table 6) also did not indicate funnel plot asymmetry for the relationship between attitudes toward violence and benevolent sexism $\left(b_{1}=0.458,95 \%\right.$ CI $[-0.714$, 1.631], $p=.442)$ and between attitudes toward violence and hostile sexism $\left(b_{1}=0.203,95 \%\right.$ CI [$1.232,1.639], p=.781)$. The slope coefficients associated with the standard error for the effect sizes of the relationship between violent behavior and hostile sexism were not also significant, $b_{1}=0.853$, $95 \%$ CI $[-0.346,2.052], p=.161$, whereas in the case of benevolent sexism, the slope coefficients were significant, $b_{1}=-2.068,95 \%$ CI [-3.355, -0.782], $p=.002$. This means that there was a funnel 
plot asymmetry in the relationship between benevolent sexism and violent behavior. However, the slope coefficient was negative, which is the opposite of what would be expected under publication bias and the small-study effect. Therefore, the analysis of funnel plots did not show the presence of potential publication bias.
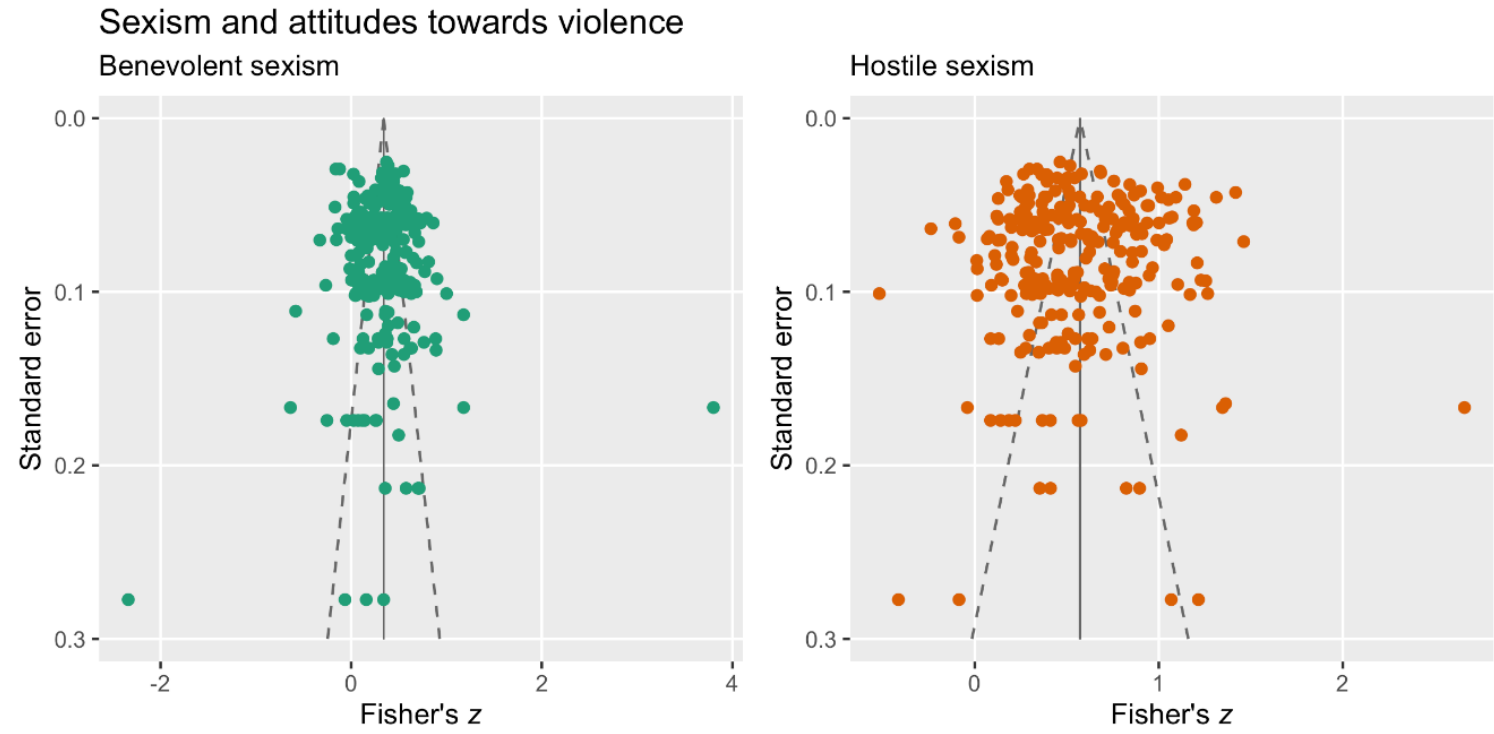

Sexism and violence behavior Benevolent sexism
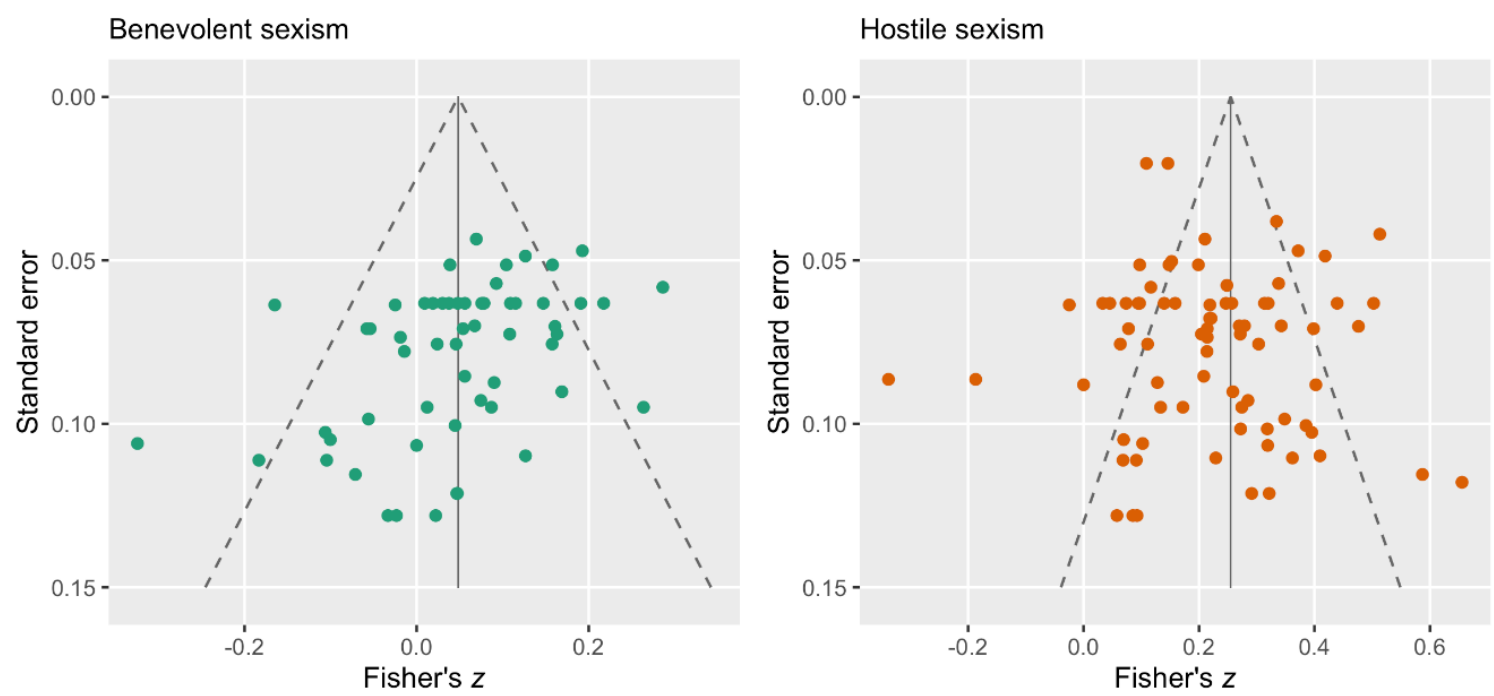

Figure 5. Funnel plots showing standard error as a function of effect size. Mean effect size (a central vertical line) and 95\% confidence intervals (dashed lines) are based on estimates from the RVE metaregression models of effect size on dummy-variable for type of sexism without intercept (Tables 2 and 4). 
PET-PEESE. For all four subsamples, intercept in PET regression was significant (see Table 6), so the intercepts from PEESE should be used as the best estimates of the true effects (attitudes toward violence and benevolent sexism: $b_{0}=0.318,95 \%$ CI [0.277, 0.359], $p<.001$; attitudes toward violence and hostile sexism: $b_{0}=0.549,95 \%$ CI [0.500, 0.598], $p<.001$; violent behavior and benevolent sexism: $b_{0}=0.134,95 \%$ CI [0.087, 0.181], $p<.001$; and violent behavior and hostile sexism: $b_{0}=0.190,95 \%$ CI [0.141, 0.239], $\left.p<.001\right)$. Graphs of the PET-PEESE estimates are shown in the Supplemental Materials. All PEESE intercepts were significantly different from zero. Three out of four were only slightly smaller compared to the original estimates from RVE meta-regressions (differences are less than 0.07), whereas in the case of the relationship between violent behavior and benevolent sexism, the PEESE intercept was even higher than the original estimates. Thus, the PETPEESE technique showed no signs of publication bias.

Overall, publication bias analysis using three different tests did not indicate substantial publication bias in the results about the relationship between ambivalent sexism and violence.

Table 6. Results from PET-PEESE technique

\begin{tabular}{lllll}
\hline Subsample & \multicolumn{3}{l}{ PET } & PEESE \\
\cline { 2 - 5 } & $b_{0}$ (intercept) & $b_{1}$ (slope) & $b_{0}$ (intercept) & $b_{1}$ (slope) \\
\hline $\begin{array}{lllll}\text { Attitudes toward } \\
\text { violence }\end{array}$ & & & & \\
Benevolent sexism & $0.298^{* * *}$ & 0.458 & $0.318^{* * *}$ & 1.566 \\
& {$[0.225,0.372]$} & {$[-0.714,1.631]$} & {$[0.277,0.359]$} & {$[-5.084,8.215]$} \\
Hostile sexism & $0.539 * * *$ & 0.203 & $0.549 * * *$ & 0.295 \\
& {$[0.450,0.628]$} & {$[-1.232,1.639]$} & {$[0.500,0.598]$} & {$[-7.898,8.489]$} \\
Violent behavior & & & & \\
Benevolent sexism & $0.213 * * *$ & $-2.068 * *$ & $0.134 * * *$ & $-12.470 * *$ \\
& {$[0.121,0.304]$} & {$[-3.355,-0.782]$} & {$[0.087,0.181]$} & {$[-20.416,-4.524]$} \\
Hostile sexism & $0.161 * * *$ & 0.853 & $0.190^{* * *}$ & 4.963 \\
& {$[0.087,0.236]$} & {$[-0.346,2.052]$} & {$[0.141,0.239]$} & {$[-4.660,14.586]$} \\
\end{tabular}

Note. ${ }^{* * *} p<.001 ; * * p<.01 ; * p<.05$. Numbers given in parentheses are the $95 \%$ confidence intervals. 


\section{Discussion}

The aim of the meta-analysis was to analyze the relationship between ambivalent sexism and violence toward women. Acquired results expand the existing knowledge about the different predictors of violence toward women (see, for review, Flood \& Pease, 2009), especially, about the role of subjectively negative (hostile) and subjectively positive (benevolent) sexist attitudes in violence toward women as well as about significant moderators of these relationships.

The meta-analysis results confirmed that both hostile and benevolent sexism independently and significantly impact on a support of attitudes that justify and legitimize violence against women. At the same time, if the contribution of hostile sexism is substantial $(\beta=.42)$, then the contribution of benevolent sexism is relatively small $(\beta=.09)$. With regards to violent behavior, the results are quite different: while both types of sexism show significant effect on the violent behavior, only in the case of hostile sexism this effect is positive $(\beta=.25)$, whereas in the case of benevolent sexism the effect is negative $(\beta=-.07)$.

First of all, it is important to note that sexism shows a stronger connection with the support of attitudes toward male-to-female violence than with violent behavior. This result confirms that sexist attitudes strongly support the discourse that justifies violence, but the manifestation of violent behavior can also be associated with other individual (Capaldi et al., 2012) and social factors (Anderson \& Bushman, 2002).

Second, the obtained results are in line with previous research, that has repeatedly pointed out that different forms of hostility toward women (e.g., the belief that women are less competent than men) are associated with the manifestation of or support for violence toward them (Birkley \& Eckhardt, 2015; Forbes et al., 2004; Herrero et al., 2017). According to the results obtained, the hostility that is operationalized in hostile sexism through the belief that women seek more power than men is also significantly connected with violence against women. This generally confirms that men's desire to consolidate their higher status is connected to suppressing women through violence and that 
women with high levels of hostile sexism can justify male violence, thereby maintaining the gender status quo (Langhinrichsen-Rohling et al., 2012).

The effect of benevolent sexism, however, requires additional discussion. On the one hand, it is worth noting that the effect of benevolent sexism is weak for both attitudes toward violence and violent behaviors. From a practical viewpoint, the effect may not reflect any noticeable influence on attitudes or violent behavior in real life. On the other hand, a negative association between benevolent sexism and violent behavior may indicate that benevolent sexism may offer some protective factor against violence. Indeed, the notion that women who conform to traditional gender roles should be protected does not comply with the infliction of violence on them. Simultaneously, in situations where gender roles are violated, a woman can no longer count on benevolent sexism to protect her from violence since hostile sexism will support the manifestation of violence against her. In other words, if benevolent attitudes existed completely apart from hostile ones, they could, to some extent, contribute to the protection of women from violence. However, because sexists most often share both hostile and benevolent attitudes at once (Napier et al., 2010), protection extends only to those women who correspond to gender roles and ends at the moment they cease to align to these roles. As a result, the defense against violence implied by benevolent sexism can become another way of controlling women, though, compared to hostile sexism, it presents itself as a safer and more convenient strategy. Indeed, sexists may consider that paternalistic attitudes toward women will not be condemned by society (as opposed to, for example, hostility toward women) because paternalism in some spheres is viewed as socially desirable behavior (e.g., programs of state support for lowincome families or orphans). As a result, sexists may first try to control women with benevolent sexism using the 'soft power' of a mixture of protection, adoration, and financial dependence. But if women violate traditional gender roles, they lose the basis for benevolence toward them and therefore can no longer be controlled by benevolent sexism. In this case, hostile sexism comes into play and it justifies violence against women who no longer meet gender expectations (Abrams et al., 2003; 
Sakalli-Uğurlu et al., 2007). Taken together, benevolent sexism cannot protect or insulate against violence, it simply hides the other side of sexism.

The results of the moderator analysis add new details to the picture described. When it comes to attitudes, hostile sexism is most strongly associated with attitudes toward sexual violence. Hostile sexist beliefs contain the idea that women use dishonest ways to gain power. Such ways can include, for example, false accusations of sexual harassment or provoking men to be sexually active in order to use this against men, e.g., to control and manipulate them (Payne et al., 1999). These beliefs coincide with various rape and sexual harassment myths that also suggest that women themselves provoke men into sexual behavior and exaggerate the frequency and significance of the cases of rape and sexual harassment.

When it comes to behavior, hostile sexism was weakly associated with physical violence. In modern developed societies, the 'cost' of physical violence (not necessarily in relation to women, but in relation to any person) can be very high. Physical violence toward women violates social norms and can lead to social censure and ostracism (which will negatively affect the status of a man who has demonstrated such behavior) (Rudman \& Glick, 2008). As a result, men try to avoid physical violence by using other forms of control over women. We demonstrated that the correlations between hostile sexism and psychological, sexual, or other violence do not differ. This may be evidence that in real interaction, the act of abuse may be an aggregation of different types of violence and at the moment of aggression it is difficult to separate them from each other (Murphy \& O'Leary, 2005). Moreover, all types of violence can incorporate a feeling of contempt or hatred toward women, making all types of violence applicable to sexist beliefs.

Our results also showed that at the behavioral level, hostile sexism is less associated with violence against intimate partners than against other women. In close relationships, it is easy to use paternalism toward women and, as a consequence, use benevolent sexism to control women, while saving violence as a reserve instrument to reclaim control when it seems that it has been lost. Moreover, individualized information about an intimate partner (personal characteristics and 
experience of interaction with them) can weaken the role of general beliefs about women, which are fixed in sexist attitudes (Cohn et al., 2009; Hockett et al., 2016).

Surprisingly, the results show that the relationship between benevolent sexism and attitudes toward violence is most pronounced in countries with a high level of gender equality. In general, the opposite result would be more expected. Napier with colleagues (2010) found that in genderegalitarian countries, people who endorsed benevolent sexism were more satisfied with life because benevolent sexism allows gender-based violence to be masked. Perhaps, since in countries with high gender equality benevolent sexists can demonstrate their attitudes without fear of being punished (in contrast to hostile sexism), precisely benevolent sexism might be associated with the approval and maintenance of violence as a way to preserve the gender hierarchy. These findings may also be a statistical anomaly because the analysis did not cover the whole spectrum of countries with different levels of gender equality.

In our analysis, we did not find confirmation that the study's characteristics (respondents' gender and sample type) were significant moderators of the relationship between hostile and benevolent sexism, and violence. Sample type emerged as a significant predictor only in the multivariate moderation analysis of the relationship between hostile sexism and attitudes toward violence, but the $p$-value was slightly below $(p=.032)$ the conventional level $(p=.05)$. Our results did not demonstrate the role of the respondents' gender in the relationship between both types of sexism and attitudes toward violence. Interestingly, we found a lack of differences in the links between ambivalent sexism and attitudes toward violence in men and women. However, it is likely that the fact that women have lower levels of sexism than men and they generally maintain violent male-to-female attitudes to a lesser extent may not affect the strength of the relationship between ambivalent sexism and violence, since both attitudes are low. Another important point that in most of the analyzed studies, respondents were forced to identify themselves as male or female, while selfcategorization can be more complex. Therefore, the division of respondents only into men and women may not reflect the real picture 


\section{Limitations and future directions}

Our meta-analysis has several limitations, which are important to be considered in interpreting the results. First, since ethical restrictions limit the possibility to provoke violent behavior in studies (Ethical Principles of Psychologists and Code of Conduct, 2002), there are few studies that have investigated violent behavior and its relationship to sexism. As a result, the data set relating to violent behavior was smaller than the data set for attitudes toward violence. Additionally, in the data set about violent behavior, we combined real behavior (observed in experiments) and self-reported behavior. At the same time, the association between sexist attitudes and self-reported behavior may be less pronounced, due to the social desirability or undesirability of answering self-reported violent behavior (for example, individuals can downplay or 'hush up' their participation in acts of violence) (Renzetti et al., 2018). Moreover, most data about self-report behavior was collected by the Conflict tactic scale or reverse Conflict tactic scale which was seriously criticized for low internal consistency of some subscales (e.g., scale of sexual violence), ignoring the context of violence, and high social desirability (Chapman \& Gillespie, 2019; Jones et al., 2017). Therefore, the results obtained using these scales may not fully reflect the actual number of violent acts and describe the situation with sexual violence worse, which could have impact the revealed correlations between ambivalent sexism and various types of violence.

In general, future research should pay more attention to the study of actual violent behavior. Moreover, it should clearly identify what is being studied: attitudes or behavior. At the moment, many contradictions in the results related to the relationship between sexism and violence link to the fact that some of the data were obtained from the study of attitudes, and some from the study of behavior. As we have shown, sexism is much more strongly associated with discourse supporting violence (attitudes) than with actual behavior. This means that a clearer distinction between the study of attitudes toward violence and the study of behavior can contribute to a deeper understanding of the role of sexism in the manifestation of violence, clarify the predictive potential of the Ambivalent 
sexism theory, and become the basis for developing more effective programs to combat violence against women.

Second, there may be other important moderators that were not taken into account in our analysis. One of these moderators might be the measurements of different types of violence. In the studies we analyzed, the diversity of measurements of violence was so great that it was impossible for all types of violence to be singled out into subgroups of methods sufficiently for the necessary analysis to be conducted. However, such an analysis could be productive for a deeper understanding of the relationship between sexism and violence. Moreover, according to the Ambivalent Sexism Theory, an important factor that moderates the relationship between sexism and violence is the degree to which a 'victim' follows traditional gender roles (Cohn et al., 2009; Hockett et al., 2016). However, in many studies that have been analyzed in our meta-analysis, data about victim behavior were not available. Additionally, lack of information in the studies did not allow us to check the role of other potential moderators: the characteristics of the sample (for example, its representativeness) or sexism' measures (full and short scales).

Third, our conclusions cannot be generalized to groups excluded from the analysis (e.g., police officers, offenders, etc.). Undoubtedly, the specific characteristics of these groups that may impact the relationship between sexism and violence make them important in understanding the role of sexism in the manifestation of violence. More research is needed to clarify this role. Finally, we recommend future researchers to pre-register their meta-analysis (or other studies) as an attempt to produce more cofirmatory research.

\section{Methodological implications}

The results of our meta-analysis have two methodological implications that will be useful for researchers who are interested in understanding the relationship between sexism and violence toward women. First of all, the effect sizes identified in the meta-analysis can be used for a priori power analyses to determine the required sample size to obtain effects with the required statistical power. This will contribute to improving the research quality and a more accurate interpretation of the results 
obtained. Second, we have demonstrated that both hostile and benevolent sexism are related to attitudes toward male-to-female violence and violent behavior to varying degrees. This result has to be taken into account, since it is obvious that calculating a single indicator of ambivalent sexism is insufficient, especially in the case of analysis of the relationship between ambivalent sexism and violent behavior.

\section{Conclusion}

The results of this meta-analysis demonstrate that sexism in any of its manifestations is associated with the maintenance of a culture of violence against women. At an attitudinal level, ambivalent sexism relates to various beliefs and myths that justify violence, and at the behavioral level, it links to aggression and violent behavior against women. The feeling that a paternalistic-benevolent form of sexism can protect women from violence is false. Our results once again confirm that there are no harmless forms of sexism. People should pay more attention to combating the spread of not only hostile but also paternalistic sexist attitudes. Only this can help to reduce violence against women and preserve their physical and psychological well-being, and, consequently, general human capital.

\section{Author Contributions}

EA conceptualized the research program. EA, OG, MB collected and coding data. AL analyzed the data. EA, AL, MB writing text, revised the text and approved the final version of the manuscript for submission and resubmission. OG commented the text in the early stages of preparation.

\section{References}

*Abrams, D., Viki, G. T., Masser, B., \& Bohner, G. (2003). Perceptions of Stranger and Acquaintance Rape: The Role of Benevolent and Hostile Sexism in Victim Blame and Rape 
Proclivity. Journal of Personality and Social Psychology, 84(1), 111-125.

https://doi.org/10.1037/0022-3514.84.1.111

*Allen, C. T., Swan, S. C., \& Raghavan, C. (2009). Gender symmetry, sexism, and intimate partner violence. Journal of Interpersonal Violence, 24(11), 1816-1834.

https://doi.org/10.1177/0886260508325496

Alvarez, C., Lameiras-Fernandez, M., Holliday, C. N., Sabri, B., \& Campbell, J. (2018). Latina and Caribbean Immigrant Women's Experiences With Intimate Partner Violence: A Story of Ambivalent Sexism. Journal of Interpersonal Violence. https://doi.org/10.1177/0886260518777006

Anderson, C. A., \& Anderson, K. B. (2008). Men who target women: Specificity of target, generality of aggressive behavior. Aggressive Behavior, 34(6), 605-622. https://doi.org/10.1002/ab.20274

Anderson, C. a, \& Bushman, B. J. (2002). Human Aggression. Annual Review of Psychology, 53(1), 27-51. https://doi.org/10.1146/annurev.psych.53.100901.135231

*Angelone, D. J., Mitchell, D., \& Grossi, L. (2015). Men's Perceptions of an Acquaintance Rape: The Role of Relationship Length, Victim Resistance, and Gender Role Attitudes. Journal of Interpersonal Violence, 30(3), 2278-2303. https://doi.org/10.1177/0886260514552448

*Angelone, D. J., Mitchell, D., \& Smith, D. (2018). The Influence of Gender Ideology, Victim Resistance, and Spiking a Drink on Acquaintance Rape Attributions. Journal of Interpersonal Violence, 33(20), 3186-3210. https://doi.org/10.1177/0886260516635318

*Anton, C. M. (2011). The psychometric properties of a scale that assesses men's tolerance of sexual harassment. Texas Tech University.

*Arbach, K., Vaiman, M., Bobbio, A., Bruera, J., \& Lumello, A. (2019). Inventario de Sexismo Ambivalente: Invarianza factorial entre géneros y relación con la violencia de pareja. 
Interdisciplinaria: Revista de Psicología y Ciencias Afines, 36(1).

https://doi.org/10.16888/interd.36.1.5

Archer, J. (2006). Cross-Cultural Differences in Physical Aggression Between Partners: A SocialRole Analysis. Personality and Social Psychology Bulletin, 10(2), 133-153. https://doi.org/10.1207/s15327957pspr1002

*Barker, A., \& Galliher, R. V. (2017). A Mediation Model of Sexual Assault among Latter-Day Saints. Journal of Aggression, Maltreatment and Trauma, 26(3), 316-333. https://doi.org/10.1080/10926771.2016.1272657

Barreto, M., \& Ellemers, N. (2005). The burden of benevolent sexism: How it contributes to the maintenance of gender inequalities. European Journal of Social Psychology, 35(5), 633-642. https://doi.org/10.1002/ejsp.270

*Begany, J. J., \& Milburn, M. A. (2002). Psychological predictors of sexual harassment: Authoritarianism, hostile sexism, and rape myths. Psychology of Men \& Masculinity, 3(2), 119126. https://doi.org/10.1037//1524-9220.3.2.119

*Bendixen, M., \& Kennair, L. E. O. (2017). When less is more: Psychometric properties of Norwegian short-forms of the Ambivalent Sexism Scales (ASI and AMI) and the Illinois Rape Myth Acceptance (IRMA) Scale. Scandinavian Journal of Psychology, 58(6), 541-550. https://doi.org/10.1111/sjop.12392

*Berke, D. S., \& Zeichner, A. (2016). Testing a Dual Process Model of Gender-Based Violence: A Laboratory Examination. Violence and Victims, 31(2), 200-214. https://doi.org/10.1891/08866708.VV-D-14-00060

Beydoun, H. A., Beydoun, M. A., Kaufman, J. S., Lo, B., \& Zonderman, A. B. (2012). Intimate partner violence against adult women and its association with major depressive disorder, 
depressive symptoms and postpartum depression: A systematic review and meta-analysis. Social Science and Medicine, 75(6), 959-975. https://doi.org/10.1016/j.socscimed.2012.04.025

*Bhanot, S. (2010). An assessment of the intersection between love and violence: Do romance narratives support the development, continuation and attitudinal tolerance of intimate partner violence? In Dissertation Abstracts International: Section B: The Sciences and Engineering (Vol. 71, Issues 3-B). http://ezpprod1.hul.harvard.edu/login?url=http://search.ebscohost.com/login.aspx?direct=true \&db=psyh\& AN=2010-99180-504\&site=ehost-live \&scope=site

Birkley, E. L., \& Eckhardt, C. I. (2015). Anger, hostility, internalizing negative emotions, and intimate partner violence perpetration: A meta-analytic review. Clinical Psychology Review, 37(1), 40-56. https://doi.org/10.1016/j.cpr.2015.01.002

Bonilla Algovia, E., \& Rivas Rivero, E. (2019). Creencias distorsionadas sobre la violencia de género en docentes en formación de Colombia. Revista Colombiana de Educación, 1(77), 87-106. https://doi.org/10.17227/rce.num77-9571

*Bosson, J. K., Parrott, D. J., Swan, S. C., Kuchynka, S. L., \& Schramm, A. T. (2015). A dangerous boomerang: Injunctive norms, hostile sexist attitudes, and male-to-female sexual aggression. Aggressive Behavior, 41(6), 580-593. https://doi.org/10.1002/ab.21597

*Burnay, J. (2019). Sexualization and aggression against women: A focus on sexualized characters in video games. https://orbi.uliege.be/bitstream/2268/235658/1/Jonathan Burnay thèse.pdf\%0Ahttp://files/124/Burnay - Sexualization and aggression against women A focu.pdf

Byrne, C. A., Resnick, H. S., Kilpatrick, D. G., Best, C. L., \& Saunders, B. E. (1999). The socioeconomic impact of interpersonal violence on women. Journal of Consulting \& Clinical Psychology, 67(3), 362-366. 
*Çamaş, G. G., \& Meşe, G. (2016). Sosyal hiyerarşi : cinsel şiddet mitlerini anlamak. Türk Psikoloji Dergisi, 31(78), 62-74.

*Canto, J. M., Perles, F., \& Martín, J. S. (2014). El papel del autoritarismo de derechas, del sexismo y de la cultura del honor en la aceptación de los mitos sobre la violación. Revista de Psicologia Social, 29(2), 296-318. https://doi.org/10.1080/02134748.2014.918822

Capaldi, D. M., Knoble, N. B., Shortt, J. W., \& Kim, H. K. (2012). A Systematic Review of Risk Factors for Intimate Partner Violence. Partner Abuse, 3(2), 231-280. https://doi.org/10.1891/1946-6560.3.2.231

Carter, E. C., \& McCullough, M. E. (2014). Publication bias and the limited strength model of selfcontrol: has the evidence for ego depletion been overestimated? Frontiers in Psychology, 5. https://doi.org/10.3389/fpsyg.2014.00823

*Castro, Y. R., Magalhães, M. J., \& Caldas, J. (2010). Sexismo Ambivalente: Actitudes Y Creencias Hacia La Violencia De Género. Revista Ártemis, 11, 133-139.

*Čeponytė, M., \& Žardeckaitè-Matulaitienè, K. (2018). Seksistinių nuostatų reikšmė seksualinio priekabiavimo atpažinimui. Informacijos Mokslai, 80(March), 61-80. https://doi.org/10.15388/Im.2017.80.11672

*Chapleau, K. M., Oswald, D. L., \& Russell, B. L. (2007). How ambivalent sexism toward women and men support rape myth acceptance. Sex Roles, 57(1-2), 131-136. https://doi.org/10.1007/s11199-007-9196-2

Chapman, H., \& Gillespie, S. M. (2019). The Revised Conflict Tactics Scales (CTS2): A review of the properties, reliability, and validity of the CTS2 as a measure of partner abuse in community and clinical samples. Aggression and Violent Behavior, 44(November 2018), 27-35. https://doi.org/10.1016/j.avb.2018.10.006 
Child, J. C., Devries, K. M., Watts, C. H., Rosenfeld, L., Pallitto, C., Lim, S., Mak, J. Y. T., Vos, T., Garcia-Moreno, C., Engell, R. E., Abrahams, N., Bacchus, L. J., Falder, G., \& Petzold, M. (2013). The Global Prevalence of Intimate Partner Violence Against Women. Science, 340(6140), 1527-1528. https://doi.org/10.1126/science.1240937

Cho, H. (2012). Racial Differences in the Prevalence of Intimate Partner Violence Against Women and Associated Factors. Journal of Interpersonal Violence, 27(2), 344-363. https://doi.org/10.1177/0886260511416469

*Cohn, E. S., Dupuis, E. C., \& Brown, T. M. (2009). In the eye of the beholder: Do behavior and character affect victim and perpetrator responsibility for acquaintance rape? Journal of Applied Social Psychology, 39(7), 1513-1535. https://doi.org/10.1111/j.1559-1816.2009.00493.x

Connelly, K., \& Heesacker, M. (2012). Why Is Benevolent Sexism Appealing?: Associations With System Justification and Life Satisfaction. Psychology of Women Quarterly, 36(4), 432-443. https://doi.org/10.1177/0361684312456369

Connor, R. A., Glick, P., \& Fiske, S. T. (2016). Ambivalent Sexism in the 21st Century. In C. Sibley \& F. Barlow (Eds.), Cambridge Handbook of the Psychology of Prejudice (pp. 295-320). Cambridge University Press. https://doi.org/doi:10.1017/9781316161579.013

Corradi, C., \& Stöckl, H. (2016). The lessons of history: The role of the nation-states and the EU in fighting violence against women in 10 European countries. Current Sociology, 64(4), 671-688. https://doi.org/10.1177/0011392116640457

*Correia, I., Alves, H., Morais, R., \& Ramos, M. (2015). The legitimation of wife abuse among women: The impact of belief in a just world and gender identification. Personality and Individual Differences, 76, 7-12. https://doi.org/10.1016/j.paid.2014.11.041

*Covell, A. (1998). Characteristics of college males who are likely to sexually harass women: A test 
of a mediated model. University of Southern California, USA.

*Crittenden, C. (2009). Examing attitudes and perceptions of sexual harassment on a university of campus: What role do myths and stereotypes play? University of Tennessee, USA.

*Cromer, L. D. M., \& Freyd, J. J. (2007). What influences believing child sexual abuse disclosures? The roles of depicted memory persistence, participant gender, trauma history, and sexism. Psychology of Women Quarterly, 31(1), 13-22. https://doi.org/10.1111/j.14716402.2007.00327.x

*Cross, E. J., Overall, N. C., Hammond, M. D., \& Fletcher, G. J. O. (2017). When Does Men's Hostile Sexism Predict Relationship Aggression? The Moderating Role of Partner Commitment. Social Psychological and Personality Science, 8(3), 331-340. https://doi.org/10.1177/1948550616672000

*Cross, E. J., Overall, N. C., \& McNulty, J. K. (2019). An interdependence account of sexism and power: Men's hostile sexism, biased perceptions of low power, and relationship aggression. Journal of Personality and Social Psychology, 117(2), 338-363. https://doi.org/10.1037/pspi0000167

*Davies, M., Gilston, J., \& Rogers, P. (2012). Examining the Relationship Between Male Rape Myth Acceptance, Female Rape Myth Acceptance, Victim Blame, Homophobia, Gender Roles, and Ambivalent Sexism. Journal of Interpersonal Violence, 27(14), 2807-2823. https://doi.org/10.1177/0886260512438281

De Barros, I. C., Sani, A., \& Santos, L. (2019). Gender and same-sex intimate partner violence: A systematic literature review. Trends in Psychology, 27(1), 127-139. https://doi.org/10.9788/TP2019.1-10

Del Re, A. C. (2013). compute.es: Compute Effect Sizes. R package version 0.2-2 (R package version 
0.2-2).

Devries, K. M., Child, J. C., Bacchus, L. J., Mak, J., Falder, G., Graham, K., Watts, C., \& Heise, L. (2014). Intimate partner violence victimization and alcohol consumption in women: A systematic review and meta-analysis. Addiction, 109(3), 379-391. https://doi.org/10.1111/add.12393

*Diehl, C., Rees, J., \& Bohner, G. (2012). Flirting With Disaster: Short-Term Mating Orientation and Hostile Sexism Predict Different Types of Sexual Harassment. Aggressive Behavior, 38(6), 521-531. https://doi.org/10.1002/ab.21444

*Diehl, C., Rees, J., \& Bohner, G. (2018). Predicting Sexual Harassment From Hostile Sexism and Short-Term Mating Orientation: Relative Strength of Predictors Depends on Situational Priming of Power Versus Sex. Violence Against Women, 24(2), 123-143. https://doi.org/10.1177/1077801216678092

*Diener, J. M. (2016). Individual Variables Related to Rape Myth Acceptance and Bystander Intervation: Implications for Sexual Assault Prevention (Issue April). Western Carolina University.

Dokkedahl, S., Kok, R. N., Murphy, S., Kristensen, T. R., Bech-Hansen, D., \& Elklit, A. (2019). The psychological subtype of intimate partner violence and its effect on mental health: protocol for a systematic review and meta-analysis. Systematic Reviews, 8(1), 198. https://doi.org/10.1186/s13643-019-1118-1

*Durán, M., Campos-Romero, I., \& Martínez-Pecino, R. (2015). Obstáculos en la comprensión de la violencia de género: Influencia del sexismo y la formación en género [Obstacles towards gender violence comprehension: Influence of sexism and academic training in gender issues]. Acción Psicológica, 11(2), 97. https://doi.org/10.5944/ap.11.2.14177 
*Durán, M., Megías, J. L., \& Moya, M. (2018). Male Peer Support to Hostile Sexist Attitudes Influences Rape Proclivity. Journal of Interpersonal Violence, 33(14), 2180-2196. https://doi.org/10.1177/0886260515624212

*Durán, M., Moya, M., \& Megias, J. L. (2011). It's his right, it's her duty: Benevolent sexism and the justification of traditional sexual roles. Journal of Sex Research, 48(5), 470-478. https://doi.org/10.1080/00224499.2010.513088

*Durán, M., Moya, M., Megías, J. L., \& Viki, G. T. (2010). Social perception of rape victims in dating and married relationships: The role of perpetrator's benevolent sexism. Sex Roles, 62(78), 505-519. https://doi.org/10.1007/s11199-009-9676-7

*Durán, M., \& Rodríguez-Domínguez, C. (2020). Social perception of situations of sexual cyberviolence: The role of sexist attitudes and the victim's transgression of gender roles / Percepción social de situaciones de ciberviolencia sexual: el rol de las actitudes sexistas y la transgresión de rol de . Revista de Psicologia Social, 35(1), 148-174. https://doi.org/10.1080/02134748.2019.1682295

Eagly, A. H., \& Wood, W. (2012). Social Role Theory. In Handbook of Theories of Social Psychology (pp. 458-476). SAGE Publications Ltd. https://doi.org/10.4135/9781446249222.n49

Ebbeler, C., Grau, I., \& Banse, R. (2017). Cultural and Individual Factors Determine Physical Aggression Between Married Partners: Evidence From 34 Countries. In Journal of CrossCultural Psychology (Vol. 48, Issue 7). https://doi.org/10.1177/0022022117719497

Egger, M., Smith, G. D., Schneider, M., \& Minder, C. (1997). Bias in meta-analysis detected by a simple, graphical test. BMJ, 315(7109), 629-634. https://doi.org/10.1136/bmj.315.7109.629

*Ercan, N. (2009). The Predictors of Attitudes Toward Physical Wife Abuse: Ambivalent Sexism, System Justification and Religious Orientation. Middle East Technical University. 
*Erdem, A., \& Sahin, R. (2017). Undergraduates’ Attitudes toward Dating Violence: Its Relationship with Sexism and Narcissism. International Journal of Higher Education, 6(6), 91. https://doi.org/10.5430/ijhe.v6n6p91

Ethical Principles of Psychologists and Code of Conduct. (2002). American Psychologist, 57(12), 1060-1073. https://doi.org/10.1037/0003-066X.57.12.1060

*Exposito, F., Herrera, M. C., Moya, M., \& Glick, P. (2010). Don’t Rock the Boat: Women's Benevolent Sexism Predicts Fears of Marital Violence. Psychology of Women Quarterly, 34, 36-42.

*Eyssel, F., \& Bohner, G. (2007). The rating of sexist humor under time pressure as an indicator of spontaneous sexist attitudes. Sex Roles, 57(9-10), 651-660. https://doi.org/10.1007/s11199-0079302-5

*Feinberg, C. (2015). Sexism and how it mediates the relationship between gender and rape myth acceptance. Rowan University.

*Fernández-Fuertes, A. A., Carcedo, R. J., Orgaz, B., \& Fuertes, A. (2018). Sexual Coercion Perpetration and Victimization: Gender Similarities and Differences in Adolescence. Journal of Interpersonal Violence, 33(16), 2467-2485. https://doi.org/10.1007/s00787-007-0647-7

Fisher, Z., \& Tipton, E. (2015). robumeta: An R-package for robust variance estimation in metaanalysis (arXiv:1503.02220).

Fisher, Z., Tipton, E., \& Zhipeng, H. (2017). robumeta: Robust Variance Meta-Regression. $R$ package version 2.0 .

Flood, M., \& Pease, B. (2009). Factors influencing attitudes to violence against women. Trauma, Violence, and Abuse, 10(2), 125-142. https://doi.org/10.1177/1524838009334131

Follingstad, D. R. (2007). Rethinking current approaches to psychological abuse: Conceptual and 
methodological issues. Aggression and Violent Behavior, 12(4), 439-458.

https://doi.org/10.1016/j.avb.2006.07.004

*Fonte D. (n.d.). Unpublished data.

Foran, H. M., \& O’Leary, K. D. (2008). Alcohol and intimate partner violence: A meta-analytic review. Clinical Psychology Review, 28(7), 1222-1234.

https://doi.org/10.1016/j.cpr.2008.05.001

*Forbes, G. B., \& Adams-Curtis, L. E. (2001). Experiences With Sexual Coercion in College Males and Females. Journal of Interpersonal Violence, 16(9), 865-889. https://doi.org/10.1177/088626001016009002

*Forees, G. B., Adams-Curtis, L. E., \& White, K. B. (2004). First- and Second-Generation Measures of Sexism, Rape Myths and Related Beliefs, and Hostility Toward Women. Violence Against Women, 10(3), 236-261. https://doi.org/10.1177/1077801203256002

*Fox, J., \& Potocki, B. (2015). Lifetime Video Game Consumption, Interpersonal Aggression, Hostile Sexism, and Rape Myth Acceptance: A Cultivation Perspective. Journal of Interpersonal Violence, 31(10), 1912-1931. https://doi.org/10.1177/0886260515570747

*Freeman, L. L. (2006). The Impact of a Woman's Prior Sexual History on Men's Ability to Discriminate Unwanted Sexual Behavior in a Date Rape Scenario [University of Mississippi]. https://search.proquest.com/docview/220297257?accountid=12834

*Garaigordobil, M., \& Aliri, J. (2013). Ambivalent sexism inventory: Standardization and normative data in a sample of the Basque country. Behavioral Psychology / Psicología Conductual, 21(1), $173-186$.

*García-Ael, C., Recio, P., \& Silván-Ferrero, P. (2018). Psychometric Properties of the Inventory of Beliefs about Intimate Partner Violence (IBIPV). Anales de Psicología, 34(1), 135-145. 
https://doi.org/10.6018/analesps.34.1.232901

Garcia-Moreno, C., Jansen, H. A., Ellsberg, M., Heise, L., \& Watts, C. H. (2006). Prevalence of intimate partner violence: findings from the WHO multi-country study on women's health and domestic violence. Lancet, 368(9543), 1260-1269. https://doi.org/10.1016/S01406736(06)69523-8

Gaunt, R. (2013). Ambivalent sexism and perceptions of men and women who violate gendered family roles. Community, Work and Family, 16(4), 401-416. https://doi.org/10.1080/13668803.2013.779231

*Gerger, H., Kley, H., Bohner, G., \& Siebler, F. (2007). The acceptance of modern myths about sexual aggression scale: development and validation in German and English. Aggressive Behavior, 33(5), 422-440. https://doi.org/10.1002/ab.20195

*Gervais, S. J., Davidson, M. M., Styck, K., Canivez, G., \& DiLillo, D. (2018). The development and psychometric properties of the Interpersonal Sexual Objectification Scale-Perpetration Version. Psychology of Violence, 8(5), 546-559. https://doi.org/10.1037/vio0000148

*Giger, J. C., Gonçalves, G., \& Almeida, A. S. (2017). Adaptation of the Domestic Violence Myth Acceptance Scale to Portuguese and Tests of Its Convergent, Divergent, and Predictive Validities. Violence Against Women, 23(14), 1790-1810. https://doi.org/10.1177/1077801216666724

Glick, P., \& Fiske, S. T. (1996). The Ambivalent Sexism Inventory: Differentiating hostile and benevolent sexism. Journal of Personality and Social Psychology, 70(3), 491-512. https://doi.org/10.1037/0022-3514.70.3.491

Glick, P., \& Fiske, S. T. (2001). An Ambivalent Alliance. Hostile and benevolent sexism as complementary jutifications for gender inequality. American Psychologist, 56(2), 109-118. 
https://doi.org/10.1037//O003-066X.56.2.109

Glick, P., Fiske, S. T., Mladinic, A., Saiz, J. L., Abrams, D., Masser, B., Adetoun, B., Osagie, J. E., Akande, A., Alao, A., Annetje, B., Willemsen, T. M., Chipeta, K., Dardenne, B., Dijksterhuis, A., Wigboldus, D., Eckes, T., Six-Materna, I., Expósito, F., ... López, W. L. (2000). Beyond prejudice as simple antipathy: Hostile and benevolent sexism across cultures. Journal of Personality and Social Psychology, 79(5), 763-775. https://doi.org/10.1037/0022-3514.79.5.763

*Glick, P., Sakalli-Uğurlu, N., Ferreira, M. C., \& Aguiar de Souza, M. (2002). Ambivalent sexism and attitudes toward wife abuse in Turkey and Brazil. Psychology of Women Quarterly, 26(4), 292-297. https://doi.org/10.1111/1471-6402.t01-1-00068

Glick, P., Wilkerson, M., \& Cuffe, M. (2015). Masculine identity, ambivalent sexism, and attitudes toward gender subtypes: Favoring masculine men and feminine women. Social Psychology, 46(4), 210-217. https://doi.org/10.1027/1864-9335/a000228

Gölge, Z. B., Sanal, Y., Yavuz, S., \& Arslanoglu-Çetin, E. (2016). Attitudes toward Wife Abuse of Police Officers and Judiciary Members in Turkey: Profession, Gender, Ambivalent Sexism and Sex Roles. Journal of Family Violence, 31(6), 785-796. https://doi.org/10.1007/s10896-0169823-1

*Gracia, E., Martín-Fernández, M., Marco, M., Santirso, F. A., Vargas, V., \& Lila, M. (2018). The Willingness to Intervene in Cases of Intimate Partner Violence Against Women (WI-IPVAW) scale: Development and validation of the long and short versions. Frontiers in Psychology, 9(JUL), 1-16. https://doi.org/10.3389/fpsyg.2018.01146

*Gray, J. A. (2011). The role of context in the interpretation of sexist humor. Western Carolina University, USA.

Gul, P., \& Kupfer, T. R. (2019). Benevolent Sexism and Mate Preferences: Why Do Women Prefer 
Benevolent Men Despite Recognizing That They Can Be Undermining? Personality and Social Psychology Bulletin, 45(1), 146-161. https://doi.org/10.1177/0146167218781000

*Hall, J. A. (2011). Unpublished data.

*Hall, J. A., \& Canterberry, M. (2011). Sexism and Assertive Courtship Strategies. Sex Roles, 65(1112), 840-853. https://doi.org/10.1007/s11199-011-0045-y

Hammock, G. S., Richardson, D. S., Williams, C., \& Janit, A. S. (2015). Perceptions of Psychological and Physical Aggression Between Heterosexual Partners. Journal of Family Violence, 30(1), 13-26. https://doi.org/10.1007/s10896-014-9645-y

Hammond, M. D., Milojev, P., Huang, Y., \& Sibley, C. G. (2018). Benevolent Sexism and Hostile Sexism Across the Ages. Social Psychological and Personality Science, 9(7), 863-874. https://doi.org/10.1177/1948550617727588

*Hammond, M. D., \& Overall, N. C. (2013). When relationships do not live up to benevolent ideals: Women's benevolent sexism and sensitivity to relationship problems. European Journal of Social Psychology, 43(3), 212-223. https://doi.org/10.1002/ejsp.1939

*Hantzi, A., Lampridis, E., Tsantila, K., \& Bohner, G. (2015). Validation of the greek acceptance of modern myths about sexual aggression (AMMSA) Scale: Examining Its relationships with sexist and conservative political beliefs. International Journal of Conflict and Violence, 9(1), 121-133.

*Harrington, A. G., Overall, N. C., \& Cross, E. J. (2020). Masculine gender role stress, low relationship power, and aggression toward intimate partners. Psychology of Men \& Masculinities, April. https://doi.org/10.1037/men0000262

*Harris, E. A., Thai, M., \& Barlow, F. K. (2017). Fifty Shades Flipped: Effects of Reading Erotica Depicting a Sexually Dominant Woman Compared to a Sexually Dominant Man. Journal of Sex Research, 54(3), 386-397. https://doi.org/10.1080/00224499.2015.1131227 
Hedges, L. V., Tipton, E., \& Johnson, M. C. (2010). Robust variance estimation in meta-regression with dependent effect size estimates. Research Synthesis Methods, 1(1), 39-65. https://doi.org/10.1002/jrsm.5

*Hefley, K. S. (2006). Combinig General Strain Theory with Feminist Theories to Explain Rape. University of Oklahoma.

*Hegarty, P., Stewart, A. L., Blockmans, I. G. E., \& Horvath, M. A. H. (2018). The influence of magazines on men: Normalizing and challenging young men's prejudice with "Lads"' Mags"." Psychology of Men and Masculinity, 19(1), 131-144. https://doi.org/10.1037/men0000075

*Herrera, A., Pina, A., Herrera, M. C., \& Expósito, F. (2014). ¿Mito o realidad? Influencia de la ideología en la percepción social del acoso sexual. Anuario de Psicología Jurídica, 24(1), 1-7. https://doi.org/10.1016/j.apj.2014.07.002

*Herrera, M. Carmen, Herrera, A., \& Expósito, F. (2014). Stop Harassment! Men’s reactions to victims' confrontation. European Journal of Psychology Applied to Legal Context, 6(2), 45-52. https://doi.org/10.1016/j.ejpal.2014.06.006

*Herrera, M. del C., Herrera, A., \& Expósito, F. (2018). To confront versus not to confront: Women's perception of sexual harassment. European Journal of Psychology Applied to Legal Context, 10(1), 1-7. https://doi.org/10.1016/j.ejpal.2017.04.002

*Herrera, Mari Carmen, Expósito, F., Moya, M., \& Houston, D. (2012). “Having it All”: Women’s Perception of Impact of Female Promotion on Threat of Domestic Violence. The Spanish Journal of Psychology, 15(02), 670-679. https://doi.org/10.5209/rev_SJOP.2012.v15.n2.38878

Herrero, J., Rodríguez, F. J., \& Torres, A. (2017). Acceptability of Partner Violence in 51 Societies. Violence Against Women, 23(3), 351-367. https://doi.org/10.1177/1077801216642870

*Hill, S., \& Marshall, T. C. (2018). Beliefs about Sexual Assault in India and Britain are Explained 
by Attitudes Toward Women and Hostile Sexism. Sex Roles, 79(7-8), 421-430. https://doi.org/10.1007/s11199-017-0880-6

Hockett, J. M., Smith, S. J., Klausing, C. D., \& Saucier, D. A. (2016). Rape Myth Consistency and Gender Differences in Perceiving Rape Victims: A Meta-Analysis. Violence Against Women, 22(2), 139-167. https://doi.org/10.1177/1077801215607359

Human Development Reports. (2019). http://hdr.undp.org/en/content/table-5-gender-inequalityindex-gii

Hunter, J. E., \& Schmidt, F. L. (2004). Methods of meta-analysis (2nd ed.). Sage.

*Hurrell, K. G. (2017). Rape Myth Acceptance, Pornography Use, and Sociodemographic Factors: A Multidimensional Analysis. University of Detroit Mercy.

*Husnu, S., \& Mertan, B. E. (2017). The Roles of Traditional Gender Myths and Beliefs About Beating on Self-Reported Partner Violence. Journal of Interpersonal Violence, 32(24), 37353752. https://doi.org/10.1177/0886260515600879

*Hyatt, C. S., Berke, D. S., Miller, J. D., \& Zeichner, A. (2017). Do beliefs about gender roles moderate the relationship between exposure to misogynistic song lyrics and men's femaledirected aggression? Aggressive Behavior, 43(2), 123-132. https://doi.org/10.1002/ab.21668

Jak, S., Li, H., Kolbe, L., Jonge, H., \& Cheung, M. W. -L. (2021). Meta-analytic structural equation modeling made easy: A tutorial and web application for one-stage $<$ scp $>$ MASEM $</$ scp $>$. Research Synthesis Methods, 12(5), 590-606. https://doi.org/10.1002/jrsm.1498

Jones, R. T., Browne, K., \& Chou, S. (2017). A critique of the revised Conflict Tactics Scales-2 (CTS-2). Aggression and Violent Behavior, 37, 83-90. https://doi.org/10.1016/j.avb.2017.08.005

*Jongsma, K. (2019). The Role of Pornography Consumption in Intimate Partner Aggression. 
University of Windsor.

Jordan, C. E., Campbell, R., \& Follingstad, D. (2010). Violence and Women's Mental Health: The Impact of Physical, Sexual, and Psychological Aggression. Annual Review of Clinical Psychology, 6(1), 607-628. https://doi.org/10.1146/annurev-clinpsy-090209-151437

Jost, J. T., Banaji, M. R., \& Nosek, B. A. (2004). A Decade of System Justification Theory: Accumulated Evidence of Conscious and Unconscious Bolstering of the Status Quo. Political Psychology, 25(6), 881-919. https://doi.org/10.1111/j.1467-9221.2004.00402.x

*Judson, S. S., Johnson, D. M., \& Perez, A. L. U. (2013). Perceptions of adult sexual coercion as a function of victim gender. Psychology of Men and Masculinity, 14(4), 335-344. https://doi.org/10.1037/a0030448

*Katz, J., Merrilees, C., LaRose, J., \& Edgington, C. (2018). White Female Bystanders' Responses to a Black Woman at Risk for Sexual Assault: Associations With Attitudes About Sexism and Racial Injustice. Journal of Aggression, Maltreatment \& Trauma, 27(4), 444-459. https://doi.org/10.1080/10926771.2017.1376238

*Kelly, A. J., Dubbs, S. L., \& Barlow, F. K. (2015). Social Dominance Orientation Predicts Heterosexual Men's Adverse Reactions to Romantic Rejection. Archives of Sexual Behavior, 44(4), 903-919. https://doi.org/10.1007/s10508-014-0348-5

*Kelly, T. C. (2009). Judjments and perseptions of blame: the impact of benevolent sexism and rape type on attributions of responsobility in sexual assault. University of Toronto, USA.

*Klement, K. R., Sagarin, B. J., \& Lee, E. M. (2017). Participating in a Culture of Consent May Be Associated With Lower Rape-Supportive Beliefs. Journal of Sex Research, 54(1), 130-134. https://doi.org/10.1080/00224499.2016.1168353

*Krings, F., \& Facchin, S. (2009). Organizational Justice and Men's Likelihood to Sexually Harass: 
The Moderating Role of Sexism and Personality. Journal of Applied Psychology, 94(2), 501510. https://doi.org/10.1037/a0013391

*Kunst, J. R., Bailey, A., Prendergast, C., \& Gundersen, A. (2019). Sexism, rape myths and feminist identification explain gender differences in attitudes toward the \#metoo social media campaign in two countries. Media Psychology, 22(5), 818-843.

https://doi.org/10.1080/15213269.2018.1532300

Langhinrichsen-Rohling, J., McCullars, A., \& Misra, T. A. (2012). Motivations for Men and Women's Intimate Partner Violence Perpetration: A Comprehensive Review. Partner Abuse, 3(4), 429-468. https://doi.org/10.1891/1946-6560.3.4.429

*Lartigue, E. K. C. (2001). Perceptions of sexual harassment: the influences of physical attractiveness of the victim and comparative status. The Florida State University.

Lee, T. L., Fiske, S. T., Glick, P., \& Chen, Z. (2010). Ambivalent sexism in close relationships: (Hostile) power and (benevolent) romance shape relationship ideals. Sex Roles, 62(7-8), 583601. https://doi.org/10.1007/s11199-010-9770-x

*Lelaurain, S., Fonte, D., Aim, M. A., Khatmi, N., Decarsin, T., Lo Monaco, G., \& Apostolidis, T. (2018). “One Doesn’t Slap a Girl but...” Social Representations and Conditional Logics in Legitimization of Intimate Partner Violence. Sex Roles, 78(9-10), 637-652. https://doi.org/10.1007/s11199-017-0821-4

*Lelaurain, S., Fonte, D., Giger, J.-C., Guignard, S., \& Lo Monaco, G. (2018). Legitimizing Intimate Partner Violence: The Role of Romantic Love and the Mediating Effect of Patriarchal Ideologies. Journal of Interpersonal Violence. https://doi.org/10.1177/0886260518818427

*Lelaurain, S., Fonte, D., Graziani, P., \& Monaco, G. Lo. (2019). French Validation of the Domestic Violence Myth Acceptance Scale (DVMAS). Affilia - Journal of Women and Social Work, 
34(2), 237-258. https://doi.org/10.1177/0886109918806273

LeMaire, K. L., Oswald, D. L., \& Russell, B. L. (2016). Labeling Sexual Victimization Experiences: The Role of Sexism, Rape Myth Acceptance, and Tolerance for Sexual Harassment. Violence and Victims, 31(2), 332-346. https://doi.org/10.1891/0886-6708.VV-D-13-00148

*Lisco, C. (2013). Examining the Role of Ambivalent Sexism, Violations of Traditional Feminine Norms, and Provocation in Men's Aggression Toward Women and Female Intimate Partners [Georgia State University]. https://doi.org/10.1073/pnas.0809921106

Lonsway, K. A., Cortina, L. M., \& Magley, V. J. (2008). Sexual harassment mythology: Definition, conceptualization, and measurement. Sex Roles, 58(9-10), 599-615. https://doi.org/10.1007/s11199-007-9367-1

*Loveland, J. E. (2017). The Relationships Among Different Traits of Masculinity and Intimate Partner Violence. City University of New York.

Loveland, J. E., \& Raghavan, C. (2017). Coercive Control, Physical Violence, and Masculinity. Violence and Gender, 4(1), 5-10. https://doi.org/10.1089/vio.2016.0019

*Luna-Bernal, A. C. A., \& Laca-Arocena, F. A. (2017). Sexismo ambivalente y estilos de manejo de conflictos en estudiantes de bachillerato / Ambivalent Sexism and Conflict Handling Styles in High School Students. RIDE Revista Iberoamericana Para La Investigación y El Desarrollo Educativo, 8(15), 182-209. https://doi.org/10.23913/ride.v8i15.296

Maiuro, R. D. (2001). Sticks and stones may break my bones, but names will also hurt me: psychological abuse in domestically violent relationships. In K. D. O’Leary \& R. D. Maiuro (Eds.), Psychological Abuse in Violent Domestic Relations. Springer.

*Makin-Byrd, K., \& Azar, S. T. (2011). Beliefs and Attributions of Partner Violence Perpetrators: The Physical and Psychological Violence of Adolescent Males. Violence and Victims, 26(2), 
177-190. https://doi.org/10.1891/0886-6708.26.2.177

Marques, J. M., \& Paez, D. (1994). The 'Black Sheep Effect': Social Categorization, Rejection of Ingroup Deviates, and Perception of Group Variability. European Review of Social Psychology, 5(1), 37-68. https://doi.org/10.1080/14792779543000011

*Martín-Fernández, M., Gracia, E., Marco, M., Vargas, V., Santirso, F. A., \& Lila, M. (2018). Measuring acceptability of intimate partner violence against women: Development and validation of the A-IPVAW scale. European Journal of Psychology Applied to Legal Context, 10(1), 26-34. https://doi.org/10.5093/ejpalc2018a3

*Martinez-Pecino, R., \& Durán, M. (2016). I Love You but I Cyberbully You: The Role of Hostile Sexism. Journal of Interpersonal Violence, 34(4), 812-825. https://doi.org/10.1177/0886260516645817

*Masser, B., Lee, K., \& McKimmie, B. M. (2010). Bad woman, Bad victim? Disentangling the effects of victim stereotypicality, gender stereotypicality and benevolent sexism on acquaintance rape victim blame. Sex Roles, 62(7-8), 494-504. https://doi.org/10.1007/s11199-009-9648-y

*Masser, B., Viki, G. T., \& Power, C. (2006). Hostile sexism and rape proclivity amongst men. Sex Roles, 54(7-8), 565-574. https://doi.org/10.1007/s11199-006-9022-2

*Megías, J. L., Romero-Sánchez, M., Durán, M., Moya, M., \& Bohner, G. (2011). Spanish Validation of the Acceptance of Modern Myths about Sexual Aggression Scale (AMMSA). The Spanish Journal of Psychology, 14(2), 912-925.

https://doi.org/10.5209/rev_SJOP.2011.v14.n2.37

*Megías, J. L., Toro-García, V., \& Carretero-Dios, H. (2018). The Acceptance of Myths About Intimate Partner Violence Against Women (AMIVAW) Scale: Development and Validation in Spanish and English. Psychology of Women Quarterly, 42(1), 44-61. 
https://doi.org/10.1177/0361684317742638

Messinger, A. M. (2011). Invisible Victims: Same-Sex TPV in the National Violence Against Women Survey. Journal of Interpersonal Violence, 26(11), 2228-2243. https://doi.org/10.1177/0886260510383023

*Methot-Jones, T., Book, A., \& Gauthier, N. Y. (2019). Less than human: psychopathy, dehumanization, and sexist and violent attitudes towards women. Personality and Individual Differences, 149(January), 250-260. https://doi.org/10.1016/j.paid.2019.06.002

Montesanti, S. R., \& Thurston, W. E. (2015). Mapping the role of structural and interpersonal violence in the lives of women: Implications for public health interventions and policy. $B M C$ Women's Health, 15(1), 1-13. https://doi.org/10.1186/s12905-015-0256-4

Moore, T. M., Stuart, G. L., Meehan, J. C., Rhatigan, D. L., Hellmuth, J. C., \& Keen, S. M. (2008). Drug abuse and aggression between intimate partners: A meta-analytic review. Clinical Psychology Review, 28(2), 248-275. https://doi.org/10.1016/j.cpr.2007.05.003

*Morelli, M., Bianchi, D., Baiocco, R., Pezzuti, L., \& Chirumbolo, A. (2016). Not-allowed sharing of sexts and dating violence from the perpetrator's perspective: The moderation role of sexism. Computers in Human Behavior, 56(1), 163-169. https://doi.org/10.1016/j.chb.2015.11.047

Morgan, C. S., \& Walker, A. J. (1983). Predicting Sex Role Attitudes. Social Psychology Quarterly, 46(2), 148-151.

*Muñoz-Ponce, N. N., Espinobarros-Nava, F., Romero-Méndez, C. A., \& Rojas-solís, J. L. (2020). Sexismo, celos y aceptación de violencia en jóvenes universitarios mexicanos. Revista Katharsis, 29, 3-21. https://doi.org/10.25057/25005731.1284

Murnen, S. K., Wright, C., \& Kaluzny, G. (2002). If “boys will be boys,” then girls will be victims? A meta-analytic review of the research that relates masculine ideology to sexual aggression. Sex 
Roles, 46(11-12), 359-375. https://doi.org/10.1023/A:1020488928736

Murphy, C. M., \& O’Leary, K. D. (2005). Psychological aggression predicts physical aggression in early marriage. Journal of Consulting and Clinical Psychology, 57(5), 579-582. https://doi.org/10.1037/0022-006x.57.5.579

Napier, J. L., Thorisdottir, H., \& Jost, J. T. (2010). The joy of sexism? A multinational investigation of hostile and benevolent justifications for gender inequality and their relations to subjective well-being. Sex Roles, 62(7-8), 405-419. https://doi.org/10.1007/s11199-009-9712-7

*Obeid, N., Chang, D. F., \& Ginges, J. (2010). Beliefs about wife beating: An exploratory study with lebanese students. Violence Against Women, 16(6), 691-712. https://doi.org/10.1177/1077801210370465

Obierefu, P. O., \& Ezeugwu, C. R. (2017). Risk and Protective Psychological Factors in Rape Supportive Attitude: a Systematic Review. Journal of Psychological \& Educational Research, 25(2), 141-164.

*Ohse, D. M., \& Stockdale, M. S. (2008). Age comparisons in workplace sexual harassment perceptions. Sex Roles, 59(3-4), 240-253. https://doi.org/10.1007/s11199-008-9438-y

*Osborn, K., Davis, J. P., Button, S., \& Foster, J. (2018). Juror Decision Making in Acquaintance and Marital Rape: The Influence of Clothing, Alcohol, and Preexisting Stereotypical Attitudes. Journal of Interpersonal Violence, in press. https://doi.org/10.1177/0886260518768566

*Papp, L. J., \& Erchull, M. J. (2017). Objectification and System Justification Impact Rape Avoidance Behaviors. Sex Roles, 76(1-2), 110-120. https://doi.org/10.1007/s11199-016-0660-8

Parrott, D. J., \& Zeichner, A. (2003). Effects of Trait Anger and Negative Attitudes Towards Women on Physical Assault in Dating Relationships. Journal of Family Violence, 18(5), 301-307. https://doi.org/10.1023/A:1025169328498 
*Pauwels, B. G. (2002). Blaming the Victim of Rape: The Culpable Control Model Perspective. University of Iowa.

Payne, D. L., Lonsway, K. A., \& Fitzgerald, L. F. (1999). Rape Myth Acceptance: Exploration of Its Structure and Its Measurement Using the Illinois Rape Myth Acceptance Scale. Journal of Research in Personality, 33(1), 27-68.

*Pedersen, S. H., \& Strömwall, L. A. (2013). Victim Blame, Sexism and Just-World Beliefs: A Cross-Cultural Comparison. Psychiatry, Psychology and Law, 20(6), 932-941. https://doi.org/10.1080/13218719.2013.770715

*Persson, S., Dhingra, K., \& Grogan, S. (2018). Attributions of victim blame in stranger and acquaintance rape: A quantitative study. Journal of Clinical Nursing, 27(13-14), 2640-2649. https://doi.org/10.1111/jocn.14351

*Pica, E., Sheahan, C. L., \& Pozzulo, J. (2020). Prior Allegations of Harassment Impact Mock Jurors' Perceptions of Sexual Harassment in a Criminal Trial. Sex Roles, 82(9-10), 541-549. https://doi.org/10.1007/s11199-019-01076-2

Plichta, S. B. (2004). Intimate partner violence and physical health consequences: Policy and practice implications. Journal of Interpersonal Violence, 19(11), 1296-1323. https://doi.org/10.1177/0886260504269685

*Pozo Muñoz, C., Martos Méndez, M. J., \& Alonso Morillejo, E. (2010). Do secondary students manifest sexist attitudes? Electronic Journal of Research in Educational Psychology, 8(2), 541560.

Pustejovsky, J. (2017). clubSandwich: Cluster Robust (Sandwich) Variance Estimators with SmallSample Corrections. $R$ package version 0.2.3.

*Read, G. L., Lynch, T., \& Matthews, N. L. (2018). Increased Cognitive Load during Video Game 
Play Reduces Rape Myth Acceptance and Hostile Sexism after Exposure to Sexualized Female Avatars. Sex Roles, 79(11-12), 683-698. https://doi.org/10.1007/s11199-018-0905-9

*Rebeiz, M. J., \& Harb, C. (2010). Perceptions of rape and attitudes toward women in a sample of lebanese students. Journal of Interpersonal Violence, 25(4), 735-752. https://doi.org/10.1177/0886260509334410

Renzetti, C. M., Lynch, K. R., \& DeWall, C. N. (2018). Ambivalent Sexism, Alcohol Use, and Intimate Partner Violence Perpetration. Journal of Interpersonal Violence, 33(2), 183-210. https://doi.org/10.1177/0886260515604412

*Resendez, J. R., \& Hughes, J. S. (2016). Introducing the Date and Acquaintance Rape Avoidance Scale. Violence and Victims, 31(4), 664-679. https://doi.org/10.1891/0886-6708.VV-D-1400086R2

*Rey-Anacona, C. A., Gonzalez Cruz, Y., Jimenez Sanchez, V., \& Saavedra Guajardo, V. (2017). Sexismo y agresiones en el noviazgo en adolescentes Españoles, Chilenos y Colombianos. Behavioral Psychology / Psicología Conductual, 25(2), 297-314.

*Riley, C. E., \& Yamawaki, N. (2018). Who Is Helpful? Examining the Relationship Between Ambivalent Sexism, Right-Wing Authoritarianism, and Intentions to Help Domestic Violence Victims. SAGE Open, 8(2). https://doi.org/10.1177/2158244018781899

*Rodríguez-Domínguez, C., Segura, M. D., \& Martínez-Pecino, R. (2018). Ciberagresores En El Noviazgo Adolescente Y Su Relación Con La Violencia Psicológica, El Sexismo Y Los Celos Cyber [Ciber Aggressors in Dating Relationships and Its Relation With Psychological Violence, Sexism and Jealousy]. Health and Addictions, 18(1), 17-27. https://doi.org/10.21134/haaj.v18i1.329

*Rojas-Solís, J. L., \& Raimúndez, E. C. (2011). Sexism and physical, sexual and verbal-emotional 
aggression in courtship relationships in university students. Electronic Journal of Research in Educational Psychology, 9(2), 541-564.

Rollè, L., Giardina, G., Caldarera, A. M., Gerino, E., \& Brustia, P. (2018). When intimate partner violence meets same sex couples: A review of same sex intimate partner violence. Frontiers in Psychology, 9(AUG), 1-13. https://doi.org/10.3389/fpsyg.2018.01506

Rollero, C., Bergagna, E., \& Tartaglia, S. (2019). What is Violence? The Role of Sexism and Social Dominance Orientation in Recognizing Violence Against Women. Journal of Interpersonal Violence. https://doi.org/10.1177/0886260519888525

*Rollero, C., \& Tartaglia, S. (2019). The Effect of Sexism and Rape Myths on Victim Blame. Sexuality \& Culture, 23(1), 209-219. https://doi.org/10.1007/s12119-018-9549-8

*Romero-Sànchez, M., Megías, J. L., Carretero-Dios, H., \& Neira, L. R. (2013). Version colombiana de la escala Acceptance of Modern Myths about Sexual Aggression: primeros análisis psicométricos [Colombian version of the Acceptance of Modern Myths about Sexual Aggression scale: First psychometric analyses]. Revista Latinoamericana de Psicologiaía, $45(1), 121-134$.

Rotundo, M., Nguyen, D.-H., \& Sackett, P. R. (2001). A meta-analytic review of gender differences in perceptions of sexual harassment. Journal of Applied Psychology, 86(5), 914-922. https://doi.org/10.1037//0021-9010.86.5.914

*Rudman, L. A., \& Glick, P. (2008). The Social Psychology of Gender: How Power and Intimacy Shape Gender Relations. Guilford Press.

*Rudman, L. A., \& Mescher, K. (2012). Of Animals and Objects: Men's Implicit Dehumanization of Women and Likelihood of Sexual Aggression. Personality and Social Psychology Bulletin, 38(6), 734-746. https://doi.org/10.1177/0146167212436401 
*Russell, B. L., \& Oswald, D. (2016). When Sexism Cuts Both Ways: Predictors of Tolerance of Sexual Harassment of Men. Men and Masculinities, 19(5), 524-544. https://doi.org/10.1177/1097184X15602745

*Russell, B. L., \& Trigg, K. Y. (2004). Tolerance of Sexual Harassment: An Examination of Gender Differences, Ambivalent Sexism, Social Dominance, and Gender Roles. Sex Roles, 50(7/8), 565-573. https://doi.org/10.1023/B:SERS.0000023075.32252.fd

*Sakalli-Uğurlu, N., Salman, S., \& Turgut, S. (2010). Predictors of Turkish Women's and Men's Attitudes toward Sexual Harassment: Ambivalent Sexism, and Ambivalence Toward Men. Sex Roles, 63(11), 871-881. https://doi.org/10.1007/s11199-010-9847-6

*Sakalli-Uğurlu, N., Yalçin, Z. S., \& Glick, P. (2007). Ambivalent sexism, belief in a just world, and empathy as predictors of Turkish students' attitudes toward rape victims. Sex Roles, 57(11-12), 889-895. https://doi.org/10.1007/s11199-007-9313-2

*Sakalli, N. (2001). Beliefs about wife beating among Turkish college students: The Effects of Patriarchy, Sexism, and Sex Differences. Sex Roles, 44(9/10), 599-610.

Samji, K., \& Vasquez, E. A. (2019). The link between myths about sexual aggression and sexual objectification via hostile attitudes toward women. Journal of Sexual Aggression, O(0), 1-9. https://doi.org/10.1080/13552600.2019.1676924

*Saunders, B. A., Scaturro, C., Guarino, C., \& Kelly, E. (2017). Contending with Catcalling: The Role of System-justifying Beliefs and Ambivalent Sexism in Predicting Women's Coping Experiences with (and Men's Attributions for) Stranger Harassment. Current Psychology, 36(2), 324-338. https://doi.org/10.1007/s12144-016-9421-7

Shackelford, T., \& Besser, A. (2007). Predicting Attitudes toward Homosexuality: Insights from Personality Psychology. Individual Differences Research, 5(2), 106-114. 
Shen, A. C. T., Chiu, M. Y. L., \& Gao, J. (2012). Predictors of Dating Violence Among Chinese Adolescents: The Role of Gender-Role Beliefs and Justification of Violence. Journal of Interpersonal Violence, 27(6), 1066-1089. https://doi.org/10.1177/0886260511424497

*Shilinsky, A. N. (2016). Does benevolence benefit? Understanding the role of benevolent sexism sub-factors in predicting sexual aggression among men. Rowan University, USA.

*Shim, J. W. (2006). Online pornography and rape myth acceptance: Sexually degrading content, anonymous viewing conditions, and the activation of antisocial attitudes. [Indiana University]. http://ovidsp.ovid.com/ovidweb.cgi?T=JS\&PAGE=reference \&D=psyc5\&NEWS=N\&AN=2007 $-99011-026$

Sibley, C. G., \& Duckitt, J. (2008). Personality and prejudice: a meta-analysis and theoretical review. Personality and Social Psychology Review, 12(1954), 248-279. https://doi.org/10.1177/1088868308319226

*Siebler, F., Sabelus, S., \& Bohner, G. (2008). A Refined Computer Harassment Paradigm: Validation, and Test of Hypotheses about Target Characteristics. Psychology of Women Quarterly, 32(32), 22-35. https://doi.org/10.1111/j.1471-6402.2007.00404.x

*Simonson, K. (2001). Perceptions of physical, sexual, and psychological abuse in relation to personal experience with interpersonal violence, witnessing parental violence and sexist beliefs. The University of Akron, USA.

Smith-Marek, E. N., Cafferky, B., Dharnidharka, P., Mallory, A. B., Dominguez, M., High, J., Stith, S. M., \& Mendez, M. (2015). Effects of Childhood Experiences of Family Violence on Adult Partner Violence: A Meta-Analytic Review. Journal of Family Theory \& Review, 7(4), 498519. https://doi.org/10.1111/jftr.12113

*Soto-Quevedo, O. A. (2012). The role of ambivalent sexism and transgression of gender stereotype 
on attribution of blame to female victims of intimate partner violence. Acta Colombiana de Psicología, 15(1), 135-148.

Stanley, T. D., \& Doucouliagos, H. (2014). Meta-regression approximations to reduce publication selection bias. Research Synthesis Methods, 5(1), 60-78. https://doi.org/10.1002/jrsm.1095

*Stewart, A. L. (2014). The Men's Project : A Sexual Assault Prevention Program Targeting College Men. Psychology of Men \& Masculinity, 15(4), 481-485.

Stith, S. M., Rosen, K. H., Middleton, K. A., Busch, A. L., Lundeberg, K., \& Carlton, R. P. (2000). The Intergenerational Transmission of Spouse Abuse: A Meta-Analysis. Journal of Marriage and Family, 62(3), 640-654. https://doi.org/10.1111/j.1741-3737.2000.00640.x

Stith, S. M., Smith, D. B., Penn, C. E., Ward, D. B., \& Tritt, D. (2004). Intimate partner physical abuse perpetration and victimization risk factors: A meta-analytic review. Aggression and Violent Behavior, 10(1), 65-98. https://doi.org/10.1016/j.avb.2003.09.001

*Stoll, L. C., Lilley, T. G., \& Block, R. (2018). The Effects of Gender-Blind Sexism on Rape Myth Acceptance: Results From a Nationally Representative Study. Journal of Interpersonal Violence, in press. https://doi.org/10.1177/0886260518807912

Suarez, E., \& Gadalla, T. M. (2010). Stop blaming the victim: A meta-analysis on rape myths. Journal of Interpersonal Violence, 25(11), 2010-2035. https://doi.org/10.1177/0886260509354503

*Suchovicki, M. (2011). Hostile and Benevolent Sexism as Predictors of the Endorsement of Rape Myths and Sexual Harassment Myths as a Function of Gender. Walden University, USA.

Sugarman, D. B., \& Frankel, S. L. (1996). Patriarchal ideology and wife-assault: A meta-analytic review. Journal of Family Violence, 11(1), 13-40. https://doi.org/10.1007/BF02333338

Swann, W. B. (2012). Self-Verification Theory. In Handbook of Theories of Social Psychology (pp. 
23-42). SAGE Publications Ltd. https://doi.org/10.4135/9781446249222.n27

Swim, J. K., Aikin, K. J., Hall, W. S., \& Hunter, B. A. (1995). Sexism and racism: Old-fashioned and modern prejudices. Journal of Personality and Social Psychology, 68(2), 199-214. https://doi.org/10.1037/0022-3514.68.2.199

Swim, J. K., \& Campbell, B. (2003). Sexism: Attitudes, Beliefs, and Behaviors. In R. Brown \& S. Gaetner (Eds.), Blackwell handbook of social psychology: Intergroup processes (pp. 218-237). Blackwell.

Swim, J. K., Eyssell, K. M., Murdoch, E. Q., \& Ferguson, M. J. (2010). Self-Silencing to Sexism. Journal of Social Issues, 66(3), 493-507. https://doi.org/10.1111/j.1540-4560.2010.01658.x

Swim, J. K., \& Hyers, L. L. (2009). Sexism. In T. D. Nelson (Ed.), Handbook of Prejudice, Stereotyping, and Discrimination (pp. 407-430). Psychology Press.

*Tang, W. Y., \& Fox, J. (2016). Men's harassment behavior in online video games: Personality traits and game factors. Aggressive Behavior, 42(6), 513-521. https://doi.org/10.1002/ab.21646

*Tang, W. Y., Reer, F., \& Quandt, T. (2020). Investigating sexual harassment in online video games: How personality and context factors are related to toxic sexual behaviors against fellow players. Aggressive Behavior, 46(1), 127-135. https://doi.org/10.1002/ab.21873

*Tapara, A. (2017). Rapists Among Us ? Rape Proclivity and Correlates in a New Zealand Sample of Men. University of Waikato.

*Tarhan, S., Çetin Gündüz, H., \& Ekşioğlu, S. (2017). Ambivalent sexism, gender and attitudes towards violence against women in marriage $<$ p $>$ Çelişik duygulu cinsiyetçilik, toplumsal cinsiyet ve evlilikte kadına yönelik şiddete ilişkin tutumlar. Journal of Human Sciences, 14(2), 1894. https://doi.org/10.14687/jhs.v14i2.4474

*Taschler, M., \& West, K. (2017). Contact with Counter-Stereotypical Women Predicts Less Sexism, 
Less Rape Myth Acceptance, Less Intention to Rape (in Men) and Less Projected Enjoyment of Rape (in Women). Sex Roles, 76(7-8), 473-484. https://doi.org/10.1007/s11199-016-0679-x

*Thomae, M., \& Viki, G. T. (2013). Why did the woman cross the road? The effect of sexist humor on men's rape proclivity. Journal of Social, Evolutionary, and Cultural Psychology, 7(3), 250269. https://doi.org/10.1037/h0099198

*Thomas, C. A., \& Esses, V. M. (2004). Individual differences in reactions to sexist humor. Group Processes and Intergroup Relations, 7(1), 89-100. https://doi.org/10.1177/1368430204039975

*Toplu-Demirtaş, E., Öztemür, G., \& Fincham, F. D. (2020). Perceptions of Dating Violence: Assessment and Antecedents. Journal of Interpersonal Violence, in press. https://doi.org/10.1177/0886260520914558

*Toplu Demirtaş, E. (2015). Psychological aggression perpetration among dating college students: The interplay of societal, parental, and personal factors. Middle East Technical University, USA.

*Toplu Demirtaş, E., Hatipoğlu-Sümer, Z., \& Fincham, F. D. (2017). Intimate Partner Violence in Turkey: The Turkish Intimate Partner Violence Attitude Scale-Revised. Journal of Family Violence, 32(3), 349-356. https://doi.org/10.1007/s10896-016-9852-9

*Trangsrud, H. B. (2010). Examination of victim and perpetrator blame in date rape scenarios and exploration of ambivalent sexism subtypes as predictors of male and female rape myths among a sample of college students. University of Missouri-Kansas City.

*Troche, S. J., \& Herzberg, P. Y. (2017). On the role of dominance and nurturance in the confluence model: A person-centered approach to the prediction of sexual aggression. Aggressive Behavior, 43(3), 251-262. https://doi.org/10.1002/ab.21685

*Ubillos-Landa, S., Goiburu-Moreno, E., Puente-Martínez, A., Pizarro-Ruiz, J.-P., \& Echeburúa- 
Odriozola, E. (2017). Assessment of Distorted Thoughts About Women and Violence of Basque-speaking Secondary School Students. Revista de Psicodidáctica, 22(1), 1-8. https://doi.org/10.1387/RevPsicodidact.16124

Vandello, J. A., \& Cohen, D. (2003). Male Honor and Female Fidelity: Implicit Cultural Scripts that Perpetuate Domestic Violence. Journal of Personality and Social Psychology, 84(5), 997-1010. https://doi.org/10.1037/0022-3514.84.5.997

*Vidal-Fernández, A., \& Megías, J. L. (2014). Attributions of Blame to Battered Women when they are perceived as Feminists or as "Difficult to Deal With." Spanish Journal of Psychology, 17(2014), E21. https://doi.org/10.1017/sjp.2014.26

Viechtbauer, W. (2010). Conducting Meta-Analyses in R with the metafor Package. Journal of Statistical Software, 36(3), 1-48. https://doi.org/10.18637/jss.v036.i03

*Viki, G. T., \& Abrams, D. (2002). But She Was Unfaithful: Benevolent Sexism and Reactions to Rape Victims Who Violate Traditional Gender Role Expectations. Sex Roles, 47(5/6), 289-293. https://doi.org/10.1023/A

*Viki, G. T., Chiroro, P., \& Abrams, D. (2006). Hostile Sexism, Type of Rape, and Self-Reported Rape Proclivity Within a Sample of Zimbabwean Males. Violence Against Women, 12(8), 789800. https://doi.org/10.1177/1077801206291663

Vivolo-Kantor, A. M., DeGue, S., DiLillo, D., \& Cuadra, L. E. (2013). The Mediating Effect of Hostility Toward Women on the Relationship Between Childhood Emotional Abuse and Sexual Violence Perpetration. Violence and Victims, 28(1), 178-192. https://doi.org/10.1891/08866708.28 .1 .178

*Waubert de Puiseau, B., \& Roessel, J. (2013). Exploring sexual harassment and related attitudes in Beninese high schools: a field study. Psychology, Crime \& Law, 19(8), 707-726. 
https://doi.org/10.1080/1068316X.2013.793336

*Whitaker, M. P. (2013). Centrality of Control-Seeking in Men's Intimate Partner Violence Perpetration. Prevention Science, 14(5), 513-523. https://doi.org/10.1007/s11121-012-0332-z

Williams, C., Richardson, D. S., Hammock, G. S., \& Janit, A. S. (2012). Perceptions of physical and psychological aggression in close relationships: A review. Aggression and Violent Behavior, 17(6), 489-494. https://doi.org/10.1016/j.avb.2012.06.005

Yakubovich, A. R., Stöck1, H., Murray, J., Melendez-Torres, G. J., Steinert, J. I., Glavin, C. E. Y., \& Humphreys, D. K. (2018). Risk and protective factors for intimate partner violence against women: Systematic review and meta-analyses of prospective-longitudinal studies. American Journal of Public Health, 108(7), e1-e11. https://doi.org/10.2105/AJPH.2018.304428

*Yalsin, M. A., \& Özturk, E. (2018). The Relationship Between Social Attitudes Towards Female Sexual Assault Victims and Belief in a Just World and Ambivalent Sexism. Turkiye Klinikleri Journal of Forensic Medicine and Forensic Sciences, 15(2), 43-51. https://doi.org/10.5336/forensic.2017-59044

*Yamawaki, N., Darby, R., \& Queiroz, A. (2007). The Moderating Role of Ambivalent Sexism: The Influence of Power Status on Perception of Rape Victim and Rapist. The Journal of Social Psychology, 147(1), 41-56. https://doi.org/10.3200/SOCP.147.1.41-56

*Yamawaki, N., Ostenson, J., \& Brown, C. R. (2009). The Functions of Gender Role Traditionality, Ambivalent Sexism, Injury, and Frequency of Assault on Domestic Violence Perception. Violence Against Women, 15(9), 1126-1142. https://doi.org/10.1177/1077801209340758

Yodanis, C. L. (2004). Gender inequality, violence against women, and fear: A cross-national test of the feminist theory of violence against women. Journal of Interpersonal Violence, 19(6), 655675. https://doi.org/10.1177/0886260504263868 
Yuvarajan, E., \& Stanford, M. S. (2016). Clergy Perceptions of Sexual Assault Victimization.

Violence Against Women, 22(5), 588-608. https://doi.org/10.1177/1077801215605919

*Zapata-Calvente, Antonella L., Moya, M., Bohner, G., \& Megías, J. L. (2019). Automatic Associations and Conscious Attitudes Predict Different Aspects of Men's Intimate Partner Violence and Sexual Harassment Proclivities. Sex Roles, 81(7-8), 439-455.

https://doi.org/10.1007/s11199-019-1006-0

*Zapata-Calvente, Antonella Ludmila, \& Megías, J. L. (2017). Social perception of intimate partner violence according to the motivations and sex of the aggressor and the ideology and sex of the observers / Percepción social de la violencia de pareja en función de las motivaciones y sexo del/a agresor/a y de la ideo. Revista de Psicologia Social, 32(2), 301-332. https://doi.org/10.1080/02134748.2017.1297355

Zlotnick, C., Johnson, D. M., \& Kohn, R. (2006). Intimate Partner Violence and Long-Term Psychosocial Functioning in a National Sample of American Women. Journal of Interpersonal Violence, 21(2), 262-275. 


\section{Appendix}

Main Characteristics and Effect Sizes Information of Independent Samples Included in the Meta-Analysis

\begin{tabular}{|c|c|c|c|c|c|c|c|c|c|c|}
\hline Independent samples & $\begin{array}{l}\text { Publication } \\
\text { status }\end{array}$ & $\begin{array}{l}\text { Total } \\
\text { sample } \\
\text { size }\end{array}$ & $\begin{array}{l}\mathbf{N} \text { of } \\
\text { women }\end{array}$ & $\begin{array}{l}\text { Sample } \\
\text { type }\end{array}$ & Country & $\begin{array}{l}\text { Level of } \\
\text { violence }\end{array}$ & $\begin{array}{l}\text { Type of } \\
\text { violence }\end{array}$ & $\begin{array}{l}\text { Violenc } \\
\text { e target }\end{array}$ & $r_{\mathrm{bv}}$ & $r_{\text {hv }}$ \\
\hline \multirow[t]{2}{*}{ Abrams et al. (2003) Study 1} & $\mathrm{P}$ & 65 & 34 & Stud & UK & Attitudes & Sexual & Non-IP & .61 & .64 \\
\hline & $\mathrm{P}$ & 65 & 34 & Stud & UK & Attitudes & Psychological & Non-IP & .41 & .46 \\
\hline \multirow[t]{3}{*}{ Abrams et al. (2003) Study 2} & $\mathrm{P}$ & 111 & 0 & Stud & UK & Attitudes & Psychological & Non-IP & .33 & .31 \\
\hline & $\mathrm{P}$ & 111 & 0 & Stud & UK & Attitudes & Sexual & Non-IP & .48 & .55 \\
\hline & $\mathrm{P}$ & 111 & 0 & Stud & UK & Attitudes & Sexual & Non-IP & .29 & .40 \\
\hline Algovia \& Rivero(2019) & $\mathrm{P}$ & 126 & 0 & Stud & Colombia & Attitudes & Other & IP & .368 & .516 \\
\hline Algovia \& Rivero(2019) & $\mathrm{P}$ & 317 & 317 & Stud & Colombia & Attitudes & Other & IP & .318 & .209 \\
\hline Allen et al. (2009) & $\mathrm{P}$ & 92 & 0 & Stud & US & SR behavior & Other & IP & -.22 & .08 \\
\hline Angelone et al. (2015) & $\mathrm{P}$ & 284 & 0 & Stud & US & Attitudes & Psychological & Non-IP & .07 & .43 \\
\hline Angelone et al. (2018) & $\mathrm{P}$ & 504 & 255 & Stud & US & Attitudes & Sexual & Non-IP & .123 & .395 \\
\hline Anton (2011) & $\mathrm{U}$ & 108 & 0 & Stud & US & Attitudes & Sexual & Non-IP & .29 & .44 \\
\hline \multirow[t]{3}{*}{ Arbach et al. (2019) } & $\mathrm{P}$ & 178 & 0 & GP & Argentina & SR behavior & Physical & IP & .126 & .093 \\
\hline & $\mathrm{P}$ & 178 & 0 & GP & Argentina & SR behavior & Physical & IP & .022 & .061 \\
\hline & $\mathrm{P}$ & 178 & 0 & GP & Argentina & SR behavior & Psychological & IP & .034 & .228 \\
\hline Barker \& Galliher (2017) & $\mathrm{P}$ & 208 & 131 & Stud & US & Attitudes & Sexual & Non-IP & .277 & .38 \\
\hline \multirow[t]{2}{*}{ Begany \& Milburn (2002) } & $\mathrm{P}$ & 104 & 0 & Stud & US & Attitudes & Sexual & Non-IP & .17 & .43 \\
\hline & $\mathrm{P}$ & 104 & 0 & Stud & US & Attitudes & Sexual & Non-IP & .19 & .53 \\
\hline \multirow[t]{2}{*}{ Bendixen \& Kennair (2017) Study 2} & $\mathrm{P}$ & 758 & 758 & Stud & Norway & Attitudes & Sexual & Non-IP & .33 & .31 \\
\hline & $\mathrm{P}$ & 758 & 758 & Stud & Norway & Attitudes & Sexual & Non-IP & .06 & .13 \\
\hline \multirow[t]{2}{*}{ Bendixen \& Kennair (2017) Study 2} & $\mathrm{P}$ & 490 & 0 & Stud & Norway & Attitudes & Sexual & Non-IP & .15 & .30 \\
\hline & $\mathrm{P}$ & 490 & 0 & Stud & Norway & Attitudes & Sexual & Non-IP & .02 & .19 \\
\hline Berke \& Zeichner (2016) & $\mathrm{P}$ & 168 & 0 & Stud & US & Behavior & Physical & Non-IP & -.013 & .193 \\
\hline \multirow[t]{2}{*}{ Bhanot (2010) } & $\mathrm{U}$ & 401 & 258 & GP & UK & Attitudes & Physical & IP & .32 & .36 \\
\hline & $\mathrm{U}$ & 401 & 258 & GP & UK & Attitudes & Sexual & IP & .38 & .48 \\
\hline
\end{tabular}




\begin{tabular}{|c|c|c|c|c|c|c|c|c|c|c|}
\hline \multirow{3}{*}{ Bosson et al. (2015) } & $\mathrm{U}$ & 401 & 258 & GP & UK & Attitudes & Psychological & IP & .42 & .46 \\
\hline & $\mathrm{P}$ & 202 & 0 & GP & US & SR behavior & Sexual & IP & .05 & .07 \\
\hline & $\mathrm{P}$ & 202 & 0 & GP & US & Behavior & Sexual & Non-IP & -.05 & .19 \\
\hline Burnay (2019) & $\mathrm{U}$ & 574 & 207 & GP & Belgium & Attitudes & Sexual & Non-IP & .39 & .63 \\
\hline Canto et al. (2014) & $\mathrm{P}$ & 131 & 131 & Stud & Spain & Attitudes & Sexual & Non-IP & .56 & .53 \\
\hline Canto et al. (2014) & $\mathrm{P}$ & 83 & 0 & Stud & Spain & Attitudes & Sexual & Non-IP & .32 & .49 \\
\hline \multirow[t]{2}{*}{ Castro et al. (2010) } & $\mathrm{P}$ & 346 & 346 & Stud & Portugal & Attitudes & Psychological & Non-IP & .08 & .28 \\
\hline & $\mathrm{P}$ & 346 & 346 & Stud & Portugal & Attitudes & Other & Non-IP & .05 & .17 \\
\hline \multirow[t]{2}{*}{ Castro et al. (2010) } & $\mathrm{P}$ & 130 & 0 & Stud & Portugal & Attitudes & Psychological & Non-IP & .06 & .40 \\
\hline & $\mathrm{P}$ & 130 & 0 & Stud & Portugal & Attitudes & Other & Non-IP & .22 & .20 \\
\hline Čeponytè \& Žardeckaitè-Matulaitienè (2018) & $\mathrm{P}$ & 98 & 98 & Stud & Turkey & Attitudes & Sexual & Non-IP & .150 & .434 \\
\hline Čeponyte \& Žardeckaitè-Matulaitienè (2018) & $\mathrm{P}$ & 247 & 0 & Stud & Turkey & Attitudes & Sexual & Non-IP & .328 & .317 \\
\hline Chapleau et al. (2007) & $\mathrm{P}$ & 409 & 267 & Stud & US & Attitudes & Sexual & Non-IP & .3133 & .57 \\
\hline \multirow[t]{2}{*}{ Cohn et al. (2009) Study 1} & $\mathrm{P}$ & 250 & 136 & Stud & US & Attitudes & Sexual & Non-IP & -.12 & -.21 \\
\hline & $P$ & 250 & 136 & Stud & US & Attitudes & Psychological & Non-IP & .08 & .24 \\
\hline \multirow[t]{2}{*}{ Cohn et al. (2009) Study 2} & $\mathrm{P}$ & 274 & 167 & Stud & US & Attitudes & Sexual & Non-IP & .03 & -.09 \\
\hline & $P$ & 274 & 167 & Stud & US & Attitudes & Psychological & Non-IP & .12 & .29 \\
\hline Correia et al. (2015) & $\mathrm{P}$ & 284 & 284 & GP & US & Attitudes & Physical & IP & .13 & .25 \\
\hline \multirow[t]{2}{*}{ Covell (1998) } & $\mathrm{U}$ & 208 & 0 & Stud & US & Attitudes & Sexual & Non-IP & .29 & .67 \\
\hline & $\mathrm{U}$ & 208 & 0 & Stud & US & Attitudes & Sexual & Non-IP & .43 & .43 \\
\hline \multirow[t]{2}{*}{ Crittenden (2009) } & $\mathrm{U}$ & 308 & 178 & Stud & US & Attitudes & Sexual & Non-IP & .299 & NA \\
\hline & $\mathrm{U}$ & 308 & 178 & Stud & US & Attitudes & Sexual & Non-IP & .254 & NA \\
\hline Cromer \& Freyd (2007) & $\mathrm{P}$ & 318 & 227 & Stud & US & Attitudes & Sexual & Non-IP & .20 & .11 \\
\hline Cross et al. (2017) Study 2 & $\mathrm{P}$ & 91 & 0 & GP & New Zealand & Behavior & Psychological & IP & -.00 & .26 \\
\hline Cross et al. (2019) Study 1 & $P$ & 78 & 0 & GP & New Zealand & SR behavior & Other & IP & -.05 & .39 \\
\hline Cross et al. (2019) Study 2 & $\mathrm{P}$ & 98 & 0 & GP & New Zealand & Behavior & Other & IP & -.09 & .34 \\
\hline Cross et al. (2019) Study 3 & $P$ & 119 & 0 & GP & New Zealand & SR behavior & Other & IP & .06 & .23 \\
\hline \multirow[t]{2}{*}{ Cross et al. (2019) Study 4} & $\mathrm{P}$ & 207 & 0 & GP & New Zealand & SR behavior & Other & IP & .06 & .30 \\
\hline & $\mathrm{P}$ & 207 & 0 & GP & New Zealand & Attitudes & Other & IP & -.13 & .12 \\
\hline Cross et al. (2019) Study 4 & $\mathrm{P}$ & 299 & 299 & GP & New Zealand & Attitudes & Other & IP & -.04 & .11 \\
\hline Davies et al. (2012) & $\mathrm{P}$ & 323 & 177 & Stud & UK & Attitudes & Sexual & Non-IP & .04 & .43 \\
\hline
\end{tabular}




\begin{tabular}{|c|c|c|c|c|c|c|c|c|c|c|}
\hline & $\mathrm{P}$ & 323 & 177 & Stud & UK & Attitudes & Psychological & Non-IP & .10 & .37 \\
\hline \multirow[t]{3}{*}{ Diehl et al. (2012) } & $\mathrm{P}$ & 100 & 0 & Stud & Germany & Attitudes & Sexual & Non-IP & NA & .68 \\
\hline & $\mathrm{P}$ & 100 & 0 & Stud & Germany & Behavior & Sexual & Non-IP & NA & .18 \\
\hline & $\mathrm{P}$ & 100 & 0 & Stud & Germany & Behavior & Sexual & Non-IP & NA & .23 \\
\hline \multirow[t]{2}{*}{ Diehl et al. (2018) } & $\mathrm{P}$ & 85 & 0 & Stud & Germany & Behavior & Sexual & Non-IP & NA & .18 \\
\hline & $\mathrm{P}$ & 85 & 0 & Stud & Germany & Behavior & Sexual & Non-IP & NA & .27 \\
\hline Diener (2016) & $\mathrm{U}$ & 173 & 137 & Stud & US & Attitudes & Sexual & Non-IP & .38 & .60 \\
\hline Durán et al. (2018) & $\mathrm{P}$ & 67 & 0 & Stud & Spain & Attitudes & Sexual & Non-IP & NA & .22 \\
\hline Durán et al. (2011) & $\mathrm{P}$ & 75 & 39 & Stud & Spain & Attitudes & Sexual & Non-IP & .428 & .331 \\
\hline Durán et al. (2010) Study 1a & $\mathrm{P}$ & 206 & 113 & Stud & Spain & Attitudes & Psychological & Non-IP & .17 & .52 \\
\hline Durán et al. (2010) Study 2 & $\mathrm{P}$ & 201 & 104 & Stud & Spain & Attitudes & Psychological & Non-IP & .29 & .46 \\
\hline Durán \& Rodríguez-Domínguez (2020) & $\mathrm{P}$ & 301 & 169 & Stud & Spain & Attitudes & Psychological & Non-IP & .51 & .53 \\
\hline Durán et al. (2015) & $\mathrm{P}$ & 147 & 76 & Stud & Spain & Attitudes & Other & Non-IP & .50 & .71 \\
\hline \multirow[t]{4}{*}{ Ercan (2009) } & $\mathrm{U}$ & 385 & 228 & GP & Turkey & Attitudes & Other & IP & NA & .563 \\
\hline & $\mathrm{U}$ & 385 & 228 & GP & Turkey & Attitudes & Other & IP & NA & .365 \\
\hline & $\mathrm{U}$ & 385 & 228 & GP & Turkey & Attitudes & Other & IP & -.129 & .215 \\
\hline & $\mathrm{U}$ & 385 & 228 & GP & Turkey & Attitudes & Other & IP & NA & .434 \\
\hline \multirow[t]{2}{*}{ Erdem \& Sahin (2017) } & $\mathrm{P}$ & 1171 & 456 & Stud & Turkey & Attitudes & Psychological & IP & -.127 & .274 \\
\hline & $\mathrm{P}$ & 1171 & 456 & Stud & Turkey & Attitudes & Physical & IP & -.0996 & .251 \\
\hline Exposito et al. (2010) & $\mathrm{P}$ & 210 & 210 & Stud & Spain & Attitudes & Other & Non-IP & .23 & .06 \\
\hline Eyssel \& Bohner (2007) & $\mathrm{P}$ & 65 & 0 & Stud & Germany & Attitudes & Sexual & Non-IP & .32 & .45 \\
\hline Feinberg (2015) & $\mathrm{U}$ & 626 & 319 & Stud & US & Attitudes & Sexual & Non-IP & .234 & .530 \\
\hline Fernández-Fuertes et al. (2018) & $\mathrm{P}$ & 532 & 0 & GP & Spain & SR behavior & Sexual & IP & .05 & .16 \\
\hline \multirow[t]{2}{*}{ Fonte (n.d.) } & $\mathrm{U}$ & 149 & 149 & Stud & France & Attitudes & Other & IP & .57 & .59 \\
\hline & $\mathrm{U}$ & 149 & 149 & Stud & France & Attitudes & Other & IP & .17 & .30 \\
\hline \multirow[t]{2}{*}{ Fonte (n.d.) } & $\mathrm{U}$ & 105 & 0 & Stud & France & Attitudes & Other & IP & .38 & .59 \\
\hline & $\mathrm{U}$ & 105 & 0 & Stud & France & Attitudes & Other & IP & .17 & .40 \\
\hline Forbes \& Adams-Curtis (2001) & $\mathrm{P}$ & 140 & 0 & Stud & US & SR behavior & Sexual & IP & .05 & .19 \\
\hline Forees et al. (2004) & $\mathrm{P}$ & 157 & 157 & Stud & US & Attitudes & Sexual & Non-IP & .51 & .50 \\
\hline \multirow[t]{2}{*}{ Forees et al. (2004) } & $\mathrm{P}$ & 107 & 0 & Stud & US & Attitudes & Sexual & Non-IP & .24 & .62 \\
\hline & $\mathrm{P}$ & 102 & 0 & Stud & US & SR behavior & Psychological & IP & .04 & .34 \\
\hline
\end{tabular}




\begin{tabular}{|c|c|c|c|c|c|c|c|c|c|c|}
\hline & $\mathrm{P}$ & 106 & 0 & Stud & US & SR behavior & Sexual & IP & -.05 & .31 \\
\hline Fox \& Potocki (2015) & $\mathrm{P}$ & 351 & 155 & GP & US & Attitudes & Sexual & Non-IP & NA & .55 \\
\hline Freeman (2006) & $\mathrm{U}$ & 112 & 0 & Stud & US & Attitudes & Sexual & Non-IP & .41 & .41 \\
\hline Garaigordobil \& Aliri (2013) & $\mathrm{P}$ & 768 & 768 & Stud & Spain & Attitudes & Other & Non-IP & .33 & .53 \\
\hline Garaigordobil \& Aliri (2013) & $\mathrm{P}$ & 687 & 0 & Stud & Spain & Attitudes & Other & Non-IP & .28 & .57 \\
\hline García-Ael et al. (2018) & $\mathrm{P}$ & 592 & 592 & GP & Spain & Attitudes & Other & Non-IP & .23 & .22 \\
\hline \multirow{3}{*}{ García-Ael et al. (2018) } & $\mathrm{P}$ & 592 & 592 & GP & Spain & Attitudes & Other & Non-IP & .22 & .16 \\
\hline & $\mathrm{P}$ & 577 & 0 & GP & Spain & Attitudes & Other & Non-IP & .36 & .37 \\
\hline & $\mathrm{P}$ & 577 & 0 & GP & Spain & Attitudes & Other & Non-IP & .35 & .37 \\
\hline Gerger et al. (2007) Study 1 & $\mathrm{P}$ & 201 & 106 & Stud & Germany & Attitudes & Sexual & Non-IP & .53 & .79 \\
\hline Gerger et al. (2007) Study 2 & $\mathrm{P}$ & 40 & 0 & Stud & Germany & Attitudes & Sexual & Non-IP & .37 & .82 \\
\hline Gerger et al. (2007) Study 4 & $\mathrm{P}$ & 280 & 197 & GP & Germany & Attitudes & Sexual & Non-IP & .33 & .76 \\
\hline Gerger et al. (2007) Study 4 & $\mathrm{P}$ & 551 & 403 & GP & UK & Attitudes & Sexual & Non-IP & .45 & .80 \\
\hline \multirow[t]{2}{*}{ Gervais et al. (2018) Study 3b } & $\mathrm{P}$ & 296 & 0 & GP & US & Attitudes & Sexual & Non-IP & .17 & .31 \\
\hline & $\mathrm{P}$ & 471 & 471 & GP & US & Attitudes & Sexual & Non-IP & .12 & .11 \\
\hline Giger et al. (2017) Study 3 & $\mathrm{P}$ & 72 & 72 & GP & Portugal & Attitudes & Other & Non-IP & .47 & .52 \\
\hline Giger et al. (2017) Study 3 & $\mathrm{P}$ & 68 & 0 & GP & Portugal & Attitudes & Other & Non-IP & .28 & .39 \\
\hline Glick et al. (2002) & $\mathrm{P}$ & 436 & 0 & GP & Brazil & Attitudes & Physical & Non-IP & .23 & .56 \\
\hline Glick et al. (2002) & $\mathrm{P}$ & 182 & 0 & GP & Turkey & Attitudes & Physical & IP & .14 & .38 \\
\hline Glick et al. (2002) & $\mathrm{P}$ & 421 & 421 & GP & Turkey & Attitudes & Physical & Non-IP & .15 & .24 \\
\hline Glick et al. (2002) & $\mathrm{P}$ & 212 & 212 & GP & Brazil & Attitudes & Physical & IP & .22 & .39 \\
\hline Gracia et al. (2018) & $\mathrm{P}$ & 490 & 0 & GP & Spain & Attitudes & Psychological & Non-IP & NA & .48 \\
\hline \multirow{5}{*}{ Gracia et al. (2018) } & $\mathrm{P}$ & 490 & 0 & GP & Spain & Attitudes & Other & Non-IP & NA & .32 \\
\hline & $\mathrm{P}$ & 490 & 0 & GP & Spain & Attitudes & Other & Non-IP & NA & .40 \\
\hline & $\mathrm{P}$ & 510 & 510 & GP & Spain & Attitudes & Psychological & Non-IP & NA & .25 \\
\hline & $\mathrm{P}$ & 510 & 510 & GP & Spain & Attitudes & Other & Non-IP & NA & .21 \\
\hline & $\mathrm{P}$ & 510 & 510 & GP & Spain & Attitudes & Other & Non-IP & NA & .20 \\
\hline Gray (2011) & $\mathrm{U}$ & 202 & 118 & Stud & US & Attitudes & Sexual & Non-IP & NA & .52 \\
\hline Çamaş \& Meşe (2016) & $\mathrm{P}$ & 302 & 153 & GP & Turkey & Attitudes & Sexual & Non-IP & .51 & .62 \\
\hline Hall (2011) & $\mathrm{U}$ & 454 & 0 & GP & NA & SR behavior & Psychological & Non-IP & .158 & .302 \\
\hline Hall \& Canterberry (2011) Study 1 & $\mathrm{P}$ & 134 & 0 & Stud & US & SR behavior & Psychological & Non-IP & .076 & .110 \\
\hline
\end{tabular}




\begin{tabular}{|c|c|c|c|c|c|c|c|c|c|c|}
\hline Hall \& Canterberry (2011) Study 2 & $\mathrm{P}$ & 310 & 0 & GP & US & SR behavior & Psychological & Non-IP & .079 & .283 \\
\hline Hammond \& Overall (2013) Study 1 & $\mathrm{P}$ & 86 & 0 & GP & New Zealand & SR behavior & Other & IP & .10 & .32 \\
\hline \multirow[t]{2}{*}{ Hantzi et al. (2015) } & $\mathrm{P}$ & 355 & 193 & Stud & Greece & Attitudes & Sexual & Non-IP & .50 & .76 \\
\hline & $\mathrm{P}$ & 355 & 193 & Stud & Greece & Attitudes & Sexual & Non-IP & .43 & .64 \\
\hline \multirow[t]{2}{*}{ Harrington et al. (2020) Study 3} & $\mathrm{P}$ & 207 & 0 & GP & US & SR behavior & Physical & IP & NA & .245 \\
\hline & $\mathrm{P}$ & 207 & 0 & GP & US & SR behavior & Psychological & IP & NA & .236 \\
\hline \multirow[t]{2}{*}{ Harrington et al. (2020) Study 4} & $\mathrm{P}$ & 221 & 0 & GP & US & SR behavior & Physical & IP & NA & .200 \\
\hline & $\mathrm{P}$ & 221 & 0 & GP & US & SR behavior & Psychological & IP & NA & .201 \\
\hline Harris et al. (2017) & $\mathrm{P}$ & 52 & 52 & GP & US & Attitudes & Sexual & Non-IP & .323 & .392 \\
\hline Harris et al. (2017) & $\mathrm{P}$ & 73 & 0 & GP & US & Attitudes & Sexual & Non-IP & .314 & .596 \\
\hline \multirow[t]{3}{*}{ Hefley (2006) } & $\mathrm{U}$ & 298 & 0 & Stud & US & Attitudes & Sexual & Non-IP & .086 & .423 \\
\hline & $\mathrm{U}$ & 298 & 0 & Stud & US & SR behavior & Sexual & IP & .243 & .107 \\
\hline & $\mathrm{U}$ & 298 & 0 & Stud & US & Attitudes & Sexual & Non-IP & -.001 & .148 \\
\hline Hegarty et al. (2018) Study 1 & $\mathrm{P}$ & 388 & 0 & GP & UK & Attitudes & Sexual & Non-IP & .20 & .51 \\
\hline \multirow[t]{2}{*}{ Hegarty et al. (2018) Study 2} & $\mathrm{P}$ & 81 & 0 & Stud & UK & Attitudes & Sexual & Non-IP & .73 & .36 \\
\hline & $\mathrm{P}$ & 81 & 0 & Stud & UK & Attitudes & Sexual & Non-IP & .31 & .48 \\
\hline \multirow[t]{3}{*}{ Herrera et al. (2014) Study 2} & $\mathrm{P}$ & 65 & 55 & Stud & UK & Attitudes & Psychological & Non-IP & .10 & .11 \\
\hline & $\mathrm{P}$ & 65 & 55 & Stud & UK & Attitudes & Psychological & Non-IP & -.15 & .073 \\
\hline & $\mathrm{P}$ & 65 & 55 & Stud & UK & Attitudes & Sexual & Non-IP & .21 & .44 \\
\hline Herrera et al. (2012) & $\mathrm{P}$ & 219 & 219 & Stud & UK & Attitudes & Other & Non-IP & .16 & .07 \\
\hline \multirow[t]{2}{*}{ Herrera et al. (2014) } & $\mathrm{P}$ & 101 & 0 & Stud & Spain & Attitudes & Sexual & Non-IP & .496 & .793 \\
\hline & $\mathrm{P}$ & 101 & 0 & Stud & Spain & Attitudes & Sexual & Non-IP & .043 & .266 \\
\hline Herrera et al. (2018) & $\mathrm{P}$ & 138 & 138 & Stud & Spain & Attitudes & Sexual & Non-IP & .344 & .646 \\
\hline Hill \& Marshall (2018) & $\mathrm{P}$ & 112 & 35 & GP & India & Attitudes & Psychological & Non-IP & .06 & .63 \\
\hline Hill \& Marshall (2018) & $\mathrm{P}$ & 117 & 75 & GP & UK & Attitudes & Psychological & Non-IP & .43 & .73 \\
\hline Hurrell (2017) & $\mathrm{U}$ & 125 & 89 & GP & US & Attitudes & Sexual & Non-IP & .30 & .63 \\
\hline Husnu \& Mertan (2017) & $\mathrm{P}$ & 205 & 117 & Stud & Cyprus & Attitudes & Physical & IP & .05 & .10 \\
\hline \multirow[t]{2}{*}{ Hyatt et al. (2017) } & $\mathrm{P}$ & 193 & 0 & Stud & US & Behavior & Physical & Non-IP & .10 & .25 \\
\hline & $\mathrm{P}$ & 193 & 0 & Stud & US & Behavior & Physical & Non-IP & .15 & .19 \\
\hline \multirow[t]{2}{*}{ Jongsma (2019) } & $\mathrm{U}$ & 254 & 0 & GP & US & SR behavior & Sexual & IP & .095 & .219 \\
\hline & $\mathrm{U}$ & 254 & 0 & GP & US & SR behavior & Sexual & IP & .067 & .031 \\
\hline
\end{tabular}




\begin{tabular}{|c|c|c|c|c|c|c|c|c|c|c|}
\hline & $\mathrm{U}$ & 254 & 0 & GP & US & SR behavior & Sexual & IP & .096 & .219 \\
\hline & $\mathrm{U}$ & 254 & 0 & GP & US & SR behavior & Psychological & IP & .013 & .219 \\
\hline & $\mathrm{U}$ & 254 & 0 & GP & US & SR behavior & Psychological & IP & .055 & .179 \\
\hline & $\mathrm{U}$ & 254 & 0 & GP & US & SR behavior & Psychological & IP & .021 & .227 \\
\hline & $\mathrm{U}$ & 254 & 0 & GP & US & SR behavior & Physical & IP & .080 & .057 \\
\hline & $\mathrm{U}$ & 254 & 0 & GP & US & SR behavior & Physical & IP & .017 & .017 \\
\hline & $\mathrm{U}$ & 254 & 0 & GP & US & SR behavior & Physical & IP & .102 & .071 \\
\hline & $\mathrm{U}$ & 254 & 0 & GP & US & SR behavior & Psychological & IP & .032 & .141 \\
\hline & $\mathrm{U}$ & 254 & 0 & GP & US & SR behavior & Psychological & IP & .083 & .072 \\
\hline & $\mathrm{U}$ & 254 & 0 & GP & US & SR behavior & Psychological & IP & .006 & .170 \\
\hline & $\mathrm{U}$ & 254 & 0 & GP & US & SR behavior & Other & IP & .048 & .125 \\
\hline Judson et al. (2013) & $\mathrm{P}$ & 302 & 170 & Stud & & Attitudes & Psychological & Non-IP & .18 & .28 \\
\hline Katz et al. (2018) & $\mathrm{P}$ & 172 & 172 & Stud & US & Attitudes & Psychological & Non-IP & .37 & .43 \\
\hline \multirow[t]{3}{*}{ Kelly et al. (2015) Study 2} & $\mathrm{P}$ & 398 & 0 & GP & US & Attitudes & Sexual & Non-IP & NA & .66 \\
\hline & $\mathrm{P}$ & 398 & 0 & GP & US & Attitudes & Psychological & Non-IP & NA & .61 \\
\hline & $\mathrm{P}$ & 398 & 0 & GP & US & SR behavior & Other & IP & NA & .14 \\
\hline Kelly (2009) Study 2 & $\mathrm{U}$ & 200 & 128 & GP & Canada & Attitudes & Psychological & Non-IP & .296 & .552 \\
\hline \multirow[t]{4}{*}{ Klement et al. (2017) } & $\mathrm{P}$ & 16 & 0 & Stud & US & Attitudes & Sexual & Non-IP & .267 & .658 \\
\hline & $\mathrm{P}$ & 16 & 0 & Stud & US & Attitudes & Psychological & Non-IP & .138 & .668 \\
\hline & $\mathrm{P}$ & 16 & 0 & Stud & US & Attitudes & Sexual & Non-IP & -.059 & - \\
\hline & $\mathrm{P}$ & 16 & 0 & Stud & US & Attitudes & Sexual & Non-IP & -.769 & - \\
\hline \multirow[t]{4}{*}{ Klement et al. (2017) } & $\mathrm{P}$ & 36 & 36 & Stud & US & Attitudes & Sexual & Non-IP & .203 & .443 \\
\hline & $\mathrm{P}$ & 36 & 36 & Stud & US & Attitudes & Psychological & Non-IP & .205 & .450 \\
\hline & $\mathrm{P}$ & 36 & 36 & Stud & US & Attitudes & Sexual & Non-IP & .118 & .078 \\
\hline & $\mathrm{P}$ & 36 & 36 & Stud & US & Attitudes & Sexual & Non-IP & -.040 & .127 \\
\hline \multirow[t]{4}{*}{ Klement et al. (2017) } & $\mathrm{P}$ & 25 & 0 & GP & US & Attitudes & Sexual & Non-IP & .557 & .657 \\
\hline & $\mathrm{P}$ & 25 & 0 & GP & US & Attitudes & Psychological & Non-IP & .473 & .616 \\
\hline & $\mathrm{P}$ & 25 & 0 & GP & US & Attitudes & Sexual & Non-IP & .325 & .322 \\
\hline & $\mathrm{P}$ & 25 & 0 & GP & US & Attitudes & Sexual & Non-IP & .582 & .370 \\
\hline Klement et al. (2017) & $\mathrm{P}$ & 36 & 36 & GP & US & Attitudes & Sexual & Non-IP & -.227 & .206 \\
\hline
\end{tabular}




\begin{tabular}{|c|c|c|c|c|c|c|c|c|c|c|}
\hline & $\mathrm{P}$ & 36 & 36 & GP & US & Attitudes & Psychological & Non-IP & .022 & .362 \\
\hline & $\mathrm{P}$ & 36 & 36 & GP & US & Attitudes & Sexual & Non-IP & .068 & .176 \\
\hline & $\mathrm{P}$ & 36 & 36 & GP & US & Attitudes & Sexual & Non-IP & .109 & 337 \\
\hline Krings \& Facchin (2009) & $\mathrm{P}$ & 110 & 0 & GP & Switzerland & Attitudes & Sexual & Non-IP & .13 & .28 \\
\hline Kunst et al. (2019) & $\mathrm{P}$ & 206 & 108 & GP & Norway & Attitudes & Sexual & Non-IP & .17 & .67 \\
\hline Kunst et al. (2019) & $\mathrm{P}$ & 227 & 109 & GP & US & Attitudes & Sexual & Non-IP & .30 & .66 \\
\hline Lartigue (2001) & $\mathrm{U}$ & 240 & 120 & Stud & US & Attitudes & Sexual & Non-IP & .068 & .278 \\
\hline \multirow[t]{3}{*}{ Lelaurain et al. (2018) Study 2} & $\mathrm{P}$ & 60 & 60 & GP & France & Attitudes & Other & IP & .47 & .36 \\
\hline & $\mathrm{P}$ & 60 & 60 & GP & France & Attitudes & Psychological & IP & .51 & .42 \\
\hline & $\mathrm{P}$ & 60 & 60 & GP & France & Attitudes & Other & IP & .50 & .25 \\
\hline \multirow[t]{3}{*}{ Lelaurain et al. (2018) Study 2} & $\mathrm{P}$ & 63 & 0 & GP & France & Attitudes & Other & IP & .53 & .62 \\
\hline & $\mathrm{P}$ & 63 & 0 & GP & France & Attitudes & Psychological & IP & .25 & .41 \\
\hline & $\mathrm{P}$ & 63 & 0 & GP & France & Attitudes & Other & IP & .32 & .39 \\
\hline \multirow[t]{3}{*}{ Lelaurain, Fonte, Giger, et al., (2018) } & $\mathrm{P}$ & 120 & 120 & GP & France & Attitudes & Other & IP & .63 & .55 \\
\hline & $\mathrm{P}$ & 120 & 120 & GP & France & Attitudes & Psychological & Non-IP & .46 & .47 \\
\hline & $\mathrm{P}$ & 120 & 120 & GP & France & Attitudes & Other & Non-IP & .37 & .30 \\
\hline \multirow[t]{3}{*}{ Lelaurain, Fonte, Giger, et al., (2018) } & $\mathrm{P}$ & 115 & 0 & GP & France & Attitudes & Other & IP & .49 & .61 \\
\hline & $\mathrm{P}$ & 115 & 0 & GP & France & Attitudes & Psychological & Non-IP & .40 & .60 \\
\hline & $\mathrm{P}$ & 115 & 0 & GP & France & Attitudes & Other & Non-IP & .17 & .27 \\
\hline Lelaurain et al. (2019) Study 2 & $\mathrm{P}$ & 51 & 0 & GP & France & Attitudes & Other & IP & .24 & .65 \\
\hline Lelaurain et al. (2019) Study 2 & $\mathrm{P}$ & 232 & 232 & GP & France & Attitudes & Other & IP & .51 & .57 \\
\hline \multirow[t]{4}{*}{ Lisco (2013) } & $\mathrm{U}$ & 64 & 0 & Stud & US & SR behavior & Physical & IP & -.03 & .08 \\
\hline & $\mathrm{U}$ & 64 & 0 & Stud & US & SR behavior & Sexual & IP & .02 & .05 \\
\hline & $\mathrm{U}$ & 64 & 0 & Stud & US & SR behavior & Sexual & IP & -.02 & .07 \\
\hline & $\mathrm{U}$ & 94 & 0 & Stud & US & Behavior & Physical & Non-IP & -.09 & .06 \\
\hline \multirow[t]{2}{*}{ Loveland (2017) } & $\mathrm{U}$ & 137 & 0 & GP & US & SR behavior & Physical & IP & NA & - \\
\hline & $\mathrm{U}$ & 137 & 0 & GP & US & SR behavior & Psychological & IP & NA & $\begin{array}{r}- \\
.137\end{array}$ \\
\hline Luna-Bernal \& Laca-Arocena (2017) & $\mathrm{P}$ & 126 & 0 & Stud & Mexico & SR behavior & Other & Non-IP & .13 & .20 \\
\hline \multirow[t]{2}{*}{ Makin-Byrd \& Azar (2011) } & $\mathrm{P}$ & 132 & 0 & Stud & US & SR behavior & Psychological & IP & NA & .31 \\
\hline & $\mathrm{P}$ & 132 & 0 & Stud & US & SR behavior & Physical & IP & NA & .00 \\
\hline
\end{tabular}




\begin{tabular}{|c|c|c|c|c|c|c|c|c|c|c|}
\hline \multirow[t]{3}{*}{ Martín-Fernández et al. (2018) } & $\mathrm{P}$ & 950 & 950 & GP & Spain & Attitudes & Other & Non-IP & .37 & .33 \\
\hline & $\mathrm{P}$ & 950 & 950 & GP & Spain & Attitudes & Psychological & Non-IP & .30 & .31 \\
\hline & $\mathrm{P}$ & 950 & 950 & GP & Spain & Attitudes & Other & Non-IP & .33 & .32 \\
\hline \multirow[t]{3}{*}{ Martín-Fernández et al. (2018) } & $\mathrm{P}$ & 850 & 0 & GP & Spain & Attitudes & Other & Non-IP & .27 & .38 \\
\hline & $\mathrm{P}$ & 850 & 0 & GP & Spain & Attitudes & Psychological & Non-IP & .36 & .45 \\
\hline & $\mathrm{P}$ & 850 & 0 & GP & Spain & Attitudes & Other & Non-IP & .32 & .42 \\
\hline \multirow[t]{2}{*}{ Martinez-Pecino \& Durán (2019) } & $\mathrm{P}$ & 71 & 0 & Stud & Spain & SR behavior & Psychological & IP & .04 & .24 \\
\hline & $\mathrm{P}$ & 71 & 0 & Stud & Spain & SR behavior & Psychological & IP & .04 & .26 \\
\hline \multirow[t]{2}{*}{ Masser et al. (2010) } & $\mathrm{P}$ & 120 & 69 & Stud & Australia & Attitudes & Sexual & Non-IP & .24 & .27 \\
\hline & $\mathrm{P}$ & 120 & 69 & Stud & Australia & Attitudes & Psychological & Non-IP & .38 & .35 \\
\hline Masser et al. (2006) & $\mathrm{P}$ & 100 & 0 & Stud & UK & Attitudes & Sexual & Non-IP & .13 & .29 \\
\hline \multirow[t]{4}{*}{ Megías et al. (2018) } & $\mathrm{P}$ & 278 & 157 & Stud & Spain & Attitudes & Other & Non-IP & .55 & .66 \\
\hline & $\mathrm{P}$ & 278 & 157 & Stud & Spain & Attitudes & Physical & IP & .27 & .39 \\
\hline & $\mathrm{P}$ & 278 & 157 & Stud & Spain & Attitudes & Sexual & Non-IP & .62 & .75 \\
\hline & $\mathrm{P}$ & 278 & 157 & Stud & Spain & Attitudes & Other & Non-IP & .49 & .67 \\
\hline \multirow[t]{4}{*}{ Megías et al. (2018) } & $\mathrm{P}$ & 485 & 286 & GP & US & Attitudes & Other & Non-IP & .37 & .71 \\
\hline & $\mathrm{P}$ & 485 & 286 & GP & US & Attitudes & Physical & IP & .31 & .60 \\
\hline & $\mathrm{P}$ & 485 & 286 & GP & US & Attitudes & Sexual & Non-IP & .45 & .80 \\
\hline & $\mathrm{P}$ & 485 & 286 & GP & US & Attitudes & Other & Non-IP & .46 & .73 \\
\hline Megías et al. (2011) Study 1 & $\mathrm{P}$ & 305 & 206 & Stud & Spain & Attitudes & Sexual & Non-IP & .58 & .71 \\
\hline \multirow[t]{2}{*}{ Methot-Jones et al. (2019) Study 1} & $\mathrm{P}$ & 514 & 0 & GP & Canada & Attitudes & Sexual & Non-IP & NA & .65 \\
\hline & $\mathrm{P}$ & 514 & 0 & GP & Canada & Attitudes & Other & Non-IP & NA & .58 \\
\hline Methot-Jones et al. (2019) Study 2 & $\mathrm{P}$ & 202 & 0 & GP & Canada & Attitudes & Sexual & Non-IP & NA & .33 \\
\hline Morelli et al. (2016) & $\mathrm{P}$ & 202 & & GP & Italy & SR behavior & Other & IP & -.048 & .295 \\
\hline Muñoz-Ponce et al. (2020) & $\mathrm{P}$ & 256 & 256 & Stud & Mexico & Attitudes & Other & Non-IP & .127 & .158 \\
\hline \multirow[t]{3}{*}{ Muñoz-Ponce et al. (2020) } & $\mathrm{P}$ & 250 & 0 & Stud & Mexico & SR behavior & Physical & IP & -.138 & - \\
\hline & $\mathrm{P}$ & 250 & 0 & Stud & Mexico & SR behavior & Psychological & IP & -.021 & .183 \\
\hline & $\mathrm{P}$ & 250 & 0 & Stud & Mexico & Attitudes & Other & Non-IP & -.041 & .267 \\
\hline Obeid et al. (2010) & $\mathrm{P}$ & 206 & 97 & Stud & Lebanon & Attitudes & Physical & IP & -.25 & .105 \\
\hline Ohse \& Stockdale (2008) & $\mathrm{P}$ & 970 & 575 & GP & US & Attitudes & Sexual & Non-IP & .02 & .22 \\
\hline
\end{tabular}




\begin{tabular}{|c|c|c|c|c|c|c|c|c|c|c|}
\hline Osborn et al. (2018) Study 1 & $\mathrm{P}$ & 218 & 181 & Stud & UK & Attitudes & Sexual & Non-IP & .34 & .50 \\
\hline Osborn et al. (2018) Study 2 & $\mathrm{P}$ & 1084 & 659 & GP & UK & Attitudes & Sexual & Non-IP & .46 & .545 \\
\hline Papp \& Erchull (2017) & $\mathrm{P}$ & 294 & 294 & GP & US & Attitudes & Sexual & Non-IP & .48 & NA \\
\hline Pauwels (2002) Study 1 & $\mathrm{U}$ & 154 & 100 & Stud & US & Attitudes & Psychological & Non-IP & NA & .19 \\
\hline Pauwels (2002) Study 2 & $\mathrm{U}$ & 152 & 82 & Stud & US & Attitudes & Psychological & Non-IP & NA & .01 \\
\hline Pedersen \& Strömwall (2013) & $\mathrm{P}$ & 158 & 81 & GP & NA & Attitudes & Psychological & Non-IP & .34 & .25 \\
\hline \multirow[t]{3}{*}{ Persson et al. (2018) } & $\mathrm{P}$ & 39 & NA & GP & NA & Attitudes & Psychological & Non-IP & -.427 & - \\
\hline & $\mathrm{P}$ & 39 & NA & GP & NA & Attitudes & Sexual & Non-IP & .676 & $\begin{array}{l}.033 \\
.769\end{array}$ \\
\hline & $\mathrm{P}$ & 39 & NA & GP & NA & Attitudes & Psychological & Non-IP & .786 & .810 \\
\hline Pica et al. (2020) & $\mathrm{P}$ & 268 & 222 & Stud & Canada & Attitudes & Sexual & Non-IP & .43 & .66 \\
\hline Pozo Muñoz et al. (2010) & $\mathrm{P}$ & 962 & 474 & Stud & Spain & Attitudes & Other & IP & .238 & .233 \\
\hline Read et al. (2018) & $\mathrm{P}$ & 173 & 173 & Stud & US & Attitudes & Sexual & Non-IP & NA & .622 \\
\hline Read et al. (2018) & $\mathrm{P}$ & 114 & 0 & Stud & US & Attitudes & Sexual & Non-IP & NA & .609 \\
\hline Rebeiz \& Harb (2010) & $\mathrm{P}$ & 300 & 165 & Stud & Lebanon & Attitudes & Sexual & Non-IP & .30 & .52 \\
\hline Resendez \& Hughes (2016) & $\mathrm{P}$ & 260 & 260 & GP & US & Attitudes & Sexual & Non-IP & .375 & .592 \\
\hline \multirow[t]{3}{*}{ Rey-Anacona et al. (2017) } & $\mathrm{P}$ & 382 & 0 & Stud & $\begin{array}{l}\text { Chile, Spain, } \\
\text { Colombia }\end{array}$ & SR behavior & Physical & IP & .093 & .136 \\
\hline & $\mathrm{P}$ & 382 & 0 & Stud & $\begin{array}{l}\text { Chile, Spain, } \\
\text { Colombia }\end{array}$ & SR behavior & Physical & IP & .036 & .093 \\
\hline & $\mathrm{P}$ & 382 & 0 & Stud & $\begin{array}{l}\text { Chile, Spain, } \\
\text { Colombia }\end{array}$ & SR behavior & Psychological & IP & .125 & .162 \\
\hline Riley \& Yamawaki (2018) & $\mathrm{P}$ & 184 & 108 & Stud & US & Attitudes & Psychological & Non-IP & .13 & .17 \\
\hline Rodríguez-Domínguez et al. (2018) & $\mathrm{P}$ & 206 & 0 & Stud & Spain & SR behavior & Psychological & IP & .112 & .325 \\
\hline \multirow[t]{3}{*}{ Rojas-Solís \& Raimúndez (2011) } & $\mathrm{P}$ & 114 & 0 & Stud & Spain & SR behavior & Physical & IP & .18 & .19 \\
\hline & $\mathrm{P}$ & 114 & 0 & Stud & Spain & SR behavior & Psychological & IP & .01 & .11 \\
\hline & $\mathrm{P}$ & 114 & 0 & Stud & Spain & SR behavior & Sexual & IP & .06 & .12 \\
\hline \multirow[t]{3}{*}{ Rollero \& Tartaglia (2019) } & $\mathrm{P}$ & 264 & 145 & Stud & Italy & Attitudes & Psychological & Non-IP & .19 & .24 \\
\hline & $\mathrm{P}$ & 264 & 145 & Stud & Italy & Attitudes & Psychological & Non-IP & .01 & .29 \\
\hline & $\mathrm{P}$ & 264 & 145 & Stud & Italy & Attitudes & Sexual & Non-IP & .295 & .545 \\
\hline Romero-Sànchez et al. (2013) Study 1 & $\mathrm{P}$ & 312 & 158 & Stud & Colombia & Attitudes & Sexual & Non-IP & .37 & .72 \\
\hline Rudman \& Mescher (2012) Study 1 & $\mathrm{P}$ & 111 & 0 & Stud & US & Attitudes & Sexual & Non-IP & .23 & .23 \\
\hline
\end{tabular}




\begin{tabular}{|c|c|c|c|c|c|c|c|c|c|c|}
\hline & $\mathrm{P}$ & 111 & 0 & Stud & US & Attitudes & Sexual & Non-IP & -.19 & .07 \\
\hline & $\mathrm{P}$ & 111 & 0 & Stud & US & Attitudes & Psychological & Non-IP & .06 & .38 \\
\hline \multirow[t]{3}{*}{ Rudman \& Mescher (2012) Study 1} & $\mathrm{P}$ & 99 & 99 & Stud & US & Attitudes & Sexual & Non-IP & .04 & .17 \\
\hline & $\mathrm{P}$ & 99 & 99 & Stud & US & Attitudes & Sexual & Non-IP & .03 & .01 \\
\hline & $\mathrm{P}$ & 99 & 99 & Stud & US & Attitudes & Psychological & Non-IP & .18 & .49 \\
\hline \multirow[t]{3}{*}{ Rudman \& Mescher (2012) Study 2} & $\mathrm{P}$ & 58 & 0 & Stud & US & Attitudes & Sexual & Non-IP & NA & .29 \\
\hline & $\mathrm{P}$ & 58 & 0 & Stud & US & Attitudes & Sexual & Non-IP & NA & .23 \\
\hline & $\mathrm{P}$ & 58 & 0 & Stud & US & Attitudes & Sexual & Non-IP & NA & .20 \\
\hline Russell \& Oswald (2016) & $\mathrm{P}$ & 242 & 242 & Stud & US & Attitudes & Sexual & Non-IP & .37 & .57 \\
\hline Russell \& Oswald (2016) & $\mathrm{P}$ & 191 & 0 & Stud & US & Attitudes & Sexual & Non-IP & .27 & .68 \\
\hline Russell \& Trigg (2004) & $\mathrm{P}$ & 457 & 285 & Stud & US & Attitudes & Sexual & Non-IP & .33 & .63 \\
\hline Sakalli (2001) & $\mathrm{P}$ & 107 & 0 & Stud & Turkey & Attitudes & Physical & IP & .25 & .37 \\
\hline Sakalli (2001) & $\mathrm{P}$ & 114 & 114 & Stud & Turkey & Attitudes & Physical & IP & .16 & .30 \\
\hline \multirow[t]{2}{*}{ Sakalli-Uğurlu et al. (2010) } & $\mathrm{P}$ & 136 & 136 & Stud & Turkey & Attitudes & Sexual & Non-IP & .39 & .52 \\
\hline & $\mathrm{P}$ & 136 & 136 & Stud & Turkey & Attitudes & Sexual & Non-IP & -.01 & .01 \\
\hline \multirow[t]{2}{*}{ Sakalli-Uğurlu et al. (2010) } & $\mathrm{P}$ & 84 & 0 & Stud & Turkey & Attitudes & Sexual & Non-IP & .28 & .60 \\
\hline & $\mathrm{P}$ & 84 & 0 & Stud & Turkey & Attitudes & Sexual & Non-IP & -.37 & .17 \\
\hline Sakalli-Uğurlu et al. (2007) & $\mathrm{P}$ & 198 & 198 & Stud & Turkey & Attitudes & Psychological & Non-IP & .36 & .56 \\
\hline Sakalli-Uğurlu et al. (2007) & $\mathrm{P}$ & 227 & 0 & Stud & Turkey & Attitudes & Psychological & Non-IP & .19 & .48 \\
\hline Saunders et al. (2017) Study 2 & $\mathrm{P}$ & 117 & 0 & GP & US & Attitudes & Psychological & Non-IP & .11 & .27 \\
\hline Shilinsky (2016) & $\mathrm{U}$ & 188 & 0 & Stud & US & Behavior & Sexual & Non-IP & -.0167 & .19 \\
\hline Shim (2006) & $\mathrm{U}$ & 144 & 60 & Stud & US & Attitudes & Sexual & Non-IP & .08 & .10 \\
\hline \multirow[t]{2}{*}{ Siebler et al. (2008) Study 2} & $\mathrm{P}$ & 75 & 0 & Stud & Germany & Attitudes & Sexual & Non-IP & NA & .27 \\
\hline & $\mathrm{P}$ & 75 & 0 & Stud & Germany & Behavior & Sexual & Non-IP & NA & .46 \\
\hline Simonson (2001) & $\mathrm{U}$ & 216 & 142 & Stud & US & Attitudes & Other & Non-IP & .00 & -.08 \\
\hline Soto-Quevedo (2012) & $\mathrm{P}$ & 120 & 62 & GP & Chile & Attitudes & Psychological & Non-IP & .10 & .13 \\
\hline Stewart (2014) & $\mathrm{P}$ & 33 & 0 & Stud & US & Attitudes & Sexual & Non-IP & .38 & .69 \\
\hline Stoll et al. (2018) & $\mathrm{P}$ & 1020 & 1020 & GP & US & Attitudes & Sexual & Non-IP & .2725 & $\begin{array}{r}.526 \\
1\end{array}$ \\
\hline Stoll et al. (2018) & $\mathrm{P}$ & 980 & 0 & GP & US & Attitudes & Sexual & Non-IP & .3738 & $\begin{array}{r}.464 \\
9\end{array}$ \\
\hline Suchovicki (2011) & $\mathrm{U}$ & 163 & 0 & Stud & US & Attitudes & Sexual & Non-IP & .04 & .16 \\
\hline
\end{tabular}




\begin{tabular}{|c|c|c|c|c|c|c|c|c|c|c|}
\hline & $\mathrm{U}$ & 163 & 0 & Stud & US & Attitudes & Sexual & Non-IP & .00 & .09 \\
\hline \multirow[t]{2}{*}{ Suchovicki (2011) } & $\mathrm{U}$ & 245 & 245 & Stud & US & Attitudes & Sexual & Non-IP & .26 & .24 \\
\hline & $\mathrm{U}$ & 245 & 245 & Stud & US & Attitudes & Sexual & Non-IP & .18 & .21 \\
\hline Tang \& Fox (2016) & $\mathrm{P}$ & 425 & 0 & GP & NA & SR behavior & Psychological & Non-IP & .11 & .36 \\
\hline Tang et al. (2020) & $\mathrm{P}$ & 570 & 0 & GP & Germany & SR behavior & Sexual & Non-IP & NA & .427 \\
\hline \multirow[t]{4}{*}{ Tapara (2017) } & $\mathrm{U}$ & 118 & 0 & GP & New Zealand & Attitudes & Sexual & Non-IP & .415 & .752 \\
\hline & $\mathrm{U}$ & 118 & 0 & GP & New Zealand & Attitudes & Other & Non-IP & .039 & .287 \\
\hline & $\mathrm{U}$ & 118 & 0 & GP & New Zealand & Attitudes & Sexual & Non-IP & .003 & .124 \\
\hline & $\mathrm{U}$ & 118 & 0 & GP & New Zealand & Attitudes & Sexual & Non-IP & .198 & .304 \\
\hline Tarhan et al. (2017) & $\mathrm{P}$ & 420 & 294 & Stud & Turkey & Attitudes & Psychological & IP & .02 & .28 \\
\hline \multirow[t]{2}{*}{ Taschler \& West (2017) Study 1} & $\mathrm{P}$ & 170 & 0 & GP & UK & Attitudes & Sexual & Non-IP & .41 & .59 \\
\hline & $\mathrm{P}$ & 170 & 0 & GP & UK & Attitudes & Sexual & Non-IP & .07 & .28 \\
\hline Taschler \& West (2017) Study 2 & $\mathrm{P}$ & 280 & 280 & GP & UK & Attitudes & Sexual & Non-IP & .41 & .57 \\
\hline Thomae \& Viki (2013) Study 2 & $\mathrm{P}$ & 107 & 0 & GP & UK & Attitudes & Sexual & Non-IP & .242 & .317 \\
\hline Thomas \& Esses (2004) & $\mathrm{P}$ & 81 & 0 & Stud & US & Attitudes & Sexual & Non-IP & .14 & .39 \\
\hline \multirow[t]{2}{*}{ Toplu Demirtaş (2015) } & $\mathrm{U}$ & 304 & 0 & Stud & Turkey & SR behavior & Psychological & IP & NA & .21 \\
\hline & $\mathrm{U}$ & 304 & 0 & Stud & Turkey & Attitudes & Other & Non-IP & NA & .33 \\
\hline Toplu Demirtaş (2015) & $\mathrm{U}$ & 706 & 706 & Stud & Turkey & Attitudes & Other & Non-IP & NA & .35 \\
\hline \multirow[t]{2}{*}{ Toplu Demirtaş et al. (2017) } & $\mathrm{P}$ & 84 & 0 & Stud & Turkey & SR behavior & Psychological & IP & -.16825 & .082 \\
\hline & $\mathrm{P}$ & 84 & 0 & Stud & Turkey & SR behavior & Physical & IP & -.088 & .056 \\
\hline \multirow[t]{2}{*}{ Toplu-Demirtaş et al. (2020) } & $\mathrm{P}$ & 259 & 259 & Stud & Turkey & Attitudes & Other & Non-IP & NA & .520 \\
\hline & $\mathrm{P}$ & 259 & 259 & Stud & Turkey & Attitudes & Other & Non-IP & NA & .265 \\
\hline \multirow[t]{2}{*}{ Toplu-Demirtaş et al. (2020) } & $\mathrm{P}$ & 229 & 0 & Stud & Turkey & Attitudes & Other & Non-IP & NA & .572 \\
\hline & $\mathrm{P}$ & 229 & 0 & Stud & Turkey & Attitudes & Other & Non-IP & NA & .400 \\
\hline Trangsrud (2010) & $\mathrm{U}$ & 250 & 137 & Stud & US & Attitudes & Sexual & Non-IP & .2467 & .61 \\
\hline \multirow[t]{2}{*}{ Troche \& Herzberg (2017) } & $\mathrm{P}$ & 692 & 0 & GP & Germany & SR behavior & Sexual & IP & NA & .29 \\
\hline & $\mathrm{P}$ & 692 & 0 & GP & Germany & Attitudes & Sexual & Non-IP & NA & .75 \\
\hline Ubillos-Landa et al. (2017) & $\mathrm{P}$ & 1341 & 0 & Stud & Spain & Attitudes & Other & Non-IP & .2815 & .367 \\
\hline Ubillos-Landa et al. (2017) & $\mathrm{P}$ & 1578 & 1578 & Stud & Spain & Attitudes & Other & Non-IP & .266 & .332 \\
\hline Vidal-Fernández \& Megías (2014) & $\mathrm{P}$ & 246 & 110 & Stud & Spain & Attitudes & Psychological & Non-IP & .34 & .32 \\
\hline
\end{tabular}




\begin{tabular}{|c|c|c|c|c|c|c|c|c|c|c|}
\hline \multirow[t]{2}{*}{ Viki \& Abrams (2002) } & $\mathrm{P}$ & 57 & 28 & Stud & UK & Attitudes & Sexual & Non-IP & .42 & .52 \\
\hline & $\mathrm{P}$ & 57 & 28 & Stud & UK & Attitudes & Psychological & Non-IP & .32 & .43 \\
\hline \multirow[t]{2}{*}{ Viki et al. (2006) } & $\mathrm{P}$ & 60 & 0 & Stud & Zimbabwe & Attitudes & Sexual & Non-IP & .13 & .52 \\
\hline & $\mathrm{P}$ & 60 & 0 & Stud & Zimbabwe & Attitudes & Sexual & Non-IP & .07 & .30 \\
\hline Waubert de Puiseau \& Roessel (2013) & $\mathrm{P}$ & 59 & 59 & Stud & Germany & Attitudes & Sexual & Non-IP & .510 & .442 \\
\hline Waubert de Puiseau \& Roessel (2013) & $\mathrm{P}$ & 101 & 0 & Stud & Germany & Attitudes & Sexual & Non-IP & .265 & .217 \\
\hline \multirow[t]{2}{*}{ Whitaker (2013) } & $\mathrm{P}$ & 2421 & 0 & Stud & US & SR behavior & Physical & IP & NA & .090 \\
\hline & $\mathrm{P}$ & 2421 & 0 & Stud & US & SR behavior & Psychological & IP & NA & .115 \\
\hline Yalsin \& Özturk (2018) & $\mathrm{P}$ & 300 & 150 & GP & Turkey & Attitudes & Psychological & Non-IP & .34 & .20 \\
\hline \multirow[t]{2}{*}{ Yamawaki et al. (2007) } & $\mathrm{P}$ & 140 & 75 & Stud & US & Attitudes & Sexual & Non-IP & .279 & NA \\
\hline & $\mathrm{P}$ & 140 & 75 & Stud & US & Attitudes & Psychological & Non-IP & .353 & NA \\
\hline \multirow[t]{2}{*}{ Yamawaki et al. (2009) } & $\mathrm{P}$ & 101 & 56 & Stud & US & Attitudes & Psychological & Non-IP & .60 & -.38 \\
\hline & $\mathrm{P}$ & 101 & 56 & Stud & US & Attitudes & Physical & Non-IP & .10 & .29 \\
\hline \multirow[t]{2}{*}{ Yamawaki et al. (2009) } & $\mathrm{P}$ & 103 & 57 & Stud & Japan & Attitudes & Psychological & Non-IP & .49 & .47 \\
\hline & $\mathrm{P}$ & 103 & 57 & Stud & Japan & Attitudes & Physical & Non-IP & .42 & .24 \\
\hline Zapata-Calvente \& Megías (2017) & $\mathrm{P}$ & 125 & 125 & Stud & Spain & Attitudes & Other & Non-IP & NA & .40 \\
\hline Zapata-Calvente \& Megías (2017) & $\mathrm{P}$ & 126 & 0 & Stud & Spain & Attitudes & Other & Non-IP & NA & .40 \\
\hline \multirow[t]{2}{*}{ Zapata-Calvente et al. (2019) } & $\mathrm{P}$ & 129 & 0 & Stud & Germany & Attitudes & Sexual & Non-IP & .30 & .23 \\
\hline & $\mathrm{P}$ & 129 & 0 & Stud & Germany & Attitudes & Other & IP & .30 & .42 \\
\hline
\end{tabular}

Note. P - published, U - unpublished; GP - general population, Stud - students; SR behave - self-reported behavior; IP - intimate partner, Non-IP - non-intimate partner; $r_{\mathrm{bv}}-$ correlation between benevolent sexism and violence; $r_{\mathrm{hv}}-$ correlation between hostile sexism and violence. 
